\title{
Sex Chromosomes and Master Sex-Determining Genes in Turtles and Other Reptiles
}

\author{
Dominique Thépot
}

Citation: Thépot, D. Sex

Chromosomes and Master

Sex-Determining Genes in Turtles and Other Reptiles. Genes 2021, 12, 1822. https://doi.org/10.3390/ genes12111822

Academic Editors: Frederic Veyrunes, Jesús Page, Frederic Baudat and Michail Rovatsos

Received: 21 October 2021

Accepted: 16 November 2021

Published: 19 November 2021

Publisher's Note: MDPI stays neutral with regard to jurisdictional claims in published maps and institutional affiliations.

Université Paris-Saclay, Université de Versailles Saint-Quentin-en-Yvelines (UVSQ), INRAE, BREED, 78350 Jouy-en-Josas, France; dominique.thepot@inrae.fr

\begin{abstract}
Among tetrapods, the well differentiated heteromorphic sex chromosomes of birds and mammals have been highly investigated and their master sex-determining (MSD) gene, Dmrt1 and $S R Y$, respectively, have been identified. The homomorphic sex chromosomes of reptiles have been the least studied, but the gap with birds and mammals has begun to fill. This review describes our current knowledge of reptilian sex chromosomes at the cytogenetic and molecular level. Most of it arose recently from various studies comparing male to female gene content. This includes restriction site-associated DNA sequencing (RAD-Seq) experiments in several male and female samples, RNA sequencing and identification of Z- or X-linked genes by male/female comparative transcriptome coverage, and male/female transcriptomic or transcriptome/genome substraction approaches allowing the identification of Y- or W-linked transcripts. A few putative master sexdetermining (MSD) genes have been proposed, but none has been demonstrated yet. Lastly, future directions in the field of reptilian sex chromosomes and their MSD gene studies are considered.
\end{abstract}

Keywords: Genetic Sex Determination (GSD); lizards; snakes; squamates; homologous genes; RAD-seq; genome coverage

\section{Introduction}

Sexual reproduction is ubiquitous in all vertebrates, and the formation and development of gonads, either testes or ovaries, is determined by the sequential action of members of the same genetic network. While the downstream actors of this network are well conserved, the elements triggering the process are surprisingly variable. In Environmental Sex Determination (ESD), the future sex of the gonad depends on environmental conditions. This environmental factor is generally the incubation temperature of the developing egg, and this peculiar case is known as Temperature Sex Determination (TSD). In Genetic Sex Determination (GSD), the bipotential gonad develops into either testis or ovary based on the control of a master sex-determining (MSD) gene upstream of the whole network. This MSD gene is located on only one member of a special pair of non-identical chromosomes called sex chromosomes. The sex with an odd number of MSD is the heterogametic sex, and the other is the homogametic sex. By convention, when male is the heterogametic sex, the male specific sex chromosome is named $Y$ and the other $X$. When it is female, the female specific sex chromosome is called $W$ and the other $Z$. The MSD gene can act in two different ways, either as male or female dominant gene on the $\mathrm{Y}$ or $\mathrm{W}$ chromosome respectively, or in a dose-dependent manner as a male gene on the $\mathrm{Z}$ chromosome or a female gene on the $X$ chromosome.

Apart from extremely rare cases [1], almost all sex chromosomes evolve from a pair of autosomes as demonstrated by the persistence of a homologous region, the pseudoautosomal region, between the two members of the pair. This evolution begins with the appearance of an MSD gene, either by neofunctionalization or translocation, in one member of the pair, the proto- $Y$ for example (Figure 1). Such changes have drastic consequences for the evolution of the proto- $Y$ chromosome. For reasons not yet fully understood and highly discussed, suppression of recombination between the proto- $X$ and the proto- $Y$ occurs in 
the region of the chromosome surrounding the MSD [2]. From this point, the two proto-sex chromosomes continue to differentiate. This process includes the acquisition of sexually antagonistic genes, the degeneration of Y-linked genes, the accumulation of repetitive sequences, intrachromosomal rearrangements such as inversions, and the expansion of the non-recombining region. This continuing differentiation of the sex chromosomes may lead to the appearance of morphologically distinct chromosomes called heteromorphic sex chromosomes. Before they become morphologically distinguishable by classic cytogenetics, they are homomorphic. This is just a visual criterion, not a functional one. As a consequence, there is no linear relation between the degree of genetic differentiation between sex chromosomes and the fact that they are homomorphic or heteromorphic. Homomorphic chromosomes can be as genetically differentiated and evolutionary old as heteromorphic chromosomes. Thus, if heteromorphic chromosomes are evidence of GSD, the opposite is not true, and GSD can occur within homomorphic chromosomes. Because the non-recombining region expands stepwise across the proto- $Y$ chromosome, strata appear in the Y-chromosome. In each stratum, the remaining ancestral autosomal genes have started to diverge from their chromosome $X$ counterparts at the same time. These pairs of genes are called gametologs. The degree of divergence between gametologs can be assessed by the measure of the synonymous nucleotide substitution rate (dS or Ks) between them. So, each stratum is characterized by the Ks of its gametologs. The MSD gene is located in the oldest strata and has high Ks.
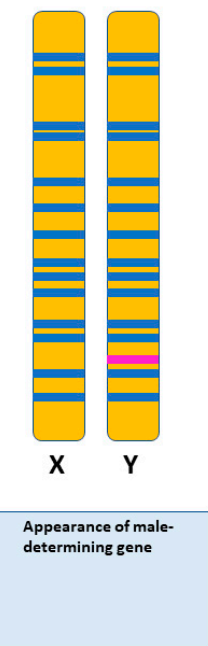
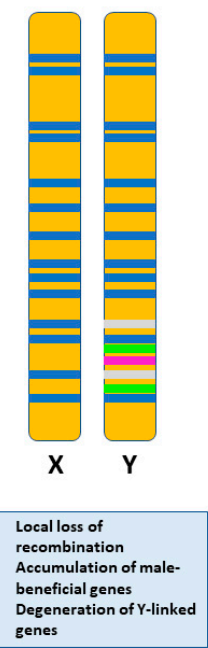
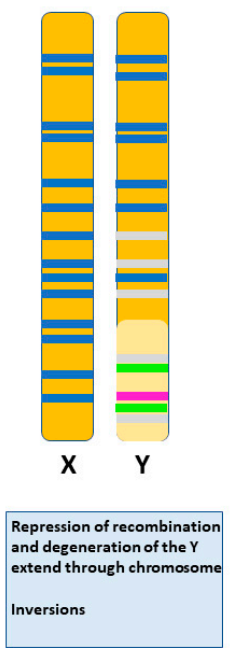

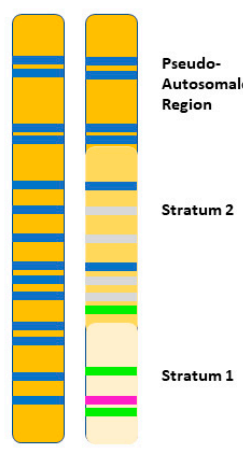

$\mathbf{X}$

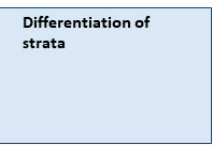

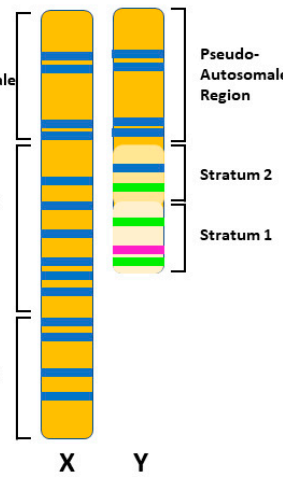

Differentiated heteromorphic

Figure 1. Current model for evolution of heteromorphic sex chromosomes from a pair of autosomes. Steps are shown from left to right. Ancestral genes are represented by dark blue lines, the maledetermining gene is represented by a pink line, male beneficial genes are represented by green lines, and degenerating genes are represented by grey lines. Faded colours in the chromosome show the appearance of strata.

Until now, only a few MSD genes have been identified in vertebrates. Their comparative study reveals the use of a restricted set of genes of the sex determination network that are likely to evolve as MSD genes. Several times, independently according to phyla, certain genes have been recruited by evolution, either in their native form or in the form of paralogs, to become the major gene for determining sex in a given species or phylum. For instance, two paralogs of Sox3, SRY in marsupials and placental mammals [3,4], and Sox3Y in the fish Oryzias dancena [5], have independently acquired this role. Similarly, Dmrt1 is probably the major gene for sex determination in birds [6,7] and fish Cynoglossus semilaevis [8]. Two of its paralogs ( $\mathrm{DmW}$ and Dmrt1Y) play this role, respectively, in the frog Xenopus laevis [9] and two species of fishes, the medaka Oryzias latipes $[10,11]$ and Oryzias curvinotus [12]. In fish, paralogs of the Gsdf gene (GsdfY in Oryzias luzonensis [13]), Gdf6 gene (Gdf6aY in Nothobranchius furzeri [14], B-Gdf6b in Astyanax mexicanus [1], Amh (Antimullerian hormone) gene (AmhY in Odontesthes hatcheri [15], Amhby in the pike Esox 
lucius [16], Amhy in Gasterosteus aculeatus [17]) or its receptor AmhR gene (Amhr2 in the Fugu Takifugu rubripes [18], Amhr2Y in the Canadian perch Perca flavescens [19], amhr2bY in ayu Plecoglossus altivelis [20]) have also become MSD genes. Finally, Amh is probably the major gene for determining sex in monotreme mammals [21,22]). It should also be added that this persistence of the same actors in the sex determination network, associated with a great variability of the MSD gene according to the phylum, had already been noted in insects, thus leading to the formula "Masters change, slaves remain" [23]. It is notable, however, that this rule is not absolute and that MSD genes can also be recruited outside the classic members of the network. This is the case in the rainbow trout Oncorhynchus mykiss where $S d Y$, a paralog of $\operatorname{Irf} 9$, a gene regulating interferons, has taken on this function [24]. $S d Y$ interacts directly with FoxL2, a major gene for pushing gonad differentiation towards the female pathway, to inhibit the aromatase promoter (Cyp19A1) and therefore the synthesis of oestrogens [25]. Two other examples are known in the catfish Ictalurus punctatus [26] and the amphibian axolotl [27]. In catfish the MSD gene is a male specific isoform of the gene BCAR1 (Breast-Cancer AntiResistance 1), an adaptor protein expressed in all tissues, which acts by binding to the alpha oestrogen receptor and therefore by inhibiting the action of oestrogens [26]. In the axolotl Ambystoma mexicanum the MSD gene is a duplication of the $A T R X$ gene (a helicase domain protein, involved in the deposition of specific histones on repeated sequences) called $A T R W$, which is specific to chromosome W [27]. The mechanism of action by which $A T R W$ would push differentiation from the gonad towards the female pathway is completely unknown at this time. However, ATRX is well known for its role in mammalian sexual differentiation, as demonstrated by the various degrees of gonadal dysgenesis observed in human XY mutated for ATRX, the most drastic phenotype being a complete male to female sex reversal [28].

This list of species with identified MSD genes includes no reptilian species so far. There are several reasons for this delay. TSD was discovered in reptiles $[29,30]$ and is a specific feature of this group among tetrapods. During the last century, it has attracted more attention from researchers in the field of reptile reproduction to the detriment of GSD. Moreover, many reptiles lack heteromorphic chromosomes, the easiest way to discover GSD, and this fact has led to the underestimation of GSD occurrence in reptiles. Genetic manipulation of embryos was unavailable in reptiles, and as no reptiles have high economic value there was no financial interest to push the research in developing reptile-specific techniques. All these reasons explain why the identification of MSD genes in reptiles still lags behind research in other groups. However, with the development of new technology, this gap is beginning to be filled and incredible progress has been accomplished during the last two decades. However, the level of knowledge is still very heterogeneous from one family to another, ranging from almost nothing to the identification of a restricted set of candidate genes.

The aim of this article is to summarize the current knowledge in each group of reptiles with a focus on turtles and less detail on squamates. In the first section, basic information will be provided for each group, concerning its phylogenic position, the occurrence of TSD or GSD, the presence or absence of heteromorphic sex chromosomes, the degree of differentiation of its sex chromosomes, the homology of sex chromosomes with chicken chromosomes, and putative MSD candidate genes. In the second section, some points about the transitions between TSD and GSD, or the repetitive selection of the same chromosomic region to become sex chromosomes will be discussed, before addressing the question of how recent methods will help to identify MSD genes in reptiles.

\section{Overview of GSD in Reptiles}

\subsection{Turtles}

The phylogenetic position of Turtles among Reptiles (=Sauria) had been a matter of controversy for a long time (see [31] for review), but the development of molecular phylogenetics clarified the situation at the beginning of the century. Molecular studies using ultraconserved elements [32], mitochondrial and nuclear genes [33,34], and finally 
the sequences of three turtle genomes $[35,36]$ led to the consensus that turtles (=Testudines) are the sister-group of Archosauria (=Birds + Crocodilians). Together, they form Archelosauria [37], the sister group of Lepidosauria (=Tuatara + Lizards + Snakes) (Figure 2).

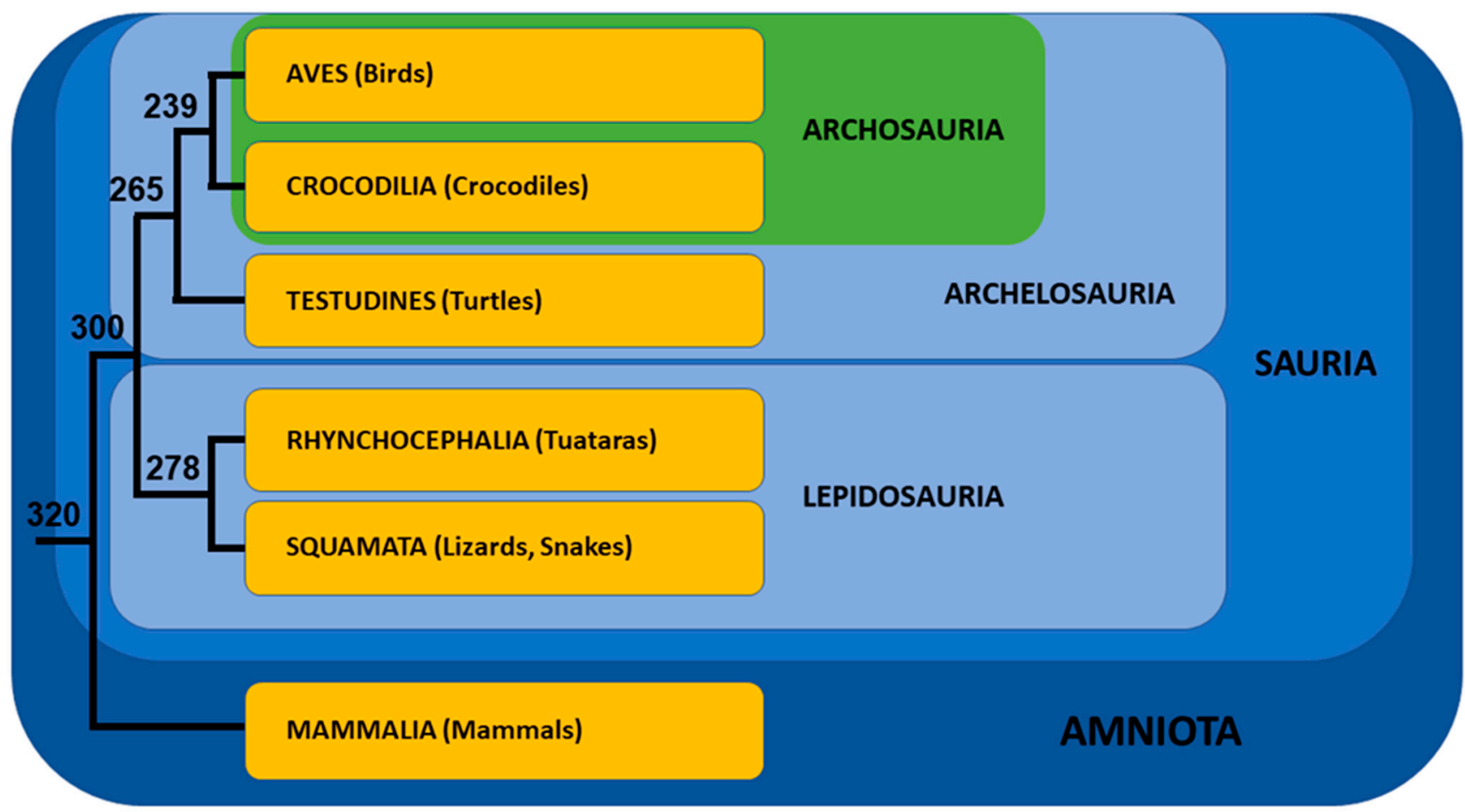

Figure 2. Phylogenic tree of amniotes. Relative position and grouping of each clade are shown. Branch lengths are not proportional to time. Numbers indicate divergence time (Myrs) from present for nodes, according to [38]. Colors indicate the different level of clades in the phylogenetic tree.

Phylogenomic analyses highlighted the evolutionary history and relative phylogenetic relationships among turtle families [37,39-41]. The first division occurred in the early Jurassic period. It separated the suborder Pleurodira, or side-necked turtles, that originated in Gondwana from the suborder Cryptodira, or hidden-necked turtles, with a northern origin located in Laurasia. Pleurodira contains three families, all distributed in the southern hemisphere. Cryptodira is divided into Trionychia, soft-shelled turtles, itself with two families, and Durocryptodira with nine families dispatched in two clades, Testudinoidea and Americhelydia (Figure 3). This phylogenetic tree is robust and widely accepted. In almost each family, the relative position of the different genera and even those of the different species is now well established.

Among Archelosauria, the turtles and the two clades of Archosauria show contrasting sex-determining mechanisms. All known Crocodilians are temperature sex-determined species [42], whereas the same ZW genetic sex-determining system is present in all bird species [43]. Slight modifications of the system exist in some birds, such as a multiple sex chromosome system in the Adélie penguin [44]. Another example is the presence of a neo-sex chromosome formed by the fusion of the $\mathrm{Z}$ chromosome with part of chromosome 4 alone or in combination with parts of chromosomes 3, 4 and 5 in Sylvioidea passerines [45]. The DMRT1 gene, located on the $\mathrm{Z}$ chromosome and present in one copy in females and two copies in males, is generally thought to be the sex-determining gene in birds $[6,7]$. However, the absence of Z0 birds to be studied and the phenotype of ZZW birds [46] leave room for the possibility of an ovary-determining gene on the W chromosome (see [47] for review). In contrast, turtles exhibit great variation in sex determination systems with TSD species, GSD species with XY chromosomes and GSD species with ZW chromosomes. As most species of turtles are TSD species, it is thought that TSD is the ancestral state in turtles and that GSD systems arose several times independently during turtle evolution [48-50]. 


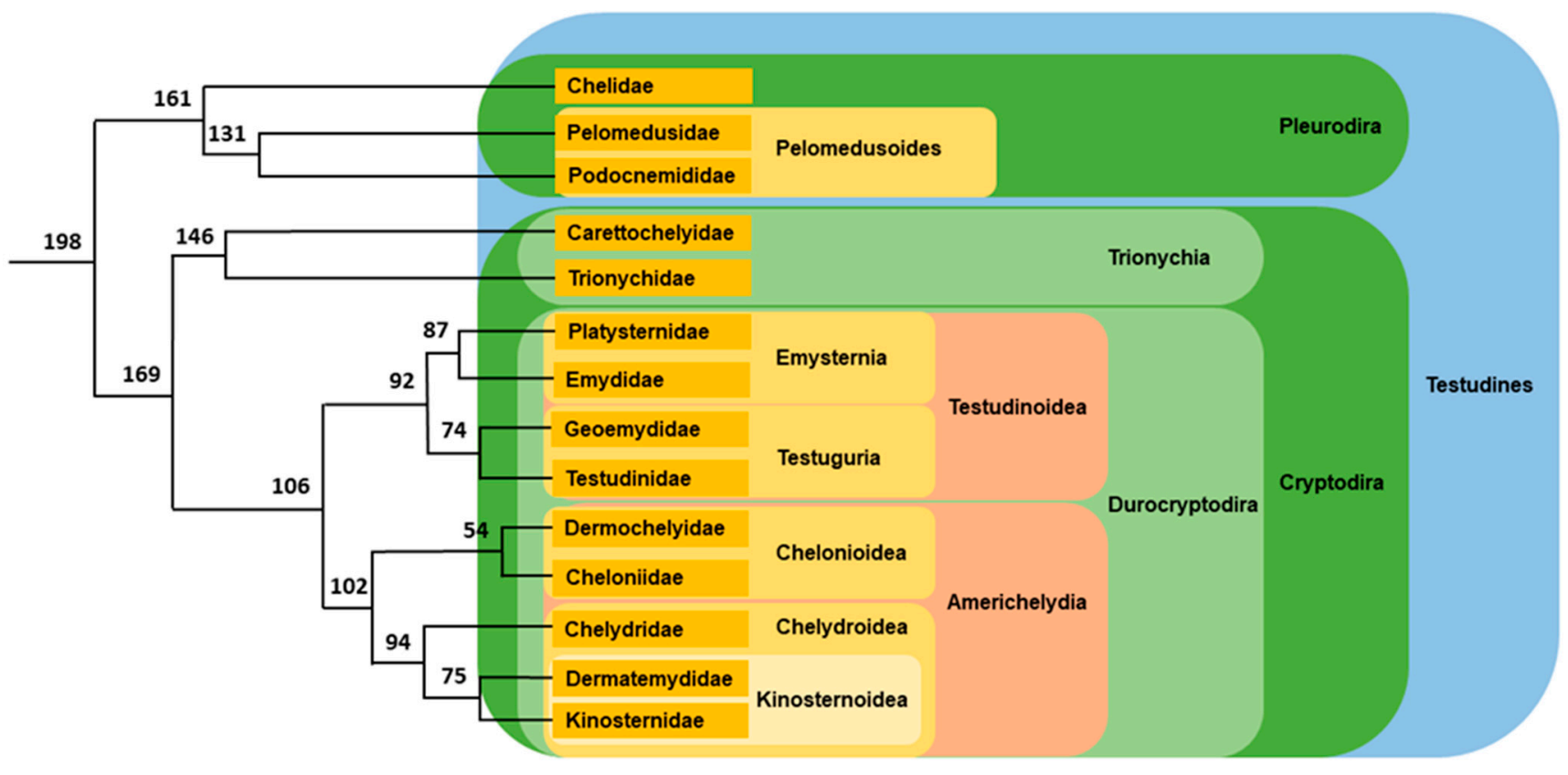

Figure 3. Phylogenic tree of turtle families. Relative positions of each turtle family and superior clade are represented. Branch lengths are not proportional to time. Numbers indicate divergence time (Myrs) from present for nodes, according to [39]. Colors indicate the different level of clades in the phylogenetic tree from the fourteen families (golden yellow) to the order (blue).

\subsubsection{Pleurodiran Turtles}

In Pleurodira, the superfamily Pelomedusoides is divided into two families. The first one, Pelomedusidae, encompasses African species dispatched into two genera: Pelomedusa with only one species recently split into 10 species [51] and Pelusios with 15-20 species [52]. The second, Podocnemididae, is composed of six South-American Podocnemis species, the South-American Peltocephalus dumerilianus (Schweiger, 1812) and the Madagascan Erymnochelys madagascariensis (Grandidier, 1867)). Among Podocnemididae, Peltocephalus is the sister group of Erymnochelys and Podocnemis, [53,54] (Figure 4). Karyotypes of Pelomedusoides examined so far (4 Pelusios species, Pelomedusa subrufa and all Podocnemididae species) show no detectable sex-chromosomes [55-63]. Moreover, TSD was demonstrated in one species of Pelusios [48], one species of Pelomedusa [48], Podocnemis expansa [64,65], Podocnemis unifilis [66], Podocnemis erythrocephala [67] and Podocnemis lewyana [68,69]. Another species, Podocnemis sextuberculata, was also cited as TSD species [67], but the studies leading to this statement are yet to be published. From field data, P. dumerilianus was first claimed to be a GSD species [70], but was later demonstrated to possess temperature-dependent sex determination [67,71]. Lastly, E. madagascariensis has TSD [72], but unfortunately this has not yet been published in peer-reviewed literature. It is thus generally accepted that TSD occurs in all Pelomedusoides species. 


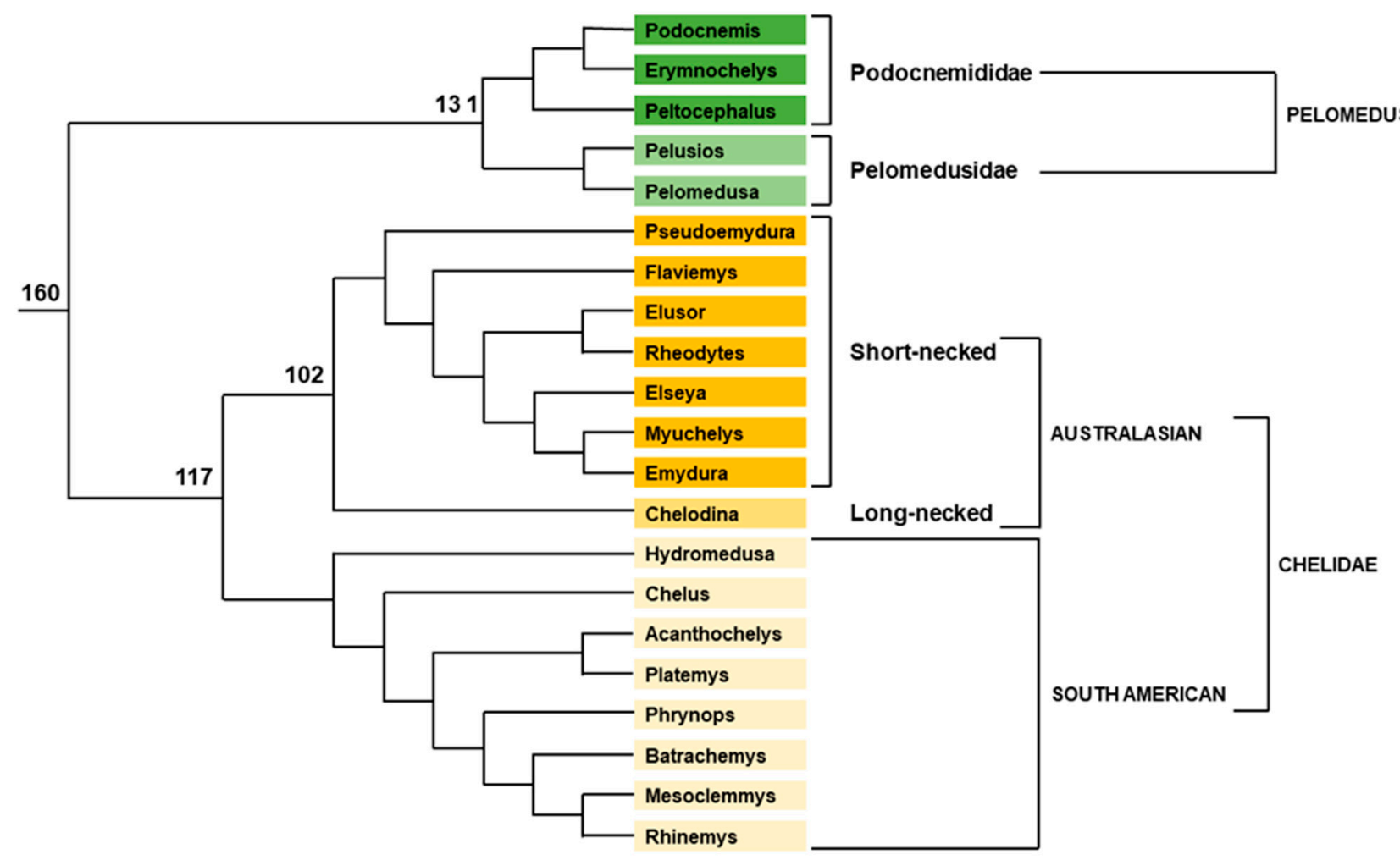

Figure 4. Phylogenic tree of pleurodiran turtles. Relative positions of each genus and superior clade are represented. Branch lengths are not proportional to time. Numbers indicate divergence time (Myrs) from present for some key nodes, according to [39]. Color of each genus indicates the different clades.

The situation is quite different in Chelidae, the last family in Pleurodira, which is divided between two clades: 23 South American species and around 35 Australasian species (Figure 4). All species tested so far by controlled incubation temperature experiments turned out to be GSD species. This includes the South American Mesoclemmys gibba, Phrynops geoffroanus, and Phrynops hilari [73], and the Australasian Emydura macquarii [74] (under the name E. signata); [75], Chelodina longicollis [76], Elusor macrurus [77], Emydura subglobosa and Elseya novaguinae [73]. However standard karyotypes of most species from different genera (Batrachemys, Chelus, Hydromedusa, Mesoclemmys, Phrynops, Platemys, Chelodina, Elseya, Emydura, Pseudoemydura, Rheodytes), showed undifferentiated homomorphic sex chromosomes [58,78-81]. Heteromorphic sex chromosomes were only described in Acanthochelys radiolata (under the name Platemys radiolata) with a heteromorphic pair of one metacentric and one acrocentric chromosome [82]. As there are five pairs of subtelomeric or acrocentric chromosomes in other Acanthochelys species and only four pairs in A. radiolata, this heteromorphic pair could be sex chromosomes that evolved from an acrocentric pair. However, only one male was studied with no female for comparison, and therefore other explanations are possible, such as chromosomal polymorphism. Moreover, in the three other Acanthochelys species, only female karyotypes have been described and the male karyotype is unknown [82]. Thus, the presence of heteromorphic sex chromosomes in $A$. radiolata and perhaps in other Acanthochelys species needs to be confirmed by the study of more animals of both sexes. Another potential sign of sex chromosome differentiation occurs in Chelus fimbriatus [78]. At the pachytene stage during male meiosis, one bivalent chromosome presents a region without pairing. Such an image could suggest the presence of an intrachromosomal inversion in one chromosome of the pair, and it is tempting to speculate that it is the first sign of $Y$ chromosome differentiation. However, only one male was studied, and this result must be replicated and confirmed by the identification of Y-specific genetic markers, which are still lacking today. The occurrence of sex macrochromosomes in South American Chelids is thus still uncertain. 
More results were obtained with the development of a new molecular cytogenetic approach: comparative genome hybridization (CGH). This method consists of independent labelling of male and female genomic DNA with two different fluorescent molecules (green and red) before cohybridization of male or female metaphasic chromosome spreads. Male or female specific parts of the sex chromosomes are thus labelled green or red, while autosomes and the pseudo-autosomal part of the sex chromosomes are labelled yellow. Using CGH allowed the identification of male-specific regions of the $\mathrm{Y}$ chromosome in several Australasian species: C. longicollis [83], E. macquarii macquarii [84], E. subglobosa [85], E. macquarii krefftii, E. novaguinae, Chelodina rugosa, C. expansa, C. reimanni, C. novaeguineae, and C. mccordi [86]. Interestingly the sex chromosome is a difficult to detect minichromosome in long-necked Chelodina $(2 \mathrm{n}=54)$, whereas it is the fourth largest macrochromosome in its sister-group, the Australasian short-necked Chelids (Emydura and Elseya) $(2 \mathrm{n}=50)$. Different scenarios for the sex chromosome evolutionary history in these species have been proposed [84-87]. They range from independent origin of sex chromosomes in Chelodina and Emydura to shared origin with either an ancestral sex minichromosome fused with a macrocromosome in Emydura or the translocation of the sex-determination region from an ancestral sex macrochromosome to a sex minichromosome in Chelodina. Because it had been suggested in Podocnemididae that the presence of interstitial telomeric repeats (ITR) may be the remnants of ancient events of (mini)chromosome fusions [88], looking for such ITRs in the Emydura Y-chromosome could have helped discern whether the fusion or the fission scenario was correct. However, it was later shown that ITRs were rare in turtles and not correlated with interchromosomal rearrangements [89]. Whatever the sex chromosome ancestral state and evolution might be, the Emydura Y-chromosome probe paints not only the entire fifth largest autosome of $C$. longicollis, but also part of its Y chromosome [87]. Therefore, both Y-chromosomes share some homologous sequences. Even though this provides no definitive evidence they carry the same sex-determination locus, it is a reasonable hypothesis. The recent study by CGH and C-banding of the South American Rhinemys rufipes allowed the discovery of a Y minichromosome in this species [90]. The sex minichromosome pair is the tiniest and the $\mathrm{Y}$ chromosome is highly heterochromatic. Interestingly, the tiniest minichromosome pair of a male Phrynops hogei exhibits the same pattern, with one member of the pair being highly heterochromatic and the other one not at all [80], suggesting the two species share the same XY sex minichromosome system. However, only one male of P. hogei (and no female) was studied, and more animals of both sexes need to be analysed before any conclusion can be drawn. The authors of the $R$. rufipes study suggest the possibility that a sex minichromosome is the ancestral state in Chelidae [90]. They do not take into account the fact that both Acanthochelys and Chelus perhaps have sex macrochromosomes, and that, therefore, the ancestry of sex minichromosome in South American Chelidae is far from being established. Moreover, the homology between Chelodina and Rhinemys sex minichromosomes remains an open question until otherwise proven.

To date, neither the synteny of the Y-minichromosome with chromosomes of other species nor its gene content are known. Genetic markers allowing comparison between Emydura, Chelodina and South American Chelid sex chromosomes are still lacking. Thus, the unicity of GSD mechanism in Chelidae remains to be demonstrated. If all Australasian Chelids share the same XY system, it will be at least 102 million years old [39]. If this is the case for all Chelids, the common XY system will be between 117 and 160 million years old [39]. The master sex-determining gene is still to be found, but some candidates can already be ruled out. Bacterial Artificial Chromosomes (BACs) carrying Chrysemys picta (another turtle) sequences from genes involved in the sex determination network were used to localize homologous genes on the chromosomes of different turtle species [91]. The tested genes were Dax1, Dmrt1, Fgf9, Fhl2, Foxl2, Gata4, Rspo1, Sf1 (=Nr5a1), Sox9 and Wt1. The ten probes gave signals on Emydura autosomes, but none of them labels Emydura sex chromosomes [91]. Consequently, these genes can be excluded as candidates for sex determination locus in Emydura. 
To summarize, all Chelids seem to possess a GSD system of sex determination with poorly differentiated XY chromosomes that can be identified only by high resolution cytogenetics. Australasian species likely share a common sex determination system involving an unknown master gene, whereas South American species remain in urgent need of investigation with modern methods.

\subsubsection{Cryptodiran Turtles}

Trionychia

The New Guinean and Australian pig-nosed turtle Carettochelys insculpta is the sole member of the Carettochelyidae family. Temperature sex determination was demonstrated experimentally in this species [92]. The Trionychidae family (softshell turtles) is composed of 30 species dispatched in two subfamilies, Trionychinae with 24 species and Cyclanorbinae with 6 species (Figure 5). The history of the Trionychidae sex-determination discovery shares some similarities with that of Chelidae. The standard karyotypes $(2 n=66$ for all species tested so far) show homomorphic chromosomes [93-95], while controlled incubation temperature experiments recover GSD species, Apalone spinifera (under the name Trionyx spiniferus) [96], Pelodiscus sinensis (under the name Trionyx sinensis) [97] and Apalone mutica $[48,98]$. As for Chelids, CGH clarified the situation, demonstrating the existence of a sex minichromosome pair ZW in P. sinensis [99]. It also definitively ruled out some erroneous claims about possible TSD in some P. sinensis populations [100]. Nuclear Organizer Region (NOR) and 18S-28S rRNA clusters are located on this minichromosome [99], with the differentiated $\mathrm{W}$ chromosome more strongly stained by such probes than the smaller $\mathrm{Z}$ chromosome. The larger size of the $\mathrm{W}$ chromosome is partly due to the amplification of the rRNA cluster at its centre. $\mathrm{W}$ chromosome differentiation also implies a paracentric inversion compared to the $\mathrm{Z}$ chromosome [101]. Later, such a NOR-bearing sex minichromosome pair was also discovered in A. spinifera [102] with the same larger $W$ chromosome. ZW sex chromosomes share homology with chicken chromosome 15 [101], even though the order of the genes is not the same. The genome assembly of P. sinensis was the first turtle genome available [36], and the sequenced animal being a female, it contains both $\mathrm{Z}$ and $\mathrm{W}$ sequences. However, the sex chromosome sequences are still unmapped, and a physical map of the sex chromosomes is still lacking. Using the linkage with chicken chromosome 15, six markers of $P$. sinensis chromosome $\mathrm{Z}$ were developed [103]. qPCR experiments dosing the gene copy number in both male and female genomic DNA allowed testing of P. sinensis, A. spinifera and eight other Tryonichids from genera Lissemys, Chitra, Amyda and Nilssonia with success [103]. Female/male ratio of 0.5 indicated that the gene was $Z$-specific, whereas a ratio of 1 indicated the gene was autosomal or pseudoautosomal. All the species were found to possess a homologous $Z$ chromosome [103]. This suggests that the common ZW system arose after the split between Carettochelyidae and Trionychidae (200 Myr) and before the split between Trionychinae and Cyclanorbinae (120 Myr). Chicken chromosome 15 is a small chromosome bearing less than 400 protein-coding genes, but despite this and the availability of the genome, the master sex-determining gene is still unknown in the family. As for Chelids, ten candidates were ruled out because none of them localized on P. sinensis Z or W chromosomes. However, Sf1 and FoxL2 mapped on Z and Y chromosome in A. spinifera but not in P. sinensis [91], demonstrating that $Z$ chromosome content slightly varies in different species of Trionychidae. Two recent studies addressed the questions of the $\mathrm{Z}$ chromosome content in genus Apalone and of the presence or absence of gene dosage compensation $[104,105]$. By comparing the read coverage between male and female genomic sequencing in Apalone ferox, selecting genes with a female to male ratio less than 0.7 , and with orthologs on chicken chromosome 15 (GGA15), 220 candidate Z-specific genes were identified [104]. The adult blood cell mRNA expression level of these genes has been evaluated. Among the 220 candidate Z-specific genes, the expression level of 102 genes could be compared between males and females. Their female to male ratio is about half those of autosomal genes, demonstrating there is no dosage compensation between males and females in this species [104]. Moreover, using the expression level in 
Caretta caretta (a TSD species of another family) as a control, the authors concluded that expression of Z-specific genes was similar to the ancestral autosomal level in males, but lowered in females. Thus, they concluded there is no global gene dosage compensation in A. ferox. The second study was performed in a closely related species, A. spinifera [105]. Low-coverage genome sequencing of one male and one female and an analysis of read depth coverage after mapping of the reads against the $P$. sinensis genome identified putative sex chromosome scaffolds in this species. A total of $2.6 \mathrm{Mb}$ of $\mathrm{W}$-specific sequence and $34.2 \mathrm{Mb}$ of Z-specific sequence was recovered, and the scaffold uncovering the pseudoautosomal boundary was identified [105]. After filtering with different criteria (homology with GGA15 genes, percentage of sequence identity, etc.), a final set of 245 Z-linked genes was established, and their RNA-seq SNP analysis revealed 119 genes without SNPs in females. The expression of these 119 Z-linked genes in different organs and at different developmental stages was compared with those of $388 \mathrm{~A}$. spinifera autosomal genes, and with orthologs of both these Z-linked and autosomal genes in Chrysemys picta, a TSD species of another family. RNA samples were collected from adults (liver and gonads), hatchlings (blood, liver, and gonads) and embryos at five different developmental stages and incubated at two different temperatures. The analysis revealed a complex pattern of dosage compensation to equilibrate expression of sex-linked genes compared to their ancestral homologs. This dosage compensation was thermosensitive, more local than global and varied by tissue and developmental stage [105].
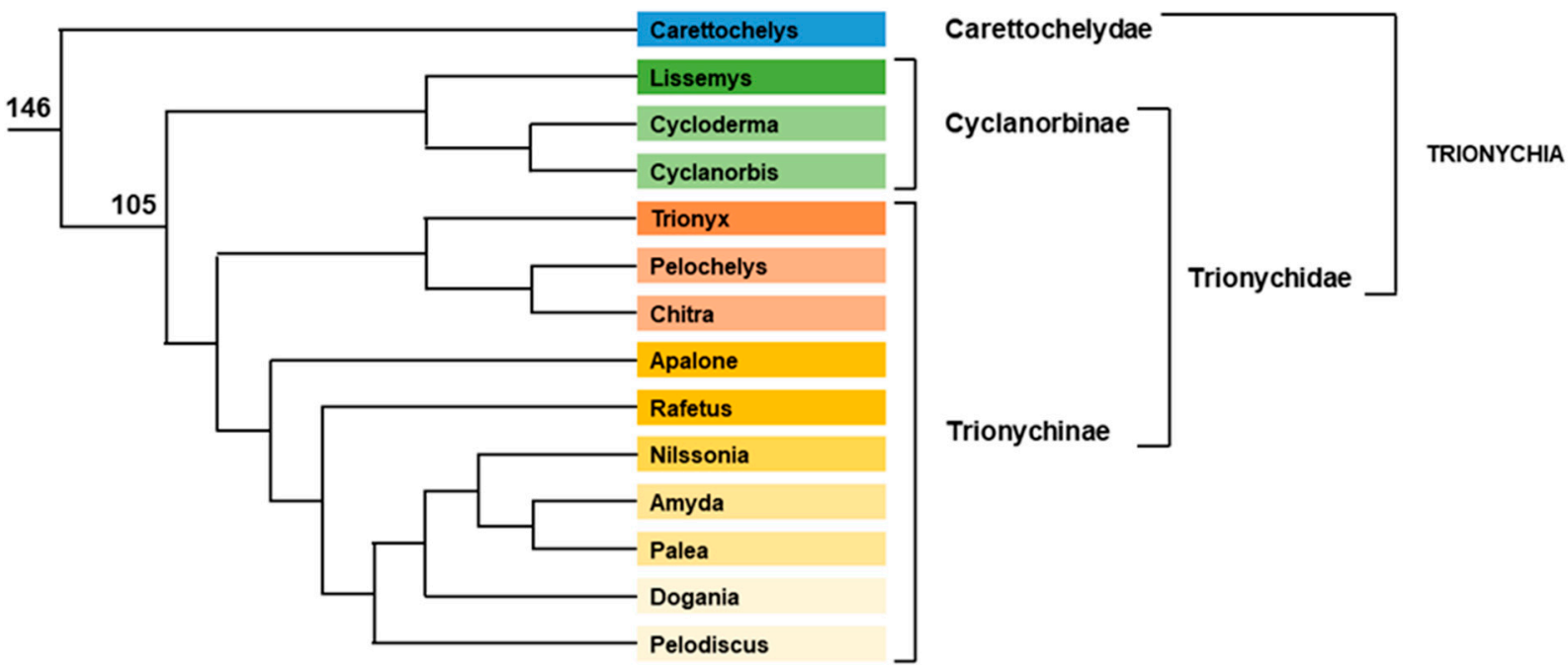

Figure 5. Phylogenic tree of trionychid turtles. Relative position of each genus and superior clade are represented. Branch lengths are not proportional to time. Numbers indicate divergence time (Myrs) from present for some key nodes, according to [39]. Color of each genus indicates the different clades.

\section{Durocryptodira}

Durocryptodira is divided in two clades: Americhelydia and Testudinoidea (Figure 3). Americhelydia

Americhelydia includes two clades. The first one, Chelonioidea, contains all sea turtles, separated into two families: Dermochelyidae, with the only leatherback sea turtle (Dermochelys coriacea), and Cheloniidae, with six species in five genera. Temperature dependent sex-determination occurs in all sea turtle species: D. coriacea [106], Chelonia mydas [107], Eretmochelys imbricata [108], Natator depressus [109], C. caretta [110], Lepidochelys olivacea [111] and Lepidochelys kempii [112].

The second clade, Chelydroidea, is divided into three families: Chelydridae with only two genera, Chelydra and Macrochelys, which exhibit TSD [48,113], Dermatemydidae with the sole species Dermatemys mawii also demonstrated TSD [114], and Kinosternidae, for which the situation is more complicated. Kinosternidae are divided in two subfamilies 
with different chromosomal numbers: Kinosterninae $(2 n=56)$, which contains the genera Kinosternon, with at least 20 species, and Sternotherus with four species, and Staurotypinae $(2 \mathrm{n}=54)$ with the genus Staurotypus, which includes two species and Claudius angustatus. Kinosterninae and Staurotypinae diverged 55 million years ago, Staurotypus and Claudius 25 million years ago, and the two Staurotypus species 5 million years ago [39]. In all species of Kinosterninae tested so far (3 Sternotherus and 10 Kinosternon), TSD occurs [48,73,115]. In contrast, the sex ratio following egg incubation at different temperatures demonstrated GSD in Staurotypus $[48,114]$ and less convincingly in Claudius because of the sample size (61 versus 7 only) for the two tested temperatures [114]. Moreover, both Staurotypus salvinii and S. triporcatus possess heteromorphic XY chromosomes [116], whereas C. angustatus exhibits homomorphic, supposed XY, sex chromosomes [116]. This cast some doubt on the reality of GSD in Claudius, which remains to be more firmly established. There is a slight difference between the two Staurotypus species. In both species the Y-chromosomes are acrocentric and smaller than the $\mathrm{X}$-chromosomes, whereas the $\mathrm{X}$ chromosomes are acrocentric in S. triporcatus and subtelomeric in S. salvinii. Using P. sinensis chromosome 6 as a probe to paint metaphase of $S$. triporcatus cells, Matsuda's laboratory demonstrated that $S$. triporcatus sex chromosomes are homologous to $P$. sinensis chromosome 6 , itself homologous to chicken $\mathrm{Z}$ chromosome [117]. Moreover, they cloned 16 S. triporcatus homologs of chicken Z-chromosome genes and used them in FISH experiments. They mapped them on the $\mathrm{X}$ and $\mathrm{Y}$ chromosomes of both Staurotypus species, demonstrating the conservation of the gene order between Staurotypus sex chromosomes and ostrich $\mathrm{Z}$ chromosome, which represents the ancestral state of the avian $Z$ chromosome [117]. Every 16 probes mapped on both $X$ and $Y$ chromosomes in the same order, suggesting these chromosomes are still in a poorly differentiated state and have not yet suffered major rearrangements, such as inversions. Among these 16 genes, Dmrt1 is of special interest because of it is pivotal in the male sex determination pathway in vertebrates, and itself or its paralogs have been selected by evolution to become the master sex-determining gene in birds, Xenopus laevis and some fishes. Dmrt1 could thus appear as a good candidate for such a role in Staurotypus, but it raises serious issues. Even if it could be due to the limits of the techniques used, Dmrt1 seems to be present in the pseudoautosomal region of both $\mathrm{X}$ and $\mathrm{Y}$ chromosomes, and not in the differentiated region. Moreover, two groups independently cloned S. triporcatus Dmrt1 from both male and female tissues and found the same sequence [117-119]. Therefore, both males and females seem to have two copies of the same Dmrt1 gene, even if the lack of Y-specific Dmrt1 could be due to sequence divergence in the region where the primers for amplification have been chosen. It is thus difficult to understand how Dmrt1 could be responsible for the sex determination in Staurotypus. A provocative hypothesis is that Dmrt1 is not the sex-determining gene. In fact, none of the $16 \mathrm{~S}$. triporcatus homologs of chicken Z-chromosome genes lie in the differentiated parts of either sex chromosomes, and the P. sinensis chromosome 6 probe does not paint these differentiated regions [117]. Although chromosomes 1, 2, 3 and 5 are homologous between S. triporcatus and its close Kinosterninae relative Sternotherus odoratus, the S.triporcatus sex chromosome pair, the fourth in size, is homologous to $S$. odoratus chromosome 7 [91]. Therefore, a fusion of S. odoratus chromosome 7, bearing Dmrt1, with one of the minichromosomes could have resulted in the S.triporcatus sex chromosome, differentiating the region homologous to the minichromosome, where the true sex determining gene would occur. Only whole genome sequencing of Staurotypus will answer this issue. The other nine candidate genes, mapped to S. triporcatus chromosomes by [91], lie on autosomes and can be ruled out. The master sex-determining gene in Staurotypinae thus remains unknown.

It has been claimed that the $\mathrm{X}$ chromosome, and not the $\mathrm{Y}$ chromosome, is the evolutionary derived chromosome in Staurotypus [120], but this is questionable. Firstly, it is based on comparisons with karyotypes of distant turtle species and not that of its nearest relative Claudius, and on an erroneous phylogenic hypothesis [93]. Secondly, it disagrees with the previous statement that "Claudius angustatus karyotype is indistinguishable from 
that of female Staurotypus" [116] which suggests that the $X$ chromosome is the ancestral state similar to the one existing in Claudius. Thirdly, the difference between the $\mathrm{X}$ and $\mathrm{Y}$ chromosomes in Staurotypus is partly due to differences in the copy number of the 18S-28S rRNA genes [117]. No available data on Claudius sex chromosomes allows to assess whether the $\mathrm{X}$ chromosome has been amplified or whether the $\mathrm{Y}$ chromosome has lost 18S-28S rRNA genes copies in Staurotypus compared to Claudius. There is, thus, a need for information about Claudius sex chromosomes before reaching a conclusion about the evolution of sex chromosomes in Staurotypinae.

\section{Testudinoidea}

Testudinoidea is divided in two clades, Testuguria and Emysternia which split one from each other 95 million years ago [39]. Testuguria is one of the less studied groups of turtles and for numerous genera the control of sex determination is still unknown. It includes two families: the Geoemydidae with 71 species, and the terrestrial Testudinidae with 65 species. No sex chromosomes have been described in Testudinidae, and all Testudinidae tested so far possess TSD. They belong to the genera Astrochelys [121], Centrochelys [122], Chelonoidis [123], Gopherus [124-126], Malacochersus [73], Manouria [127] and Testudo [30,128]. The genus Aldabrachelys is also cited as a TSD species [115], but the original source of this statement is lacking. Because of skewed sex-ratio in breeding programs, TSD is also very likely in Geochelone platynota [129] and Pyxis species [130]. No data exists for the genera Chersina, Chersobius, Homopus, Indotestudo, Kinixys, Psammobates or Stigmochelys.

Geoemydidae includes two subfamilies: Rhinoclemmydinae with 9 South or Central American Rhinoclemmys species, and Geoemydinae with 63 mainly South-Asian species composing 18 genera (Figure 6). TSD is documented in Rhinoclemmys areolata [48,73], Rhinoclemmys pulcherrima [48], Mauremys annamansis [73], Mauremys nigricans [73], Mauremys mutica [48,131-133], Mauremys sinensis [132], Mauremys japonica [134], Mauremys reevesii [135], Cuora flavomarginata [136], Melanochelys trijuga [48,73], Heosemys grandis [137] and Malayemys macrocephala [138]. Almost all studied species possess homomorphic chromosomes [89,139-143] with mostly $2 \mathrm{n}=52$, except in Rhinoclemmys punctularia $(2 n=56)$ [142] and in the two sister genera Orlitia and Malayemys $(2 n=50)[89,140,144]$. A ZZ/ZW system has been described in Pangshura smithii [145], but this observation was later demonstrated to be an error [146]. The only known exception is Siebenrockiella crassicollis $(2 n=50)$ which exhibits a heteromorphic pair of chromosomes, the $X$ being submetacentric and the $\mathrm{Y}$ being metacentric $[147,148]$. P. sinensis chromosome 5 probes paint both $S$. crassicollis sex chromosomes exclusively [148], demonstrating the strict homology between them. As $P$. sinensis chromosome 5 is homologous to chicken chromosome 5 [149], S. crassicollis sex chromosomes are also homologous to chicken chromosome 5. Fourteen $S$. crassicollis homologs of chicken chromosome 5 genes were cloned, and all mapped to $S$. crassicollis $X$ and $Y$ chromosomes, demonstrating their overall synteny despite a different gene order on chicken and S. crassicollis chromosomes [148]. However, the gene order is conserved between $S$. crassicollis $\mathrm{X}$ and $\mathrm{Y}$ chromosomes, suggesting the absence of major rearrangements. This may be interpreted as the sign that sex chromosomes are at an early stage of differentiation in this species. Although all fourteen genes are localized on the long arm of the submetacentric $X$ chromosome, the shift of the centromere put two genes on the short arm of the metacentric Y chromosome [148]. Among these fourteen genes, Wilms' tumour 1 (WT1), which is located near the pericentromeric region of the $Y$ chromosome where it begins to differentiate from the $X$ chromosome, is especially interesting. This gene encodes a transcription factor containing four zinc finger motif DNA-binding domains, which play an important role in the early formation of the urogenital system and in gonads differentiation in vertebrates. Numerous isoforms of the protein exist, and a variation of particular interest involves the omission or insertion of three amino acids (KTS) between the last two zinc finger domains, giving -KTS or + KTS isoforms. In mice, the absence of + KTS isoforms leads to complete XY sex reversal [150]. Conversely, mice with a specific change in the fourth zinc finger mimicking a mutation found in 46XX humans with testicular disorders of sex development, show masculinization of the embryonic XX gonad [151]. 
The role of WT1 in turtle gonad differentiation has not yet been entirely elucidated, but in Chelydra serpentina the ratio of +KTS/ - KTS isoforms is higher in developing gonads at male temperature than in those at female temperature [152]. Thus, WT1 seems to be a good candidate gene for the role of master sex gene in S. crassicollis. However, neither X- or Y-specific WT1 sequences or isoforms, nor differential levels of transcription from the $\mathrm{X}$ or Y WT1 gene copy, have been described, and further study is needed before definitive conclusions can be reached.

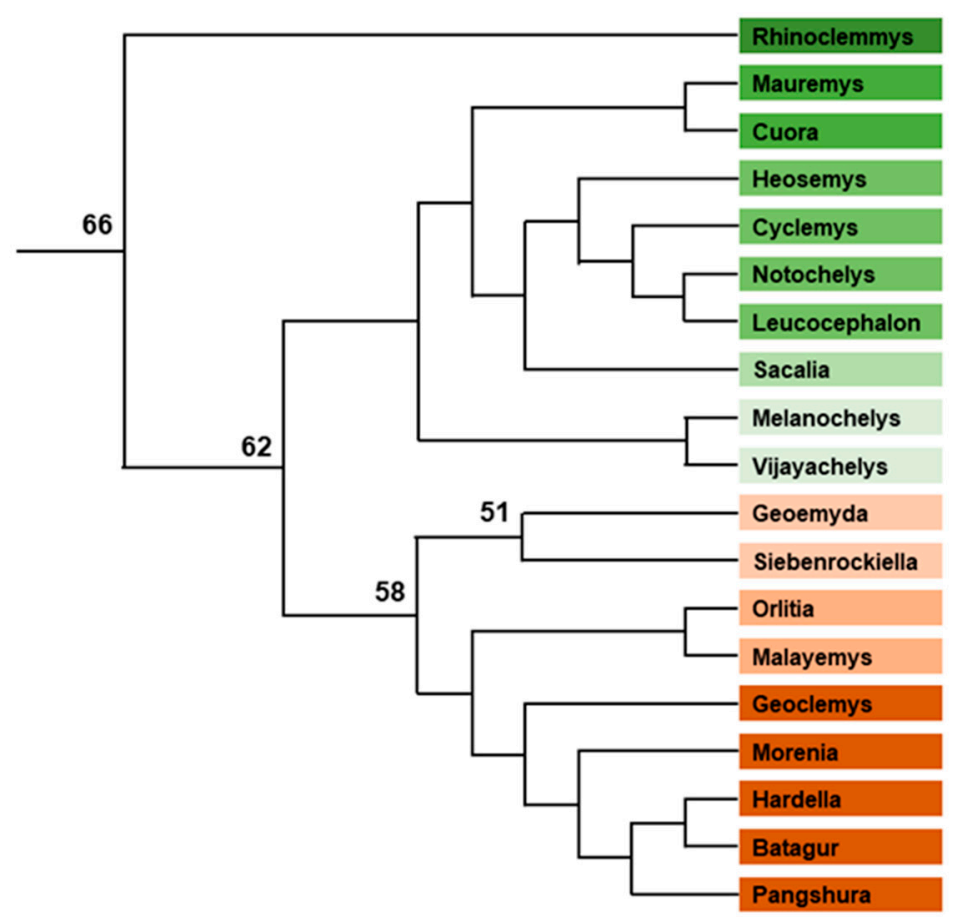

Figure 6. Phylogenic tree of geoemydid turtles. Relative position of each genus and superior clade are represented. Branch lengths are not proportional to time. Numbers indicate divergence time (Myrs) from the present for some key nodes, according to [39]. Color of each genus indicates the different clades.

The genus Siebenrockiella consists of two species. One of these, S. leytensis, is one of the rarest and most endangered turtles in the world. As Heosemys leytensis, it was first erroneously described from the Philippine Island of Leyte [153] and years later rediscovered in Palawan Island [154] and transferred to the genus Siebenrockiella [155]. The two Siebenrockiella species diverged 30 million years ago [39]. Unfortunately, the karyotype of $S$. leytensis is still unknown and thus we still do not know its chromosomic number and if heteromorphic sex chromosomes occur in this species. The genus Geoemyda, which contains two species G. spengleri and G. japonica, is the sister group of the genus Siebenrockiella and diverged from it 50 million years ago [39]. Both species possess homomorphic chromosomes $(2 n=52)$ similar to those of other Geoemydidae, and CGH fails to detect any sex-differences [146]. Their sex determination system (TSD or GSD) is also unknown. Given the apparently early state of sex chromosome differentiation in S. crassicollis, the homomorphic chromosomes in Geoemydea and the long-time divergence between the two genera, it is likely that genetic sex-determination in S. crassicollis is restricted to the genus Siebenrockiella or even to the sole species $S$. crassicollis.

Emysternia is divided into two families, Platysternidae with the sole species Platysternon megacephalum $(2 \mathrm{n}=54)$ and Emydidae $(2 \mathrm{n}=50)$ with 12 genera and 51 species (Figure 7). Being mostly composed of North American species, Emydidae has been intensively studied and TSD has been documented in 20 species that belong to 11 of the 12 genera $[30,48,73,137]$. In the last genus Glyptemys (2 species), GSD was demonstrated for the species G. insculpta [74]. The karyotype of G. insculpta was first claimed to be devoid of 
heteromorphic chromosomes $[95,156]$, but a reexamination with more modern methods has revealed the presence of a pair of heteromorphic chromosomes, the fourth largest in size, the $\mathrm{X}$ being subtelomeric and the $\mathrm{Y}$ being a little larger and submetacentic [157]. The process of chromosome $Y$ differentiation is in a relatively advanced state with a different G-banding pattern compared to the $X$ chromosome [157]. Moreover, the use of CGH shows the presence of three male-specific regions corresponding to the G-bands on the Y chromosome [157]. Lastly, hybridization with C. picta chromosome 4 BAC probes demonstrate the existence of two inversions between the $X$ and $Y$ chromosomes [157]. Thus, the $\mathrm{Y}$ chromosome has undergone many changes since it started to differentiate from the $\mathrm{X}$ chromosome. The sex chromosomes in G. insculpta are homologous to C. picta chromosome 4 [157], itself homologous to chicken chromosomes 5 (and 26) and P. sinensis chromosome 6 [158]. As S. crassicollis sex chromosomes are also homologous to chicken chromosome 5 and P. sinensis chromosome 6 [148], both G. insculpta and S. crassicollis sex chromosomes seem to be derived from the same part of the genome. It is tempting to speculate that the same region was selected twice by evolution because it encompasses an important gene of the sex differentiation network able to become a sex master gene driving evolution of a sex chromosome, but this remains to be proven. However, the WT1 gene is localized on both G. insculpta X and Y chromosomes [91] and is a good candidate for such a role. The generation of molecular markers for sex diagnostic by PCR in G. insculpta has also led to the discovery of the same XY system of sex determination in the other species of the genus, G. muhlenbergii [159]. Consequently, this sex chromosome system arose after the split of the genus Glyptemys from its sister group containing the genera Terrapene, Emys, Actinemys and Emydoidea and before the split between the two Glyptemys species. In a paper describing the sex chromosomes in G. insculpta, the authors give $-20 \mathrm{Myr}$ and $-8 \mathrm{Myr}$, respectively, for these events [157], while another paper gives a $-32 \mathrm{Myr} /-14 \mathrm{Myr}$ window [39]. Whatever the true dates, the claim of Glyptemys sex chromosomes as the youngest sex chromosomes in turtles [157] is challenged by the poor degree of differentiation of the $Y$ chromosome in S. crassicollis [148]. In this regard, the occurrence or not of sex chromosomes in S. leytensis will be of tremendous importance.

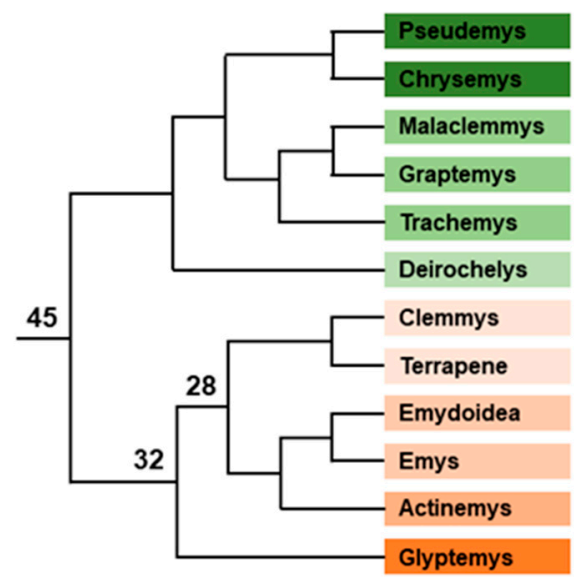

Figure 7. Phylogenic tree of emydid turtles. Relative position of each genus and superior clade are represented. Branch lengths are not proportional to time. Numbers indicate divergence time (Myrs) from present for some key nodes, according to [39]. Color of each genus indicates the different clades.

The last turtle family, the monotypic Platysternidae with the sole P. megacephalum, is the only turtle family with no information about its sex determination system. No incubation experiments at controlled temperature have even been performed. Only two publications give information about the P. megacephalum karyotype. One simply mentions that the karyotype is $2 n=54$ and refers to a future publication about turtle karyotype before adding in the addendum that "the work cited as in preparation by Kiester and Childress has been discontinued, there are presently no plans for formal publication" [160]. The 
second presents the karyotype obtained from three males and one unsexed juvenile [141]. Therefore, we do not know if the karyotype of a female has ever been examined. Even the draft of the genome of this species was obtained from a male [161].

\subsubsection{General Considerations}

Are there some possibilities that other sex chromosome systems exist in turtles? Some families such as Trionychidae, Kinosternidae or Emydidae have been highly investigated and offer no hope for this possibility, but some other taxa have been neglected and modern cytogenetics is lacking for them. The discovery of heteromorphic chromosomes in G. insculpta with modern cytogenetics is encouraging for efforts to reinvestigate some groups or species. For instance, the genus Pelusios in Pelomedusidae contains 15-20 species, but the karyotype is known for only four species and TSD has been demonstrated for only one species. South American Chelidae have been poorly investigated and merit a detailed study to determine if they share the same sex chromosome system as Australasian Chelidae. In Bataguridae, karyotype information is lacking for the genus Morenia, and the karyotype of some species such as Geoclemys hamiltoni is from unsexed animals [162]. Moreover, karyotypes of other species, such as Orlitia borneensis [142] or Hardella thurjii [89], are only known for one sex. In the genus Siebenrockiella, the karyotype of S. leytensis remains to be described and compared to those of $S$. crassicollis.

Overall, five different GSD systems exist in turtles. When looking at their phylogenetic distribution, the intuitive, simplest, and most parsimonious hypothesis is that these five systems arose independently from TSD (Figure 8A). Unexpectedly, the laboratory of N. Valenzuela published another model [50]. Using maximum likelihood procedures, they claimed that the transitions from TSD to GSD leading to GSD in Chelidae and Trionychidae were very old and occurred before they split from Pelomedusoides and Carettochelyidae, respectively. Accordingly, they postulated two putative transitions from GSD to TSD in both Carettochelyidae and the common ancestor of Pelomedusoides (Figure 8B). Moreover, the study of the rate of molecular evolution of genes implicated in sex-determination gave some support to this hypothesis [163]. If true, this model implies two testable consequences. Firstly, as recently pointed out by [164], it means that TSD in both Pelomedusoides and Carettochelyidae is a derived state and therefore not homologous to TSD in other turtles. Consequently, we expect a different mechanism for TSD in these families compared to other turtles. The deciphering of the mechanisms of TSD in reptiles has made tremendous advances recently [165-167]. In the turtle Trachemys scripta elegans, the key factor is Lysine Demethylase 6B (KDM6B or JMJD3), which promotes the male pathway by activating the male sex-determining gene Dmrt1 [166]. At female-producing temperature, likely in response to a rise in $\mathrm{Ca}^{2+}$ levels, Stat3, Signal Transducer and Activator of Transcription 3 , is phosphorylated and transcriptionally represses expression of $K D M 6 B$, pushing the gonad towards a female phenotype [167]. If such a mechanism were also active in Pelomedusoides and Carettochelyidae, this would not be in favor of Valenzuela's model. Secondly, this model entails that, for example in Pelomedusoides, the autosome homologous to the $\mathrm{X}$ chromosome of Chelidae was an $\mathrm{X}$ chromosome during the interval between the two transitions of sex-determining mechanisms. Unlike autosomes, an X chromosome spends more time in females than in males. Because gametes experience fewer division cycles in ovary than in testis, mutations occur at a slower rate in females compared to males. Therefore, an X chromosome accumulates fewer mutations than an autosome, as documented in mammals [168]. So, if Valenzuela's model is right, by comparing the substitution rate of X-linked Chelids genes with their autosomal orthologs both in Pelomedusoides and in an outgroup (some TSD cryptodirian species as C. picta for instance), one would expect a slower rate in Chelids and an intermediate rate in Pelomedusoides compared to outgroup species. The same type of reasoning can be made for the $\mathrm{Z}$ chromosome genes of Trionychidae and its orthologs in Carettochelyidae and a TSD Durocryptodirian outgroup, with the only difference being that the $\mathrm{Z}$ chromosome accumulates more mutations than autosomes. Of course, such analyses will require whole genome sequences of Carettochelys and Chelids, 
Pelomedusoides and Trionychids species, which are not yet available. However, with the growing number of available genomes, it will soon be possible to test Valuenzela's model.

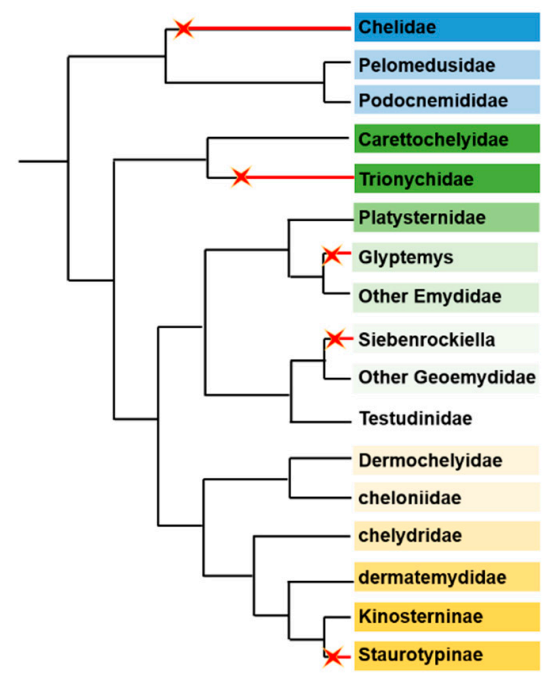

Parsimonious model $(A)$

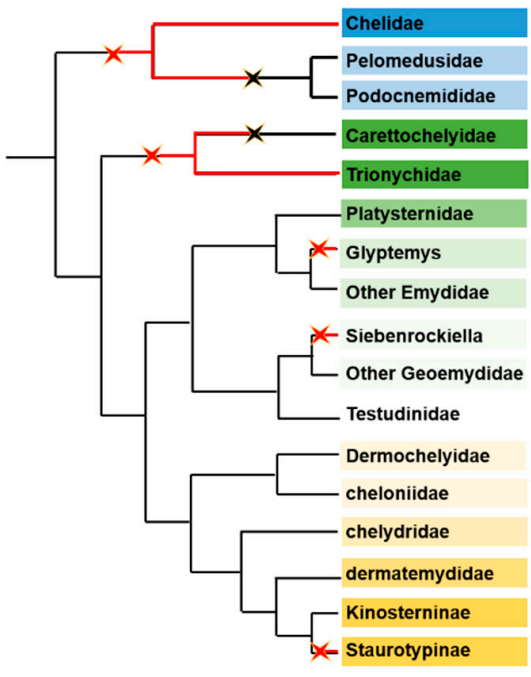

Valenzuela's model (B)

Figure 8. Models for transitions among sex-determining mechanisms in turtles. Black lines indicate branches where TSD occurs, red lines indicate branches where GSD occurs. Red stars indicate TSD to GSD transitions, black stars indicate GSD to TSD transitions. (A) Parsimonious model with five independent TSD to GSD transitions; (B) Valenzuela's model with two older TSD to GSD transitions in pleurodira and trionychia, respectively, and two putative GSD to TSD transitions in pelomedusoides and carettochelyidae, respectively.

\subsection{Lizards}

Among Lepidosauria, Rhynchocephala is represented by the two species of tuataras, which are TSD species [169]. All other Lepidosauria belong to Squamata, which is divided between the following groups (Figure 9).

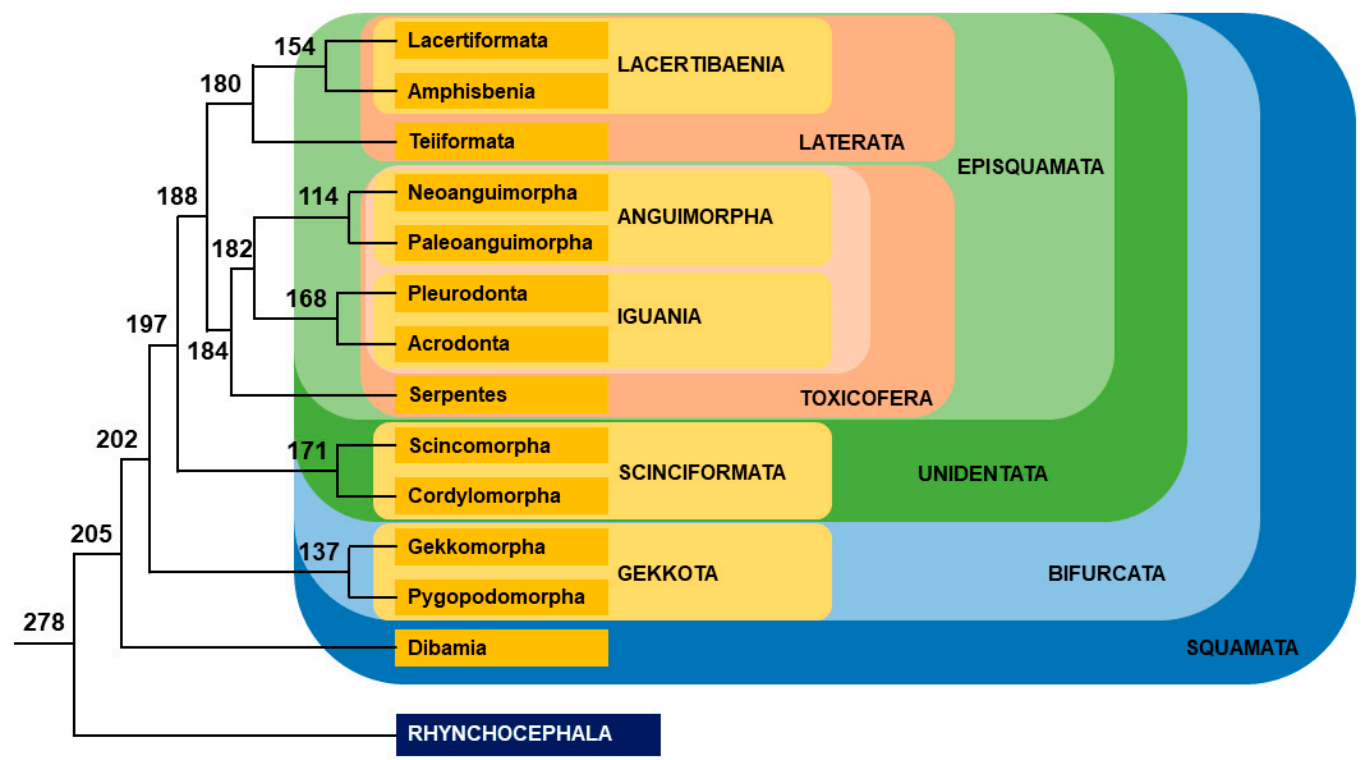

Figure 9. Phylogenic tree of squamates. Relative positions of each clade are represented following [38]. Names of clades are according to [170]. This tree has strong support, except for the position of Dibamia, which is sometimes alternatively placed as the sister group of Gekkota [171]. Branch lengths are not proportional to time. Numbers indicate divergence time (Myrs) from present for nodes, according to [38]. Colors indicate the different level of clades in the phylogenetic tree. 


\subsubsection{Dibamidae}

Dibamidae is a small family of almost limbless fossorial vermiform lizards distributed in Mexico for the genus Anelytropsis (one species) and between South East Asia and New-Guinea for the genus Dibamus (24 species). Dibamidae is either the sister group of all other Squamata (Figure 9) [38] or the sister group of Gekkota, together forming the sister group of all other Squamata [171]. The karyotype of only one species, Dibamus novaeguineae, is known [172], and it shows the presence of a heteromorphic pair of chromosomes in males. This pair, the fourth largest, is composed of a submetacentric chromosome similar to the pair found in females and thus thought to be the $X$ chromosome, and a telomeric chromosome specific to males and thought to be the $\mathrm{Y}$ chromosome. However, only one male and one female were studied, and this result needs confirmation. Whether XY chromosomes occur in other species of the family remains to be established.

\subsubsection{Gekkota}

With nearly 2000 species, Gekkota is one of the most numerous groups of lizards. Currently, it is divided into seven families but its phylogenetic tree is not yet stabilized [38,171], the position of the family Eublepharidae being the most contentious issue (Figure 10). Among Gekkota, the family Gekkonidae is by far the most numerous (1356 species). From early studies at the end of the twentieth century, it soon appeared that sex determination mechanisms were very diverse in this group. Some species, such as Eublepharis macularius possess TSD [173], whereas others exhibit sex chromosomes with either female heterogamy such as in Christinus marmoratus [174], or male heterogamy, such as in Lialis burtonis [175]. These transitions between sex determination systems can even occur in the same genus. For example, in the genus Gekko, G. gecko possesses an XX/XY sex chromosome system [176] and G. houkouensis a ZZ/ZW sex chromosome system [177]. With time, information about more species has accumulated and confirmed this variability [178-181]. In recent years, the use of restriction site-associated DNA sequencing (RAD-seq) helped greatly to identify sex determination systems in species with no known karyotype or homomorphic chromosomes. This technique amplifies and sequences DNA regions flanking specific restriction enzyme sites distributed throughout the genome in a number of male and female individuals. After validation, the presence of male specific markers indicates the species possesses $X Y$ chromosomes whereas female specific markers identify $\mathrm{ZW}$ chromosomes. In the case of TSD species, this experiment would give no sex specific fragment. This method requires only a few individuals of each sex (at least 5, ideally 10) for success. In Gekkota, RAD-seq experiments led to the identification of eight previously uncharacterized sex determination systems [182]. Coupled with a phylogenetic analysis, this revealed the existence of at least 15 independent transitions between sex determination systems in Gekkota, even within the same genus. For instance, in the genus Hemidactylus, H. frenatus has a ZZ/ZW sex chromosome system, whereas $H$. mabouia and $H$. turcicus possess an XX/XY sex chromosome system [182]. The RAD-seq method has succeessfully identified new sex chromosomes in a number of species or genera [183-185]. The lability of sex determination systems in Gekkota is reminiscent of what happens in frogs or some fishes, such as medaka $[5,10-13,186,187]$.

Among all of these identified sex determination systems, only a handful have been studied in detail. In Gekko hokouensis from Okinawajima Island (Japan), the Z chromosome is acrocentric and the $W$ chromosome subtelocentric [177]. Six homologues of chicken $\mathrm{Z}$ chromosome genes map to gecko $\mathrm{Z}$ and $\mathrm{W}$ chromosomes, demonstrating that they originated from the same pair of autosomes as in birds [177]. The differentiation of the sex chromosomes is rather advanced because several chromosome rearrangements must be postulated to explain the differences observed between the $\mathrm{Z}$ and $\mathrm{W}$ chromosomes. The $D M R T 1$ gene is present at different locations in the differentiated region of the $\mathrm{Z}$ and $\mathrm{W}$ chromosomes [177]. It represents a good candidate for the role of master sex-determining gene in this species, but there is no data about a difference in sequence or level of expression between the Z and W copies of DMRT1. Hybridization of G. hokouensis metaphases with 
$\mathrm{Z}$ and $\mathrm{W}$ chromosome probes of Christinus marmoratus, another Gekkonidae, marks the chromosome 5, not the sex chromosomes, demonstrating the sex chromosomes in these two ZW species are not homologous [188]. Moreover, just as G. hokouensis chromosome 5 is homologous to chicken chromosomes 23 and $4 p$ [189], sex chromosomes of C. marmoratus are also homologous to chicken chromosomes 23 and $4 p$. Chicken chromosome $4 p$ is homologous to mammals' X chromosome, and contains at least two genes, Sox3 and AtrX, which have been selected by evolution to become master sex-determining genes in other vertebrates. The only known member of the sex determination genetic network encoded by chicken chromosome 23 is the Rspo1 gene. It is thus a possible candidate for the role of MSD gene in this species.

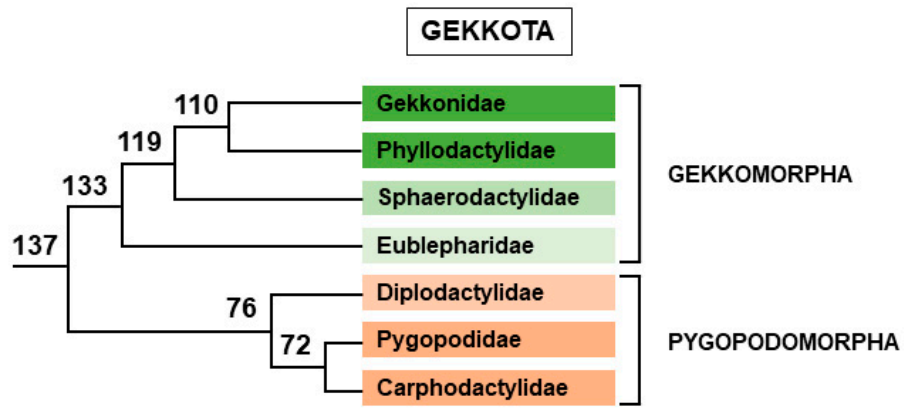

Figure 10. Phylogenic tree of Gekkota. Relative positions of each family are represented. Branch lengths are not proportional to time. Numbers indicate divergence time (Myrs) from present for nodes, according to [38]. Color of each family indicates the different clades.

Another group investigated in detail is the genus Paroedura [180,190], another member of the Gekkonidae. By classic cytology, all studied species seem to possess homomorphic chromosomes, but C-banding and CGH revealed the presence of a heterochromatic $\mathrm{W}$ chromosome in females of most species [180]. However, in a small clade of species, nested within other species with differentiated sex chromosomes, these techniques fail to detect distinguishable sex chromosomes [180]. After identification in a species with a heterochromatic $\mathrm{W}$ chromosome, $\mathrm{Z}$-specific markers show the presence of the same $\mathrm{ZW}$ system in all species with heterochromatic $W$ chromosomes, and its absence in the clade without differentiated sex chromosomes [190]. Because this ZW system is also lacking in Ebenavia, the sister group of Paroedura, and other more distantly related geckos, it likely appeared in the last common ancestor of Paroedura geckos (62-90 Myr) and was later lost in the clade with no differentiated sex chromosomes. The sex-determination system in this latter clade is thus unknown. In the other Paroedura species, the Z-specific markers are homologs to genes located to chromosomes $4 \mathrm{p}$ and 15 in chicken [190]. As mentioned previously for $C$. marmoratus, chicken chromosome $4 \mathrm{p}$ has been co-opted several times to become sex chromosomes. Chicken chromosome 15 also shows homology with sex chromosomes of Trionychidae turtles and Iguana lizards (see below). In Gekkonidae, Paroedura is closer to Christinus than to Gekko [191], and both Paroedura and Christinus sex chromosomes share homology with chicken chromosome 4p. However, it is likely that there were independent co-option events in each genus and not common ancestry, because chicken $4 \mathrm{p}$ homolog genes are autosomal in other genera classified between Paroedura and Christinus [189].

Still in Gekkonidae family, a recent study revealed the existence of both ZZ/ZW and $X X / X Y$ sex chromosome systems in the genus Cyrtodactylus [192]. Female heterogamy had previously been described by classical cytology in the species Cyrtodactylus pubisulcus [193]. By RAD-seq experiments, hundreds of female-specific RAD markers were isolated from the species $C$. pharbaungensis, and two sex-specific PCR primer pairs were validated, demonstrating this species possesses a ZZ/ZW sex chromosome system [192]. However, the same approach with the species $C$. chaunghanakwaensis led to the isolation of 166 male-specific markers and the validation of three sex-specific PCR primer pairs, indicating an $\mathrm{XX} / \mathrm{XY}$ 
sex chromosome system. Comparing these male specific markers against chicken genes using the basic local alignment search tool (BLAST) gave only two results on two different chicken chromosomes, and it was thus impossible to conclude about the homology of the C. chaunghanakwaensis sex chromosome in chicken [191]. With C. pharbaungensis, the BLAST comparison identified 38 chicken genes, half on them belonging to chicken chromosome 10 [192]. It is thus likely that the C. pharbaungensis sex chromosomes are syntenic to chicken chromosome 10. As no known member of the sex determination genetic network is located on chicken chromosome 10, no candidate for the role of MSD gene in C. pharbaungensis has been proposed so far. The sex-specific PCR primer pairs validated in C. pharbaungensis have not yet been tested in C. pubisulcus. Therefore, whether the two species share the same $\mathrm{ZZ/ZW}$ sex chromosome system or not is unknown.

In Phyllodactylidae (152 species), another gecko family, RAD-seq experiments allowed the discovery of a ZW sex chromosome system in the species Phyllodactylus wirshingi [184]. When compared with BLAST against chicken genes, only four of the 539 female-specific RAD contigs gave results, and all of them matched genes on the chicken $\mathrm{Z}$ chromosome. Thus, in P. wirshingi, sex chromosomes are homologs of chicken sex chromosomes [184].

In Sphaerodactylidae (229 species), a third gecko family, the same type of RADseq experiments demonstrated the occurrence of a ZZ/ZW system in four species of the genus Aristelliger [185]. Five out of 878 female-specific markers are homologs of genes located on both arms of chicken chromosome 2 (or for one of them, on chicken chromosome 33) which corresponds to Anolis chromosome 6 [194]. The linkage of these markers with sex chromosomes has not been tested in other genera close to Aristelliger, such as Quedenfeldtia or Teratoscincus. Therefore, the extent of this ZZ/ZW system among Sphaerodactylidae remains to be determined. Chicken chromosome 2 is also homologous to sex chromosomes of two different snake lineages (see below). No known member of the sex-determination genetic network is located on chicken chromosome 2 , but the authors of the study highlight the presence of $\beta$-catenin (CTNNB1) and $5 \alpha$-reductase (SRD5A1) genes on this chromosome [185].

In Eublepharidae (44 species), a recent study identified an $X_{1} X_{1} X_{2} X_{2} / X_{1} X_{2} Y$ sex chromosome system in Coelonyx elegans by comparing genome coverage between sexes [194]. The identified X-specific genes have homologs on chicken chromosomes 1, 6 and 11 [194]. The extent of this sex chromosome system among other Eublepharidae geckos was investigated by qPCR experiments. Only C. mitratus, the closest relative of C. elegans [195,196], shares the same system as C. elegans [194]. More precisely, both Coelonyx variegatus and C. brevis, which are also GSD species [197] but with homomorphic chromosomes [198], lack this sex-determination system. Their sex-determination system is thus still unknown. As C. mitratus and C. elegans diverged from other Coelonyx species around $34 \mathrm{Myrs}$ ago, their sex-determination system is at least as old.

In Carphodactylidae (32 species), female heterogamy was first demonstrated in the species Underwooddisaurus milii by molecular cytogenetic methods [179]. More recently, whole genome sequencing from Saltuarius cornutus, another member of the family Carphodactylidae, and U. milii was performed [199]. Comparative genome coverage analysis between sexes led to the discovery of Z-specific genes in both species. These Z-specific genes were then tested in other species of the family by qPCR experiments. In S. cornutus and three other species of the genus Saltuarius, Z-specific genes are orthologs of genes from chicken chromosomes 17, 22 and 24, whereas in $U$. milii and five species of the genus Nephrurus, they are orthologs of genes from chicken chromosome 10, and to a lesser extent from chicken chromosome 17 [199]. It is not known if there are two different ZZ/ZW systems in the genus Saltarius on one hand and the genera Nephrurus and Underwooddisaurus on the other hand, or if all these species share a common sex chromosome system with an MSD gene homologous to a chicken chromosome 17 gene. In the case of two independent ZZ/ZW systems, they are at least 15-36 Myr old in Nephrurus and Underwooddisaurus, and $16 \mathrm{Myr}$ old in Saltarius. If there is a unique sex determination system, it is at least 29-46 Myr old [199]. Both regions homologous to chicken chromosome 10 and 17 have been 
co-opted several times in lizards (C. pharbaungensis, Pogona, Corytophanidae) to become sex chromosomes.

Lastly, in Pygopodidae, a small family of Australasian limbless geckos (46 species in 6 genera), the species L. burtonis was studied in detail [200]. Similar to L. jicari, the other species of the genus, L. burtonis exhibits $\mathrm{X}_{1} \mathrm{X}_{1} \mathrm{X}_{2} \mathrm{X}_{2} / \mathrm{X}_{1} \mathrm{X}_{2} \mathrm{Y}$ sex chromosomes [181], whereas two other Pygopodidae species, Aprasia parapulchella and Delma butleri, possess XX/XY sex chromosomes [201]. Transcripts from L. burtonis blood cells (two females and four males) and from one male $L$. jicari were sequenced, and the sequences were identified by comparison with chicken and other reptilian genomes. Genes with no SNPs in all five males were selected, and their chicken homologs mapped to the chicken genome. These genes were scattered with roughly the same density over all chicken chromosomes, except on the long arm of chicken chromosome 4 (4q) which is exceptionally enriched in such genes, suggesting this syntenic block is the homolog of the X-specific region of L. burtonis [200]. This hypothesis was confirmed by qPCR experiments, which demonstrated that genes homologous to chicken chromosome $4 \mathrm{q}$ genes are $\mathrm{X}$-specific not only in L. burtonis but also in L. jicari and three other Pygopodidae genera distributed throughout the Pygopodidae family. As this $X Y$ chromosome system is shared between four different genera, it is likely it arose before the differentiation of genera from the last common ancestor of Pygopodidae, at least 30 Myrs ago [200]. However, it is restricted to Pygopodidae, as female heterogamy occurs in its sister group, Carphodactylidae (Figure 10) $[179,199]$, and so posterior to the divergence between the two families some 55 to 78 Myrs ago [200]. Moreover, the analysis of gene expression in male and female blood cells shows that only genes homologous to chicken chromosome $4 \mathrm{q}$ genes differ in their expression between sexes, these genes being significantly less transcribed in males than in female [200]. In other words, there is no global gene dosage compensation in L. burtonis.

To summarize, chromosomic regions homologous to chicken chromosomes 2, 4p, 10, 17 and $\mathrm{Z}$ have been regularly co-opted independently in several groups of geckos and other reptilian lineages, but some gecko lineages have co-opted other unique chromosomic regions homologous to chicken chromosomes 1, 4q, 6, 11, 22 and 24. As recently emphasized by [199] these changes of sex chromosome systems in Gekkota are different than those observed in some fishes or amphibians because they are much more older and evolutionary stable [199].

\subsubsection{Scinciformata}

This phylum is divided into Scincomorpha on one side, with the huge family Scincidae (1715 species), and Cordylomorpha on the other side, with three small families: Cordylidae (70 species), Gerrhosauridae (37 species) and Xantusiidae (35 species) (Figure 11). In Cordylidae, all karyotyped species possess homomorphic chromosomes, and their sex determination system is unknown. In Gerrhosauridae, conventional cytogenetic methods revealed homomorphic chromosomes in all studied species, but a ZZ/ZW sex chromosome system was recently suggested in the species Tracheloptychus petersi [202]. In this species, CGH fails to reveal sex-specific part of a chromosome, but an rRNA probe marks two minichromosomes in males and only one in females [202]. Taken together, these results argue in favor of poorly differentiated sex minichromosomes in T. petersi [202]. Heteromorphic chromosomes are also unknown in Xantusidae, but a study identified a ZZ/ZW sex chromosome system in Xantusia henshawi [203]. This RAD-seq experiment recovered no male-specific and 267 female-specific RAD markers, demonstrating the presence of $\mathrm{ZZ/ZW}$ sex chromosomes. When compared against chicken and anole lizard genomes, these female-specific RAD markers matched with 4 and 16 genes, respectively. Of these genes, four were located on chicken chromosomes 7, 12 and 18, eight of them on anole chromosome 2 (homologous to chicken chromosomes 12 and 18), and the remaining eight on unmapped scaffolds or anole chromosomes 1 and 3 [203]. Attempts to use these markers on two other Xantusia species were unsuccessful, and therefore the extent of this ZZ/ZW sex chromosome system across Xantusiidae is still unknown. However, another recent study showed that parthenogenic females of Lepidophyma smithii, another Xantusiidae 
species, could yield offspring of both sexes, suggesting that female is the heterogametic sex in this species as well [204]. Lepidophyma is the sister group of Xantusia, and it is therefore possible that the two genera share the same ZZ/ZW system, but this remains to be proved. The authors of the Xantusia study note the presence of Sox9, a major component of the male pathway in vertebrates and direct target of the male-determinant factor SRY in mammals, on chicken chromosome 18 and likely on anole chromosome 2. However, they did not mention that $C B X 2$, another well-known member of the genetic sex-determination network, is also located on chicken chromosome 18 and on anole chromosome 2. CBX2, a polycomb protein, plays a major role in sex-determination because it seems to be a powerful repressor of normal ovarian development in mammals. In mice, the disruption of its gene leads to male to female sex reversal in homozygous mutants [205]. In human, a normal girl with a $46 \mathrm{XY}$ karyotype was found bearing one different missense mutation of $C B X 2$ on each allele of the gene [206]. Moreover, in two rodent species of the genus Tokudaia where both sexes are $X 0$ with no $S R Y$ gene, $C B X 2$ is present in multiple copies in both sexes and there are two or three more copies of $C B X 2$ gene in males than in females [207]. Therefore, $C B X 2$ is a strong candidate for the role of master sex-determining gene in Tokudaia. It would be thus interesting to assess the possible roles of both Sox 9 and CBX2 in Xantusia sex determination.

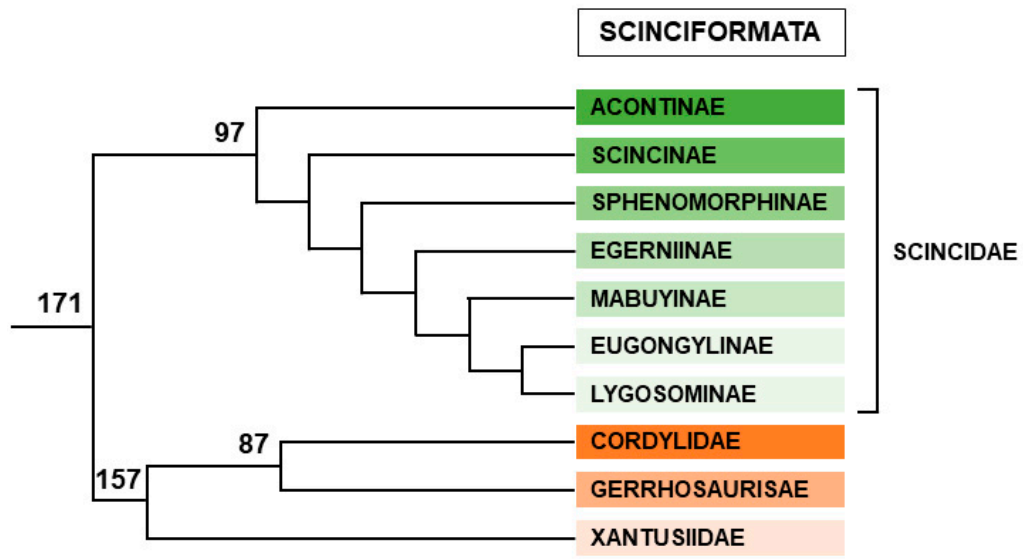

Figure 11. Phylogenic tree of Scinciformata. Relative positions of each family or subfamily are represented. Branch lengths are not proportional to time. Numbers indicate divergence time (Myrs) from present for nodes, according to [38]. Color of each family or subfamily indicates the different clades.

Skinks constitute a very successful (1718 species) cosmopolitan family since almost one of every four species of lizards belongs to their family Scincidae. Scincidae contains seven subfamilies, the most basal being Acontinae, and a second split separates Scincinae from the five remaining subfamilies (Figure 11). As with many lizards, most skinks possess homomorphic chromosomes, and heteromorphic XY chromosomes occur in only around 25 species scattered all over the family, with the highest concentration in some Australian skinks in which the heteromorphic pair is the seventh largest. Concerning sex determination, the situation has long been puzzling and the family was best known for some oddities. This included viviparous species with TSD in the genera Eulamprus [208] and Niveoscincus [209], a TSD species with heteromorphic sex chromosomes, Bassiana duperreyi [210], and a species, Niveoscincus ocellatus, with TSD-like and GSD in lowland and highland populations, respectively [211,212]. Further research has demonstrated sexreversal by temperature and existence of Y-chromosome markers in B. duperreyi $[213,214]$, and conservation of sex-linked markers in both populations of N. ocellatus [215]. Therefore, these two species likely are GSD species in which temperature can override GSD. Two recent studies shed light on a shared conserved XX/XY sex chromosome system in most skinks [216,217] In the first study, the authors sequenced male and female genomes of Scincus scincus (from basal subfamily Scincinae) and compared the coverage of exons between sexes [217] They identified 560 genes with half coverage in males compared to females. Then, they filtered these genes for the absence of polymorphisms in males, before 
mapping them to the high-quality genome of Podarcis muralis, another lizard belonging to Lacertidae. Among the 169 genes they recovered, 37 localized to a $7 \mathrm{Mb}$ region on the tenth chromosome of $P$. muralis [217]. Using qPCR, they tested 10 of these X-linked genes among 13 skink species covering all the subfamilies with the exception of Acontinae and demonstrated that all the species shared common X-linked markers. In contrast, these genes are autosomal in the three other Scinciformata families (Cordylidae, Gerrhosauridae and Xantusiidae), indicating that this $X X / X Y$ chromosome system is restricted to Scincidae and originated between 150 and $85 \mathrm{Myr}$ ago. The skink X-linked genes have homologs in chicken chromosome 1 [217]. This region contains several candidate genes for the role of master sex-determining genes, such as Stra8, Sox10, ep300 and Sbf1. A second study utilized a quite different transcriptional approach in the species Eulamprus heatwolei [216]. After obtaining transcriptomic data from brain, liver and gonads of males and females, a subtraction approach allowed the identification of Y-linked transcripts of 14 protein-coding genes. These 14 gametologs are all orthologs of genes located on a single block located on chicken chromosome 1 and anole chromosome 5 [216]. One of these gametologs is $U B E 2 H$, which was also identified as a Y-specific marker in B. duperreyi [218]. Moreover, five of the Y-linked markers previously identified in N. ocellatus [215] map to the same region of anole chromosome 5, indicating these two skinks share a homologous Y-chromosome [216]. From synonymous substitution rates of the gametologs and the divergence time between these two skinks, the authors estimate the sex chromosomes originated between 116 and $80 \mathrm{Myr}$ ago [216]. This is in good agreement with the minus 150-minus 85 Myr interval estimate of the other study [217]. Among the 14 identified gametologs, the authors emphasize PPP1R12A (Protein Phosphatase 1 Regulatory subunit12A), a gene that encodes an enzyme that interacts with the phosphoprotein phosphatase 1 catalytic subunit (PPP1C), the major dephosphorylation complex in cell. In humans, mutations in the PPP1R12A gene can lead to urogenital anomalies including sex-reversal in XY individuals [219]. Moreover, the PPP1CC gene, one of the members of the PPP1C complex, is a good candidate for the role of master sex-determining gene in Pleurodonts, another reptile lineage (see below), and the knock-out of its testis-specific isoform in mice leads to male sterility [220]. So, several results point to a role of proteins of the PPP1C complex in sex-determination. Unexpectedly, a ZZ/ZW chromosome system with differentiated chromosomes was discovered in Scincella melanostica, an Asian member of the genus [221]. This was very surprising because heteromorphic XY chromosomes have been described in S. lateralis, a North American member of the genus, and are also suspected to exist in two other North American Scincella species [222,223]. Differentiated XX/XY and ZZ/ZW chromosomes in the same genus are quite unusual in reptiles, the other known examples being in the gecko genera Gekko, Hemidactylus and Cyrtodactylus [182,192]. It should be very interesting to investigate the genus Scincella in detail using the Y-specific markers identified in other skinks.

Thus, Scincidae, with some exceptions in the genus Scincella, share a common ancestral $\mathrm{XX} / \mathrm{XY}$ chromosome system with a genomic sex-specific region homologous to chicken chromosome 1 and anole chromosome 5, whereas a ZZ/ZW chromosome system with a genomic sex-specific region homologous to chicken chromosomes 7,12 and 18 and anole chromosome 2 occurs in Xantusia and likely other Xantusiidae. In Gerrhosauridae, T. petersi possesses a ZZ/ZW chromosome system too, but its homology with the Xantusia system or lack thereof is unknown.

\subsubsection{Laterata}

Laterata are divided between Teiiformata with two families, Teiidae (171 species) and Gymnophthalmidae (270 species), and Lacertibaenia, composed of Amphisbenia (6 families, 203 species) on one side, and a single family, Lacertidae (354 species) on the other side (Figure 12). 


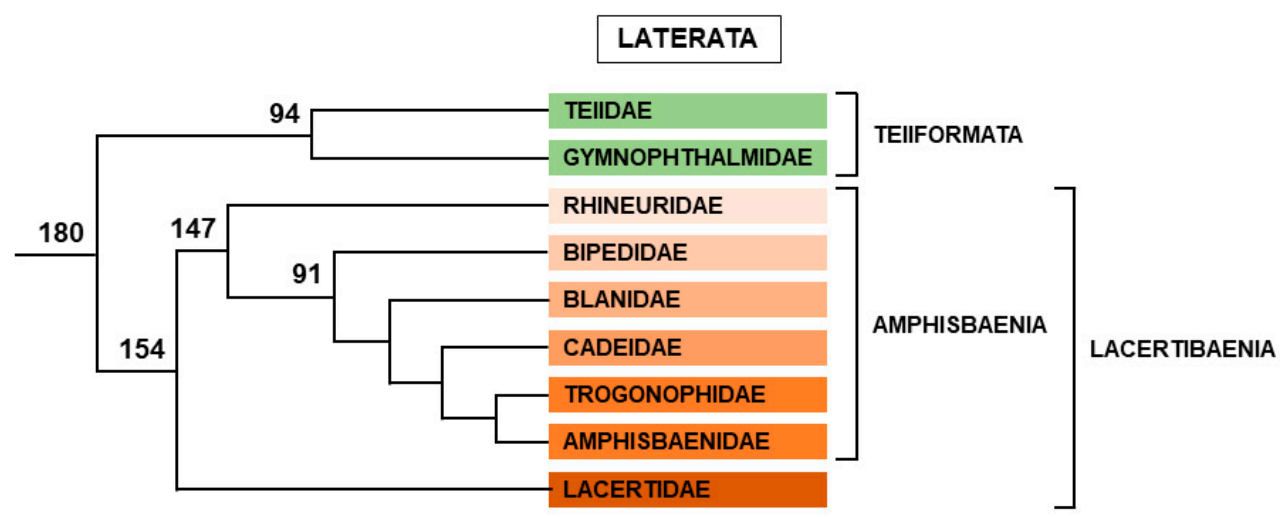

Figure 12. Phylogenic tree of Laterata. Relative positions of each family are represented. Branch lengths are not proportional to time. Numbers indicate divergence time (Myrs) from present for nodes, according to [38]. Color of each family or subfamily indicates the different clades.

In Teiidae, all species studied so far show homomorphic chromosomes, except Cnemidophorus tigris [224] and C. littoralis [225] which have conspicuous XY chromosomes. Whether this $X Y$ chromosome system extends to other genera or the whole family is unknown. In Gymnophthalmidae, heteromorphic XY chromosomes are less rare but restricted to only seven species of the sub-family Gymnophthalminae, in the genera Micrablepharus, Nothobachia, Calyptommalus and Gymnophthalmus [226-229]. All other tested species in subfamilies Gymnophthalminae, Ecpleopinae and Cercosaurinae possess homomorphic chromosomes. Whether this XY chromosome system occurs in the whole family and is homologous with those observed in the sister group Teiidae is not known.

Amphisbenia is a small group of fossorial limbless worm-like lizards, composed of 5 small families and the more numerous family Amphisbaenidae (182 species). Only karyological information is available for this group. One species, Bipes tridactylus, has a heteromorphic fourth pair of chromosomes in female and thus a ZZ/ZW system [230]. This result was established from the study of two males and three females and seems robust. The two other members of the family Bipedidae, Bipes biporus and Bipes canaliculatus [230]), and all other species studied so far possess homomorphic chromosomes. Examination of the whole group by modern methods will help to assess the extent of a ZZ/ZW system in Amphisbenia.

Lastly, Lacertidae (354 species), the common European lizards, includes species with homomorphic chromosomes and more than 35 species with female heterogamy (see Table 1 in [231], for complete references). The group of L. Kratochvíl and M. Rovatsos first identified Z-linked genes by looking for female transcripts devoid of SNPs in the species Takydromus sexlineatus [232]. Among the 85 genes found, most (51) had chicken orthologs scattered on 14 different chromosomes, but 23 genes had orthologs on chicken chromosome $4 \mathrm{p}$ and 11 genes had orthologs on chicken chromosome 17. After qPCR validation, they established that the Z-specific region of T. sexlineatus is homologous to chicken chromosome $4 p$, itself homologous to marsupial chromosome $X$, the $X$-conserved region of human chromosome $X$, and chicken chromosome 17 [232]. qPCR experiments later extended this result to Lacerta agilis and 43 other species from 25 genera covering the entire phylogenetic range of Lacertidae [231,232]. Therefore, all Lacertidae share the same ZW system, even if one or two genes sometimes exhibit autosomal (or pseudoautosomal) behaviour in one or two species, reflecting a species-specific variation of the pseudoautosomal region or species-specific translocation of some genes on autosomes. Moreover, these Z-linked genes are autosomal in Teiidae and Blanidae (an amphisbaenian family), suggesting that this ZW sex determining system took place after the split between Lacertidae and Amphisbaenia around $150 \mathrm{Myrs}$ ago, and before the split between the two sub-families of Lacertidae, approximatively 85 Myrs ago [233]. However, it would be very interesting to test these lacertid Z-linked markers in B. tridactylus, the only amphisbaenian with proven $\mathrm{ZW}$ chromosomes. 
The only known gene of the sex determination genetic network localised on chicken chromosome 17 is NR5A1 (Nuclear receptor subfamily 5, Group A, Member 1) (=Sf1, Steroidgenic factor-1). In humans, its mutation has been associated with XY sex reversal [233], and it has a very important role in testis differentiation in mice [234]. More candidates lie on chicken chromosome $4 \mathrm{p}$, especially Sox3, AtrX and AR (androgen receptor). Two paralogs of Sox3, SRY in mammals and Sox3Y in the fish O. dancena [5], have acquired the role of master sex-determining gene. In the axolotl $A$. mexicanum, ATRW the master sex-determining gene, having originated from a duplication of ATRX [27]. Lastly, $A R$ is suspected to be the male sex-determinant in the ZW type of Rana rugosa frogs [235]. It must be noted that at least one other unknown candidate exists in this syntenic block. Four species of rodents independently evolved a special feminizing $X$ chromosome, noted $X^{*}$, able to override the effect of SRY and leading to the existence of $X^{*} Y$ female (see [236] for review). It is tempting to speculate that it is the same unknown gene which was selected and mutated to assume this role in the four species. This unknown gene is perhaps specific to mammals or even rodents, but it could also be an important conserved gene of the sexdetermination network among vertebrates. If so, it could also be a good candidate for the role of master sex-determining gene in Lacertidae. Whatever the master sex-determining gene in Lacertidae, its mode of action is still unknown. In lizards from the genus Darevskia, ZZZW tetraploids are male and ZZW triploids are mostly females but with some males or intersexual animals [237]. This is rather in favour of a dosage of Z-linked gene mechanism than of a W-dominant gene mechanism, but there is still no definitive evidence.

To summarize our knowledge of GSD in Laterata, Teiiformata possess one or several XY systems, whereas only ZW systems exist in Lacertabaenia. All lacertids share the same ZW system, which arose from the co-option of a genomic block homologous to chicken chromosomes $4 \mathrm{q}$ and 17 . This lacertid $\mathrm{ZW}$ system is not present in at least one Amphisbaenian family, Blanidae (7 species), but it is still unknown if it is homologous or not with the ZW system of $B$. tridactylus, another Amphisbaenian.

\subsubsection{Toxicofera}

This clade is the most numerous one (more than 6000 species) among Squamates. It is divided between snakes (Serpentes) in one side, and two groups of lizards (Anguimorpha and Iguana) on the other side (Figure 13).

\section{Anguimorpha}

This group includes Paleoanguimorpha, with the family Varanidae (84 species of monitors (genus Varanus)) and two monotypic families (Lanthanotidae and Shinisauridae), and Neoanguimorpha, divided in Xenosauridae (12 species), Helodermatidae (5 species), Anniellidae (6 species), Diploglossidae (51 species) and Anguidae (81 species) (Figure 13).

The first evidence of sex chromosomes came from the study of the genus Varanus with the description of a ZZ/ZW sex minichromosomes in four species [238,239]. Later, this ZW system was discovered in other species [240-242]. Lastly, chromosome painting probes of Varanus komodoensis allowed the discovery of ZZ/ZW sex minichromosomes in six other species and demonstrated that the $Z$ chromosome was conserved in 12 species covering all the phylogenetic diversity of the genus [243]. Therefore, all monitors share the same ZW system. 


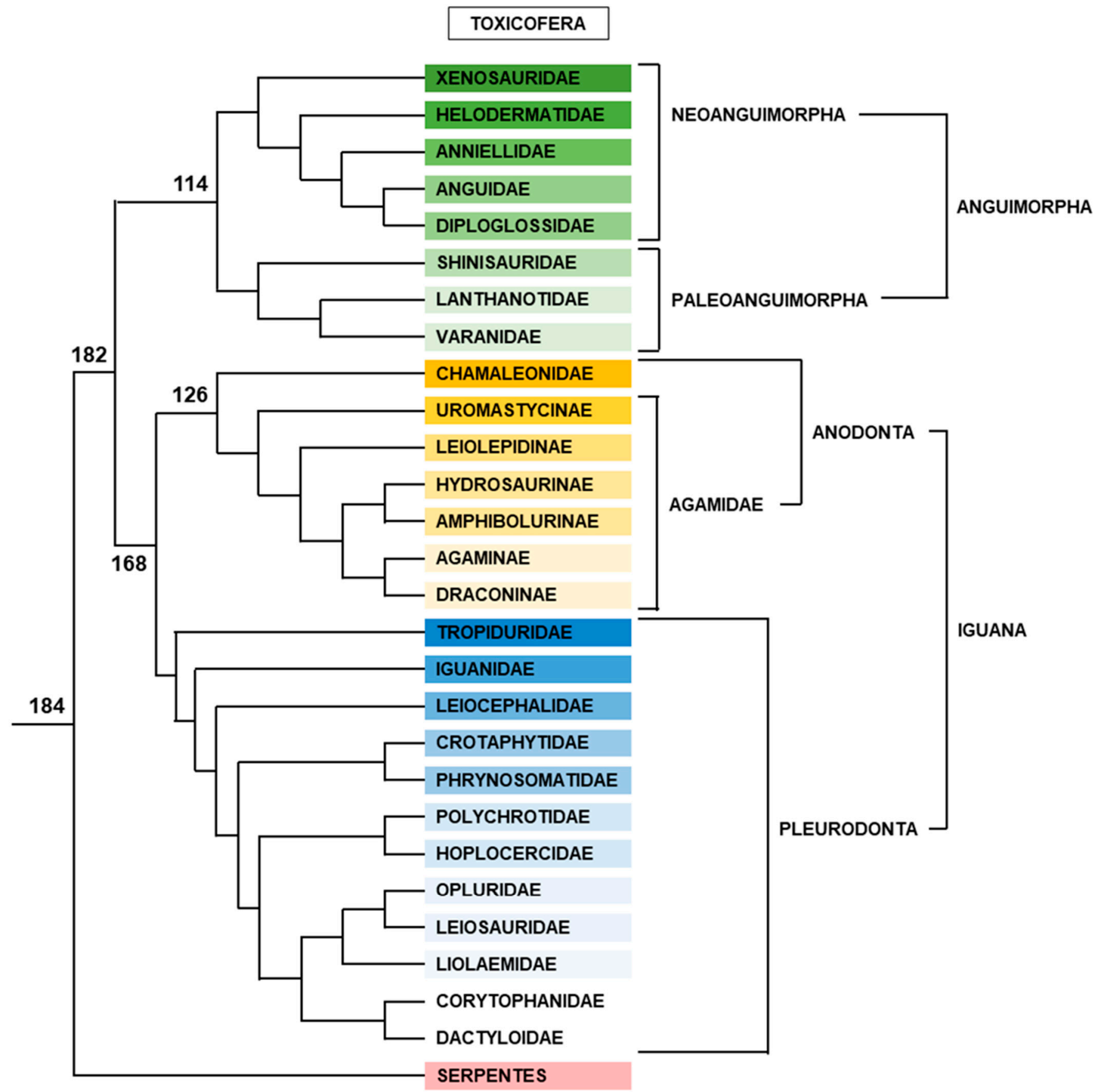

Figure 13. Phylogenic tree of Toxicofera. Relative positions of each family and superior clade are represented. Branch lengths are not proportional to time. Numbers indicate divergence time (Myrs) from present for nodes, according to [38]. Color of each family or subfamily indicates the different clades.

In another family, Helodermatidae, C-banding and CGH identified Z and W chromosomes in the Gila monster, Heloderma suspectum [244]. This raised the question of the homology of ZW systems between Varanidae and Helodermatidae. To answer this question, L. Kratochvíl and M. Rovatsos followed the same strategy that was used for Lacertidae and identified Z-linked genes by looking for female transcripts devoid of SNPs in several Varanus species [245]. They identified a Z-specific region in Varanus as homologous to chicken chromosome 28 and validated this result by qPCR experiments. Moreover, by testing Z-specific primers for $a p b a 3$ and grin $3 b$ genes in different species, they determined that these genes were Z-specific in 21 Varanus species, three Heloderma species and Abronia 
lythrochila, an Anguidae species [245]. Therefore, this ZW system is older than the divergence between Paleoanguimorpha (Varanidae) and Neoanguimorpha (Helodermatidae and Anguidae), around $115 \mathrm{Myr}$. As these genes are autosomal in Iguana and Serpentes species, this ZW system is specific to Anguimorpha. The occurrence of this ZW system in other Anguimorpha families (Diploglossidae, Xenosauridae, Anniellidae, Lanthanotidae and Shinisauridae) is unknown. Interestingly, in another Anguidae species, Anguis fragilis, these two genes are autosomal or pseudoautosomal [245]. This suggests either a change of sex chromosomes or more likely a longer pseudoautosomal region in this species. Another very important result of this study is the lack of dosage compensation in the expression of Z-linked genes in blood cells of Komodo dragon, V. komodoensis [245]. In a later study, the occurrence of a ZW system of sex chromosomes was confirmed or suggested by cytogenetics in more species. More precisely, in A. lythrochila a putative $\mathrm{W}$ chromosome was identified on a minichromosome by C-banding, and both C-banding and CGH revealed a female specific signal in two other Anguidae species: Celestus warreni and Gerrhonotus liocephalus [246].

Chicken chromosome 28 contains one major gene of the genetic sex-determination network: the Amh (anti-Müllerian hormone) gene. This gene has been independently co-opted several times to become the master sex-determining gene in some fishes, such as O. hatcheri [15] and the pike E. lucius [16]. It is also suspected to play this role in several other (but not all) Odontesthes species [247] and other fishes [248,249]. Lastly, it is very likely that Amh has also been recruited to become the MSD gene in monotremes, which exhibit the very unusual $X_{1} X_{2} X_{3} X_{4} X_{5} / Y_{1} Y_{2} Y_{3} Y_{4} Y_{5}$ sex chromosome system. In Platypus, it exists as two copies, namely $A m h Y$ located on sex chromosome $Y_{5}$, and $A m h X$, located in the oldest strata $\mathrm{S} 0$ (because the synonymous nucleotide substitution rate is highest between $\mathrm{X}_{1}-\mathrm{Y}_{5}$ gametologs) of sex chromosome $\mathrm{X}_{1}[21,22]$. Therefore, $A m h$ has been suggested as a very good candidate for the role of MSD gene in Anguimorpha [245].

Iguana

Iguana is divided in two clades: Anodonta and Pleurodonta (Figures 9 and 13).

Anodonta

This group includes two families, Chamaeleonidae (chameleons) and Agamidae (dragon lizards) (Figure 13). Sex-determination and sex chromosomes are rather poorly known in Chamaeleonidae (217 species). Old dubious records of TSD in genus Chamaeleo (see in [250]) were later demonstrated to be erroneous $[197,251]$. Controlled-temperature incubation experiments confirmed GSD in chameleons [197,252], but classical cytology failed to detect heteromorphic sex chromosomes in most species. However, CGH and C-banding experiments revealed the existence of female heterogamety in the genus Furcifer [253]. More specifically, F. oustaleti showed a classical ZW system with a highly heterochromatic $\mathrm{W}$ chromosome, whereas $F$. pardalis possessed a quite unusual $\mathrm{Z}_{1} \mathrm{Z}_{1} \mathrm{Z}_{2} \mathrm{Z}_{2} / \mathrm{Z}_{1} \mathrm{Z}_{2} \mathrm{~W}$ multiple sex chromosome system. This neo sex chromosome system likely arose from the classical one through a $\mathrm{W}$-autosome fusion [253]. Later, this rare $\mathrm{Z}_{1} \mathrm{Z}_{1} \mathrm{Z}_{2} \mathrm{Z}_{2} / \mathrm{Z}_{1} \mathrm{Z}_{2} \mathrm{~W}$ multiple sex chromosomes system was recovered in three other Furcifer species, and a classical ZZ/ZW system in F. lateralis [254]. However, CGH experiments failed to detect heteromorphic sex chromosomes in other genera such as Calumma, Chamaeleo, Rieppeleon and Trioceros [255]. The study of Rhampholeon temporalis by C-banding indicates this species may possess a $\mathrm{ZZ/ZW}$ system because heterochromatic blocks are different in the two chromosomes of the 8th pair in females; however, no males were examined and therefore this result needs confirmation [255]. Chamaeleo calyptratus is among the species where CGH failed to detect heteromorphic sex chromosomes [255]. However, RAD-seq experiments identified 13 male-specific and 2 female-specific RAD markers in this species, suggesting an $\mathrm{XX} / \mathrm{XY}$ sex chromosome system [256]. Moreover, five PCR primer pairs, derived from the malespecific markers, confirmed this result [256]. Four of these five PCR primer pairs amplified specific bands in male only in the close species Chamaeleo chamaeleon, demonstrating the two species share the same XX/XY sex chromosome system [251]. FISH experiments with 
the amplified fragment of one of these PCR primers pairs as a probe specifically stained the pericentromeric region of the short arm of only one of the two chromosomes 2 in male, identifying it as the $\mathrm{Y}$ chromosome [251]. Chromosome painting with chicken $\mathrm{Z}$ chromosome probe had previously identified the short arm of $C$. calyptratus chromosome 2 as the homolog of chicken $\mathrm{Z}$ chromosome [257]. It is thus possible that the sex chromosome of the two Chamaeleo species is homologous to the chicken $\mathrm{Z}$ chromosome, but this requires further investigation. As for the chicken homolog of Furcifer chromosome $Z$, results have not been published yet but in [258], the authors cited chicken chromosome $4 \mathrm{p}$ as a personal communication. In conclusion, Chamaeleonidae are GSD species with poorly differentiated homomorphic sex chromosomes, except in genus Furcifer, which possesses heteromorphic sex chromosomes, and at least one $\mathrm{ZW}$ system and one $\mathrm{XY}$ system exist in the genera Furcifer and Chamaeleo, respectively. In other genera, the extent of these systems or the occurrence of other systems remain to be investigated.

The second family, Agamidae (534 species), is very important because TSD was discovered in one of its members, Agama agama [29], and because this family exhibits the greatest variety of sex-determination in lizards, including TSD species, GSD species and GSD species where temperature can override genetic sex determination (see later). In Agamidae, heteromorphic sex chromosomes are rather rare and TSD seems to be the rule, but our level of knowledge is quite variable for the different subfamilies. In subfamilies Uromastycinae, Leiolepidinae and Hydrosaurinae, only some karyotypes are known, and they show no sign of heteromorphism, but their sex determination systems have never been determined. In the subfamily Draconinae, known karyotypes exhibit homomorphic chromosomes, and only the species Calotes versicolor has been studied in some detail. This species was first claimed to be a GSD species because of a lack of effect of temperature on sex-ratio [259], but later on, other experiments demonstrated TSD with a quite unusual FMFM pattern [260] and failed to identify sex-specific markers with RAD-seq [261]. Therefore, C. versicolor is now considered a TSD species [262]. In the subfamily Agaminae, TSD was demonstrated in several Agama species and ZW heteromorphic chromosomes were observed only in Phrynocephalus vlangalii, whereas other species of this genus possess homomorphic chromosomes [263]. This species is the only member of the family to have sex macrochromosomes. Nothing is known about the gene content of these sex macrochromosome pairs and their homology with chicken chromosomes, but a high-quality male genome and transcriptome of both female and male organs of P. vlangalii are available $[264,265]$. Therefore, the identification of gametologs by a transcription subtraction approach, such as those developed by D. Cortez laboratory could be possible. The last subfamily, Amphibolurinae, is the best studied. Its species are mostly Australian or New-Guinean, with only two reaching south-eastern Asia. Both TSD and GSD exist in this subfamily, and sometimes even in the same genus. For instance, the genus Amphibolurus contains both the TSD species $A$. muricatus and the GSD species A. norrisi ([250]. So far, GSD is known in the genera Amphibolurus, Ctenophorus, Diporiphora, Hypsilurus, Pogona, Rankinia, and Tympanocryptis $[250,266]$. However, sex chromosomes have been described in only 5 species (Pogona vitticeps, Pogona barbata, Diporiphora nobbi, Ctenophorus fordi and Tympanocryptis lineata), and in all cases they are ZZ/ZW sex minichromosomes $[262,267,268]$. Agamid ZZ/ZW sex minichromosomes were first discovered in P. vitticeps by CGH and C-banding [267]. It became the model species to study sex determination in this group. After isolation of markers of its $\mathrm{Z}$ and $\mathrm{W}$ sex chromosomes, establishment of its molecular cytogenetic map, and lastly sequencing of its genome, it was determined that its sex chromosomes are mostly homologous to chicken chromosome 17 and to a lesser extent homologous to chicken chromosome 23 [268-272]. The total sequence assigned to $\mathrm{Z}$ chromosome is at least $8.34 \mathrm{Mbp}$ with 219 genes [272]. The MSD gene is still unknown, but Rspo1, the only known member of the sex determination genetic network encoded by chicken chromosome 23, has been ruled out because it is localized on an autosome in P. vitticeps [273]. Among genes homologous to chicken chromosome 17 genes, NR5A1 is a strong candidate because it was mapped to $P$. vitticeps sex chromosomes by BAC hybridization, and because mutations in human and its knock-out 
in mouse both lead to male-to-female sex reversal $[233,274]$. Two other species, $P$. barbata and $D$. nobbi, share the same ZW sex determination system as $P$. vitticeps because the $P$. vitticeps sex-specific probe PvZW3 marks their sex minichromosomes [268]. Conversely, the same probe labels another minichromosome pair than the sex minichromosomes in $C$. fordi, suggesting a different ZW sex determination system than that observed in $P$. vitticeps [268]. As Tympanocryptis is relatively close to Pogona and Diporiphora, it is possible that $T$. lineata shares the same $\mathrm{ZW}$ sex determination system as $P$. vitticeps, but this remains to be demonstrated.

The influence of temperature is another very interesting point about sex-determination in $P$. vitticeps. Incubation of $P$. vitticeps eggs between $22{ }^{\circ} \mathrm{C}$ and $32{ }^{\circ} \mathrm{C}$ produced the expected 1:1 sex-ratio, but between $34^{\circ} \mathrm{C}$ and $37^{\circ} \mathrm{C}$ there was an increasing female bias leading to an almost $100 \%$ female production at higher temperatures, which could not be explained by differential lethality [275]. Moreover, genotyping with a W-specific probe demonstrated that at higher temperatures, half of the phenotypic females are genotypic males (ZZ). Thus, high temperature can override genotypic sex determination in in P. vitticeps [275]. This phenomenon is not restricted to laboratory experiments because up to $20 \%$ of females collected in the wild turned out to be ZZ sex-reversed females [276]. These ZZ sex-reversed females were fully fertile, and when mated with normal $\mathrm{ZZ}$ males gave birth to viable $\mathrm{ZZ}$ offspring the sex of which was determined by temperature only [276]. Thus, in only one generation, a GSD species can become a TSD species. This finding obliged researchers to reconsider the previous prevailing idea that GSD to TSD transitions are difficult and rare, and that sex chromosomes are an evolutionary trap [277]. However, it must be noted that despite the presence of numerous $\mathrm{ZZ}$ sex-reversed females in the wild, no isolated natural population of entirely $\mathrm{ZZ}$ individuals of both sexes has been discovered yet, suggesting there is an equilibrium between GSD and TSD that prevents the population from becoming fully TSD. The fact that the $P$. vitticeps $\mathrm{W}$ chromosome is not mandatory to produce females argues in favor of a male Z-gene dosage model of sex determination rather than a female-dominant $\mathrm{W}$-gene model.

\section{Pleurodonta}

This species-rich group (1223 species) includes 12 families (Figure 13), the most numerous being the family Dactyloidae (436 species). Classical cytogenetics has revealed that most species show no sign of chromosomal heteromorphism. However, the first lizard heteromorphic sex chromosomes were discovered in this clade, more precisely in some species of the genera Scleroporus and Anolis [278,279]. Only male heteromorphism was known in Pleurodonts. Among the species with homomorphic sex chromosomes, the species Anolis carolinensis from the family Dactyloidae became an important model organism and was the first non-avian reptile to have its genome sequenced [280]. In this species, FISH experiments with BAC probes led to the identification of the $\mathrm{X}$ chromosome as a minichromosome homologous to chicken chromosome 15 [280]. In this first study, at least $5.1 \mathrm{Mb}$ of sequence, containing 62 protein-coding genes, was assigned to this $X$ chromosome, named Linkage Group b (LGb) [280]. However, numerous scaffolds remain unanchored in the assembly, and it was hypothesized that some of them could belong to the $\mathrm{X}$ chromosome. By looking into unanchored scaffolds containing genes homologous to chicken chromosome 15 and testing them by qPCR in male and female genomic DNA, the number of X-linked genes increased to 250 [281]. Later, a comparative analysis between chicken and anole genomes suggested there were at least 374 genes on the anole $X$ chromosome [282], but another study restricted this number to 313 [283]. The FISH and qPCR experiments also demonstrated that the $\mathrm{Y}$ chromosome was highly differentiated and lacking most of the $\mathrm{X}$-chromosome genes.

The identification of the $X$ chromosome gene content allowed testing of the homology of sex chromosomes among Pleurodonts. Chromosome painting with sex chromosome paints, sequencing of chromosome-specific DNA, FISH of X-linked BACs, and qPCR of $\mathrm{X}$-linked genes demonstrated that all Anolis species, even those with large heteromorphic $X Y$ chromosomes or the multiple chromosome system $X_{1} X_{1} X_{2} X_{2} / X_{1} X_{2} Y$, share the 
same $\mathrm{X}$ chromosome gene content and thus the same sex-determination system [284-287]. Moreover, qPCR experiments with female and male genomic DNA led to the discovery of homologous sex chromosomes in almost all other pleurodont families $[285,288,289]$, with the exception of the family Corytophanidae [288,289]. Therefore, this sex chromosome system arose before the basal split between the different families 73-93 Myrs ago, and likely after the split between Pleurodonta and Acrodonta 123-168 Myrs ago. However, this last statement has been challenged by the study of gametologs.

The first attempt to identify the Y-chromosome gene content used RAD-seq experiments and led to the discovery of the only RTDR1Y gene and its X-linked partner RTDR1 (Rhabdoid tumor deletion region gene 1) [290]. A more successful male-female transcriptome/genome subtraction approach identified the complete coding sequences of seven protein-coding genes, including the previously known RTDR1Y gene [283]. Three of them, RPL6Y (Ribosomal protein L6), UBE2L3Y (Ubiquitin-conjugating enzyme E2L3) and EWSR1Y (Ewing sarcoma breakpoint region 1), exhibited ubiquitous expression like their $\mathrm{X}$-counterparts and homologs in other species. RTDR1Y was gonad specific similar to RTDR1 on the $\mathrm{X}$ chromosome and in other species. The last three genes, PPP1CCY (Protein phosphatase 1, catalytic subunit gamma isozyme), DENRY (Density-regulated protein) and SLC5A1Y (Solute carrier family 5 (sodium/glucose cotransporter), member 1) had acquired testis-specific expression, whereas their X-counterparts and homologs in other species were ubiquitously expressed (PPP1CC and DENRY) or possessed kidney-specific expression (SLC5A1Y) [283]. Moreover, phylogenetic trees of ancient XY gametologs and outgroup orthologs based on synonymous site divergences revealed that RPL6 and PPP1CC belong to the oldest stratum $\mathrm{S} 1$ and that they likely both originated before the split between Pleurodonta and Acrodonta 149-172 Myrs ago. The other Y-linked genes evolved after this split. Taken together, these results indicate that $P P P 1 C C Y$ is a very strong candidate for the role of MSD gene in Pleurodonts [283]. The PPP1CC gene is a member of the PPP1C (phosphoprotein phosphatase 1 catalytic subunit) complex, the major dephosphorylation complex in cells, and the knock-out of its testis-specific isoform in mice leads to male sterility [220]. Moreover, PPP1R12A (Protein Phosphatase 1 Regulatory subunit12A), a gene that encodes another enzyme interacting with the PPP1C complex, is a good candidate for the role of MSD gene in skinks, and in humans its mutation can lead to urogenital anomalies including sex-reversal in XY individuals [219]. Therefore, more and more, the role of the PPP1C complex and its components in sex-determination appears worthy of further investigation.

The origin of the pleurodonts XY sex-determination system before the split between pleurodonts and anodonts implies that this system persisted for a certain time in the ancestors of anodonts before the appearance and evolution of the ZW sex-determination systems observed today. A study addressed this question by analyzing male mutation bias in pleurodonts, anodonts and snakes [291]. During gametogenesis, male gametes undergo more replication cycles than female gametes, hence a greater mutation rate due to replication errors. Male mutation bias is the name given to this phenomenon. If we assume a 1:1 sex ratio in a population of an $X Y$ species, autosomes spend half their time in males and half their time in females, whereas the $Y$ chromosome spends all of its time in males and the $X$ chromosome spends one third of its time in males and two thirds in females. Consequently, the $\mathrm{Y}$ chromosome is expected to evolve faster (i.e., accumulate more mutations) than autosomes, whereas the $\mathrm{X}$ chromosome is expected to evolve more slowly than autosomes. The comparison between the synonymous substitution rates of pleurodonts $\mathrm{X}$-linked genes and those of their autosomal homologs in agamids and snakes shows that, among the tested species, the synonymous substitution rate is the highest in the six snakes because their genes remained autosomous since the split between snakes and Iguanans around $184 \mathrm{Myrs}$ ago, the lowest in the three pleurodonts because their genes stayed X-linked since the appearance of the pleurodonts' XY system (149-172 Myrs ago) just after the split between snakes and Iguanans, and intermediate in the three agamids because their genes had remained X-linked for several million years before becoming 
autosomous during agamid evolution [291]. Of course, this difference between the three groups is specific for pleurodonts' $X$-linked genes and was not observed for pleurodonts' autosomal genes. Interestingly, among the three agamid species, P. vlangalii, a ZW species from the subfamily Agaminae, showed a clearly higher synonymous substitution rate than P. vitticeps and Ctenophorus decresii, two species from the subfamily Amphibolurinae with ZW chromosomes or TSD, respectively [291]. This means that the common ancestor of Amphibolurinae species retained the pleurodont $X Y$ system longer than Phrynocephalus vlangalii. In other words, in Agamids, the Pogona ZW system is independent from and younger than the Phrynocephalus vlangalii ZW system. An estimation of the divergence times indicates that Phrynocephalus vlangalii lost the pleurodont XY system 105 Myrs ago, whereas the Pogona/Ctenophorus clade lost it only 20-60 Myrs ago [291].

The appearance of a dosage compensation mechanism in A. carolinensis constitutes another major discovery brought by the study of pleurodonts [282,283]. An early study, based on analysis of regenerating tail transcriptomes of different animals and determination of the male/female expression ratio for each gene, found a slightly incomplete dosage compensation ( 0.87 ratio, versus 1.01 ratio for autosomal genes) of $X$ chromosome genes in this species [282]. More specifically, it was suggested that complete dosage compensation occurred for the genes annotated on LGb (0.97 ratio) and incomplete dosage compensation (0.82 ratio) for those located on other scaffolds assigned to the $\mathrm{X}$ chromosome [282]. A more complete study analysed transcriptomes of four tissues and both gonads in A. caroliniensis, chicken, and four mammals [283]. Expression level of X-linked genes in anole was found to be the same in each sex, and similar to ancestral expression levels estimated from the expression levels of autosomal homologs in other studied species. Moreover, a male specific two-fold X chromosome expression up-regulation restoring the ancestral expression level was demonstrated [283]. This male-specific up-regulation is mediated by a male-specific change in the chromatin machinery. This is achieved by a specific elevated level of H4K16ac (H4 histone acetylated on the lysine 16) on the $\mathrm{X}$ chromosome in males, whereas autosomal H4K16ac levels were similar in males and females [283]. Interestingly, the expression of the APBB1 gene was the second most male-biased in anole lizard. Its protein, APBB1, is a cofactor of a histone acetyl transferase from the MYST superfamily called KAT5 which is able to up-regulate gene expression by acetylation of histones of the nucleosome. It is thus tempting to hypothesize that APBB1 is involved in the dosage compensation mechanism in A. caroliniensis. This complete dosage compensation in anole lizard shares many similarities with the dosage compensation mechanism in the fly Drosophila melanogaster. In this species, male specific $X$ chromosome up-regulation also occurs through acetylation of H4K16ac on the $\mathrm{X}$ chromosome following the action of MOF, another histone acetyl transferase from the MYST superfamily (see [292], for review). This is a striking example of convergent evolution in two highly divergent groups.

Lastly, the family Corytophanidae possesses a different XY chromosomes system. A first study used RAD-seq experiments to identify male-specific RAD tags in Basilicus vitttatus [293]. These male-specific RAD markers revealed synteny between the B. vittatus sex chromosome chicken chromosome 17, and this synteny was confirmed by qPCR of genes homologous to chicken chromosome 17 genes. These qPCR experiments in other species of the family confirmed that they all share the same synteny with chicken chromosome 17 , but also that some genes behaved similar to autosomal or pseudoautosomal in some species, suggesting a variation in length of the pseudoautosomal region, a translocation of some genes on autosomes, or a lack of differentiation of the gametologs on the $\mathrm{X}$ and Y chromosomes [293]. The authors noted the presence of the NR5A1 gene on chicken chromosome 17, and dated the appearance of this new XY system between 15-50 Myrs. Lastly, the comparison between male and female eye transcriptomes revealed a lack of dosage compensation in B. vittatus [293]. Another study used a quite different genomic and transcriptomic approach [294]. The sequencing of the B. vitttatus genome showed that the read coverage of sequences orthologous to the A. carolinensis $\mathrm{X}$ chromosome were the same in males and females, and that homologs of the A. carolinensis $\mathrm{Y}$ chromosome were no 
longer present in the genome of $B$. vittatus [294]. Thus, the general pleurodont XY system had disappeared from $B$. vittatus genome. The transcriptomic subtraction approach in $B$. vittatus led to the identification of 12 protein-coding Y-specific genes, all orthologous to genes located on chicken chromosome 17. Only $4.5 \%$ of chicken chromosome 17 genes had orthologs on the B. vittatus $Y$ chromosome, illustrating the highly differentiated state of $B$. vittatus sex chromosomes [294]. Among the twelve Y chromosome gametologs identified, only two, EHMT1Y and ZBTB34Y, showed regulatory functions, and only five, including EHMT1Y, were also present in the genome of Corytophanes hernandesii, another corytophanid [294]. Therefore, EHMT1Y, a histone lysine methyltransferase 1 encoding gene, seemed the most promising candidate for the role of MSD gene in corytophanids. However, it was expressed in many somatic tissues similar to its ancestor and was not testis specific as expected for an MSD gene. Most other Y-linked gametologs showed unusual features such as low-level expression, ubiquitous expression, or gain of kidney or blood cell expression compared with their ancestors [294]. A possible explanation for this lack of $Y$ gametologs with the expected features of a "good" MSD gene is that the MSD gene might not be a $\mathrm{Y}$ chromosome gene, but rather a dosage sensitive $\mathrm{X}$ chromosome gene. If this were the case, the study of other corytophanid species with less differentiated sex-chromosomes and longer pseudo-autosomal regions could be very helpful [193]. Contrary to the first study, male and female transcriptomic data from four somatic tissues and gonads indicated a partial dosage compensation [294]. This could be a problem for the dosage sensitive $X$ chromosome gene hypothesis, except if the dosage took place after the sex determination of the gonad. Whatever the MSD gene is, the study of gametologs and calibration by fossils dated the origination of this new XY system around 63 Myrs [294].

The ancestral pleurodont XY system is thus an old system (149-172 Myrs) which was present in the common ancestor of all species of the Iguana clade. It has persisted in Pleurodonts except in corytophanids where it was lost around $63 \mathrm{Myrs}$ ago and replaced by a new XY system with sex chromosomes homologous to chicken chromosome 17. It was also lost in all Anodonts, apparently several times independently, as its disappearance was dated to 105 Myrs ago for Phrynocephalus vlangalii and 20-60 Myrs ago for the Pogona/Ctenophorus clade. Furthermore, the new ZW system which replaced it in this latter clade also possesses sex chromosomes homologous to chicken chromosome 17. Many questions remain. Why was such a system so stable in some lineages and lost several times in other lineages? When was it lost in Chamaeleonidae and in other Agamidae, especially in the TSD species of Agaminae? Is there a reason for the independent co-option of chromosomes homologous to chicken chromosome 17 to replace the ancestral pleurodont $X Y$ system? Could this ancestral pleurodont $X Y$ system be traced back before the divergence between Anguimorpha and Iguana? Only through whole genome comparisons and detailed analyses could we begin to answer these questions.

A more detailed description of lizard karyotype features, sex determination and sex chromosome systems can be found in the present Special Issue "Sex chromosome evolution and Meiosis" [295].

\subsection{Snakes}

From a phylogenetic point of view, snakes are nested among lizards in the Iguana clade. Their phylogeny is complex and was only resolved by molecular studies (Figure 14) [38,171,191]. Among Squamates, they constitute a very successful group (3921 species). Most snakes belong to the clade Caenophidia (or modern snakes) (3238 species) which is the most recent clade to appear. The well-known boas and pythons and related families form the sister group of Caenophidia among Afrophidia (Figure 14). Snakes played an important role in the elaboration of the model of sex chromosomes evolution. By comparing chromosomes from different snake families, Susumu Ohno observed that boas possess homomorphic chromosomes whereas both Colubridae and Viperidae (two Caenophidian families) have heteromorphic $\mathrm{ZW}$ chromosomes. He also noted that $\mathrm{Z}$ and $\mathrm{W}$ chromosomes are of equal size and differ only by a pericentric inversion in most Colubridae, whereas the $W$ 
chromosome is highly degenerated and smaller than the Z chromosome in Viperidae [296]. These observations led him to propose that in vertebrates, sex chromosomes evolve from an autosome pair, first are homomorphic, then become heteromorphic but still of equal size, and finally become highly divergent in size [297].

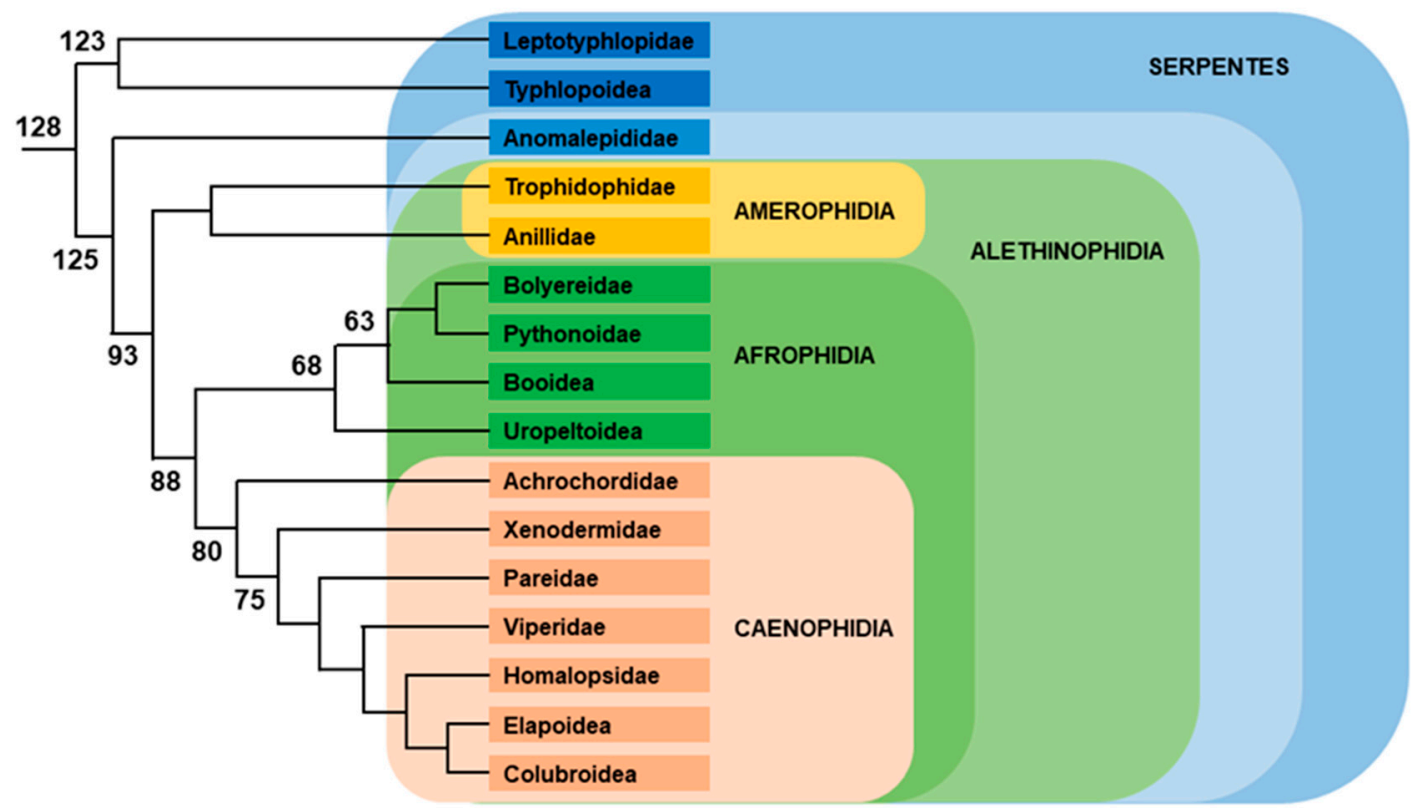

Figure 14. Phylogenic tree of snakes. Relative positions of each family and superior clade are represented. Branch lengths are not proportional to time. Numbers indicate divergence time (Myrs) from present for nodes, according to [38]. Colors indicate the different level of clades in the phylogenetic tree.

\subsubsection{Caenophidia}

All snakes from this group studied so far exhibit ZW sex chromosomes, even those from the two most basal families: Acrochordidae [298] and Xenodermidae [299]. The first snake cytogenetic map, constructed by BAC FISH experiments in the species Elaphe quadrivirgata (Colubridae), revealed that the snake $\mathrm{Z}$ chromosome is mostly homologous to chicken chromosome 2 and for a smaller part to chicken chromosome 27 [300]. Only three of the eleven probes marking the $\mathrm{Z}$ chromosome hybridize with the $\mathrm{W}$ chromosome too [300]. Moreover, these eleven probes are also localized to the $Z$ chromosome of the species Prothobothrops flavoviridis (under the older name Trimeresurus flavoviridis) (Viperidae), but none of them mapped to the $\mathrm{W}$ chromosome, suggesting a more differentiated state of the $\mathrm{W}$ chromosome in this species [300]. These probes map to Anole lizard chromosome 6 [301]. Genome sequencing of Thamnophis elegans (Colubridae) and Sistrusrus miliarus (Viperidae) confirm these results [301]. Analysis of genomic coverage of the scaffolds in both males and females revealed that in both species scaffolds homologous to A. carolinensis chromosome 6 (ACA6) show a nearly 2 -fold reduction in female coverage compared to male. These scaffolds are therefore part of the $\mathrm{Z}$ chromosome, whereas the coverage is the same for scaffolds homologous to other Anole lizard macrochromosomes. This is not the case for the non-caenophidian snake Boa constrictor (Boidae), which exhibited similar male and female coverage for all macrochromosomes [301]. Further analyses revealed the presence of 712 putative Z-linked genes and $61 \mathrm{~W}$-linked genes in S. miliarus, and 723 putative Z-linked genes and $29 \mathrm{~W}$-linked genes in T. elegans [301]. Another important result is the presence of at least two and more likely three evolutionary strata on $\mathrm{Z}$ chromosomes of both species, the older strata being central in the chromosome. Lastly, comparison of $Z$-linked genes expression in both sexes of $B$. constrictor and $S$. miliarus versus A. carolinensis demonstrate the absence of global dosage compensation in snakes [301]. The occurrence of a Z chromosome homologous to ACA6 in other caenophidian families 
was tested by qPCR experiments using six pairs of ACA6 gene specific primers [302]. This demonstrated that the $\mathrm{Z}$ chromosome is homologous to ACA6 in all caenophidian snake families (Acrochordidae, Xenodermatidae, Pareatidae, Viperidae, Homalopsidae, Colubridae, Elapidae, Lamprophidae). Only one gene, tanc2, seems autosomal or (more likely) pseudoautosomal in the most basal family, Acrochordidae [302]. Interestingly, all genes homologous to ACA6 genes are autosomal not only in Toxicofera lizards but also in non-caenophidian snakes from the families Pythonidae, Xenopeltidae, Boidae, Erycidae and Sanziniidae which belong to the sister group of Caenophidia [302]. Therefore, all caenophidian snakes share the same ZW sex chromosome system, which appeared in their last common ancestor. So far, there is no candidate gene for the role of MSD gene in Caenophidia, even if some important genes for gonad development or sex determination, such as Dazl or CTNNB1 ( $\beta$-catenin), localize on ACA6. Even if the MSD gene is still unknown, the important observation of a male Elaphe bimaculata (Colubridae) with ZZW sex chromosomes shed light on the mode of sex determination in caenophidian snakes [303]. This is more in favour of a dosage of a male gene on the $\mathrm{Z}$ chromosome, such as in birds, than in favour of a female master gene on the $\mathrm{W}$ chromosome. If this scenario is indeed the case in Caenophidia, the MSD gene should not be searched for in the gametologs of the most degenerated W chromosomes (Viperidae, Elapidae), but rather in the species with the least differentiated sex chromosomes, perhaps in the Acrochordidae family.

\subsubsection{Other Snakes}

Ohno's model assumed that boas, and by extension other related families, share the same ZW sex chromosome system with Caenophidia. With time, several lines of evidence cast some doubt on this statement. First, sequencing of $B$. constrictor genome fails to detect sequence difference between males and females in the macrochromosome homologous to ACA6 [301]), and all genes homologous to ACA6 tested so far are autosomal in boas and pythons [302]. Second, facultative parthenogenesis yields only male offspring in caenophidian snakes which is the expected result in a ZW species, but only female offspring in boas and pythons, a result expected for an $X Y$ species, and not easy to explain for a ZW species [304]. Lastly, a linkage study of a colour mutation called "coral glow" (CG) in the ball python (Python regius) demonstrated it was a sex-linked incomplete dominant mutation whose inheritance is not consistent with a $\mathrm{ZW}$ species, but rather with an XY species [305].Because both males and females can be phenotypically identified as homozygous or heterozygous for this sex-linked mutation, CG is likely localized in the pseudoautosomal region of the sex chromosomes. Moreover, as no other known traits are sex-linked in this species, the authors hypothesized that the sex chromosomes could be a pair of minichromosomes in P. regius [305]. They also hypothesized there is a possibility "that the henophidian sex chromosome share homology with the $X$ and $Y$ sex chromosomes of the pleurodont iguanians". Finally, they concluded that "identifying the molecular underpinnings of the henophidian sex determination system will require further investigation [e.g., identification of sex specific markers via RAD-seq]" [305]. Such RAD-seq experiments were published by another group one year later [306]. In their study these authors looked for the presence of an excess of female or male-specific markers in a boa (Boa imperator), a python (Python bivittatus) and a rattlesnake (Crotalus atrox), used as a caenophidian snake control [306]. As expected for a ZW species, they found an excess of female-specific RAD markers for the rattlesnake. However, they found an excess of malespecific RAD markers for boa and python, confirmed this result by PCR validation, and therefore demonstrated the presence of XY chromosomes in both species. Interestingly, the boa male-specific RAD marker confirmed by PCR is also male-specific in the very closely related species $B$. constrictor. On the contrary, the primers of the python male-specific RAD markers confirmed by PCR failed to amplify in a sex-specific manner in two related species: the ball python (P. regius) and the carpet python (Morelia spilota) [306]. The extent of this $\mathrm{XY}$ system among other python species is therefore unknown. The mapping of sex-specific RAD-seq markers to the boa genome and the search for sex-specific SNPs led 
to the identification of sex-specific scaffolds, most of them bearing genes homologous to the Anolis linkage group f (LGf) (i.e., one of the Anolis microchromosomes). Among the two python PCR-validated male-specific markers, only one gave a BLAST result in the python genome, which identified a scaffold homologous to Anolis chromosome 6 (ACA6). Moreover, among the five identified python transcripts with male-specific SNPs, three of them mapped to genomic regions homologous to ACA6 [306]. So, it seems that the same chromosome, homologous to ACA6, was independently selected to become a sex chromosome in P. bivittatus and caenophidian snakes, but as part of an XY and ZW system, respectively, whereas another chromosome, homologous to Anolis LGf was recruited in boas. This variability in sex chromosomes in snakes was also illustrated by the recent discovery of heteromorphic ZW sex chromosomes in Acrantophis sp. cf. dumerili, one of the four or five species in the family Sanziniidae [307]. This pair of heteromorphic sex chromosomes remains an exception in boas and pythons, as CGH and other cytogenetic studies failed to detect sex-specific differences in ten other species from the families Calabariidae, Sanziniidae, Candoiidae, Charanidae, Boidae and Pythonidae [307,308]. Lastly, C-banding identified a heterochromatic minichromosome in a female Myriopholis macrorhyncha, a scolecophidian snake, suggesting the presence of a ZW system of sex chromosomes in this species [309]. However, a unique female was examined, and thus this result needs to be confirmed with more animals of both sexes.

To summarize, although all caenophidian snakes share the same ZW sex chromosome system homologous to Anolis chromosome 6, non-caenophidian snakes exhibit variation in their sex chromosome systems, with at least two different $X Y$ systems identified in boas and pythons, and one ZW system identified in the boa A. sp. cf. dumerili.

\section{The Lessons from the Study of Sex Chromosomes in Reptiles}

\subsection{What We Learned}

During the last two decades incredible progress has been accomplished in the knowledge of sex chromosomes in reptiles, and it has profoundly changed our vision about sex determination in reptiles on many points. The first point is the relative abundance of TSD and GSD in reptiles. In turtles GSD is relatively rare (94 GSD species versus 262 TSD species), but it is now clear that GSD is the rule in Squamates and TSD rarer than previously thought. Currently, TSD is clearly documented in two groups only (Gekkota and Agamidae). Even in Gekkota, its occurrence is demonstrated in only a few genera (Eublepharis and Hemitheconyx in Eublepharidae, Tarentola in Phyllodactylidae, Phelsuma in Gekkonidae) (see [199] for references). Temperature can overrule GSD in a few skinks (Bassania, Niveoscincus) or agamids (Pogona), but it is rather rare. Moreover, phylogenetic reconstitution of sex-determination mechanisms among Squamates shows many transitions from TSD to GSD, or from GSD to another GSD (named turnover), but transitions from GSD to TSD seem restricted to the Agamidae family. In reptiles, the general evolution trend is thus from TSD to GSD, and a return to TSD likely constitutes a rare event.

The discovery of so many GSD systems in reptiles has changed the scientific community's opinion about the nature of these GSD systems. The discovery that many reptile groups (Chelidae, Tryonichidae, Scincidae, Pleurodonts, Lacertidae, caenophidian snakes) exhibit stable sex-chromosomes, as old as those of birds or mammals, was unexpected. Even geckos, previously thought to present a high lability of sex-determination systems, possess long-term stable sex-chromosomes that are more than 20 Myrs old [199]. Consequently, reptiles are similar to other amniotes in their stability of sex-determination systems, and different from amphibians and fishes, in which rapid turnover of sex-determination systems may occur, leading to very young sex chromosomes $[13,186,187]$. Nevertheless, some groups (geckos, non-caenophidian snakes, chameleons) show different sex-determination systems. Unsurprisingly, non-caenophidian snakes do not share the same sex determination system because they are very diverse, and their different clades diverged from each other million years ago. For instance, boas and pythons diverged from each other just after their divergence from caenophidian snakes, and the basal split between different 
families of blind snakes is much older. Our knowledge of sex determination systems in non-caenophidian snakes is too restricted to draw any conclusions but finding different sex-chromosome systems in their different families would not be unexpected. The same is true for geckos. As recently emphasized by [199], "the extant gekkotan families represent very old radiations, with the basal splits estimated to 57-180 Myrs." Thus, the occurrence of different sex chromosome systems in geckos reflects the deep phylogenetic divergence among gecko genera or families. Relatively recent turnovers between sex-chromosome systems seem restricted to a few genera (Scincella in Scincidae, Cyrtodactylus, Gekko and Hemidactylus in Gekkonidae) or families (Sphaerodactylidae, Chamaeleonidae). Such changes in sex-chromosome systems are not a specific reptilian feature. Even in mammals, which are the prototype for long-term stable sex chromosome systems, unknown different sex determination systems exist in several rodent species (for instance Nannomys minutoides, Ellobius lutescens and E. tancrei, Tokudaia osimensis and T. tokunoshimensis) and two different sex determination systems can occur in the same genus (Ellobius lutescens versus E. fuscocapillus) [236]. Therefore, reptiles do not appear very different from other amniotes.

Among amniotes, the only specific sex-chromosome change event in reptiles can be found in Agamidae family. In the subfamily Amphibolurinae, it is likely that the ancestral pleurodont's XY system was lost 20-60 Myrs ago, replaced by TSD, and that later (around 25 Myrs ago) a new ZW system appeared in the Pogona/Ctenophorus clade [294]. If true, it would be the only known change from one sex-chromosome system to another one through an intermediate TSD system. The other possibility is a direct turnover from the ancestral pleurodonts XY system to the new Pogona/Ctenophorus ZW system in the last common ancestor of all species in Amphibolurinae, followed by a transition to TSD in some species. Whatever the exact scenario, a change from a sex-chromosome system to a TSD system, similar to those demonstrated in the laboratory for $P$. vitticeps [276], is mandatory to explain TSD species in Amphibolurinae. Such a change is the only known example in Amniotes. Other transitions between two GSD systems can be explained by different theoretical hypotheses such as genetic drift, sexually antagonistic selection, accumulation of deleterious mutations or selection on sex ratio (see [310,311] for review). The discussion of these hypotheses is beyond the scope of this review, but for most transitions in reptiles, such as those observed in Pleurodonts/Corytophanidae, genetic drift (i.e., the emergence of a new MSD gene on an autosome, strong enough to overrule the ancestral MSD gene and leading to the disappearance of the old $\mathrm{Y}$ or $\mathrm{W}$ chromosome) seems the simplest explanation.

Table S1 summarizes our current knowledge of reptilian clades with GSD and sex chromosomes, including homology with chicken (GGA) chromosomes when known. In theory, any autosome can evolve into a sex chromosome if it receives a translocated copy of a dominant sex-determining gene, such as Dmrt1. However, when looking at the homology of reptilian sex chromosomes with GGA chromosomes, some GGA chromosomes are present several times, suggesting they were repeatedly selected by evolution to become sex chromosomes. For instance, GGA 17 appeared five times, GGA Z and GGA 4p four times, and GGA 2 and GGA 15 three times. Some support for this non-random selection hypothesis was statistically found among amniotes [258]. The most likely explanation for the recurrent recruitment of the same genomic regions is the presence of important genes for male or female gonad differentiation that are able to become an MSD gene (for example, Nr5a1 for GGA 17, Sox3 for GGA 4p, or Dmrt1 for GGA Z). It is of note that all members of the gonad differentiation genetic network do not have the same probability to become an MSD gene. For instance, Sox 9 , an important member of the male pathway and a direct target of SRY in mammals, also plays a major role in skeletal development. In humans, its mutation causes a severe skeletal dysplasia called campomelic dysplasia. Its recruitment as an MSD gene was thus hampered by the deleterious side-effects it would have caused. This is the likely explanation for why GGA 18 , bearing Sox9, appears only once in Table S1. Moreover, we want to emphasize that $C b x 2$ also localizes to GGA 18, and in our opinion seems a better MSD candidate than Sox9. 
Regardless of why the same genomic regions are repeatedly co-opted to evolve into sex chromosomes, this phenomenon offers the possibility to compare the evolution of a given region in two independent sex-chromosome differentiation events. Rovatsos and Kratochvíl took this opportunity to test the role of the genetic background in the evolution of dosage compensation [104]. In anole lizard (A. caroliniensis), $\mathrm{X}$ and $\mathrm{Y}$ chromosomes evolved from a genomic region homologous to GGA 15. In both males and females, $X-$ linked genes maintain their ancestral expression levels through a male specific two-fold $X$ chromosome expression up-regulation, restoring the ancestral expression level [283]. Thus, complete gene dosage compensation occurs in this species. The same genomic region homologous to GGA 15 was also selected to become Z and W chromosomes in softshell turtles from the family Trionychidae. Rovatsos and Kratochvíl looked for the presence or absence of dosage compensation in A. ferox and found that the expression level of Z-linked genes in females is roughly half of that in males. This absence of global gene dosage compensation in the softshell turtle contrasts with that observed in anole lizard, and led the authors to conclude that the apparition of dosage compensation mechanisms is independent of the genomic background. It is clear that genetic background alone does not explain the appearance or absence of dosage compensation, but to conclude that genomic background is of little importance is perhaps a little too radical for several reasons. The appearance of gene dosage compensation is thought to be mostly driven by the presence of haploinsufficient genes which need to be sufficiently expressed in the heterogametic sex. However, gene dosage compensation is only one way among others to achieve this goal: the haploinsufficient gene can also be conserved as a gametolog on the $\mathrm{Y}$ or $\mathrm{W}$ chromosome, or be translocated to an autosome. Both the loss of a gametolog or the translocation of a haploinsufficient gene are stochastic events which occur by chance and may be selected or not. As turtles and lizards diverged more than $250 \mathrm{Myrs}$ ago, there was enough time for differential loss, conservation or translocation of a few important haploinsufficient genes, which may be sufficient to explain the difference of gene dosage conservation in the two groups today. We thus need the complete list of genes in sex chromosomes of both species, those common to both species, those conserved only in one species, and their status regarding haploinsufficiency before drawing any definitive conclusions. Another point to take into consideration is the variability of the sensitivity to haploinsufficiency between species, which may slightly vary. Such a phenomenon is observed in mammals where, for instance, mutations in Sox9 or WT1 produce a phenotype when heterozygous in humans, but only when homozygous in mouse [151,312-315]. Other comparisons between reptilian species having co-opted the same genomic regions as sex chromosomes are thus necessary. The case of the two turtles, S. crassicollis and G. insculpta, which both have a XY system homologous to GGA 5 and diverged more recently ( $80 \mathrm{Myrs})$, is especially attractive.

\subsection{What Is Still to Be Discovered and How It Could Be Carried Out}

The forty-five clades in Table S1 constitute a minimal estimation of sex-chromosome variation in reptiles, because it is not known if Gymnophthalmidae and Teiidae share the same XY system, and the same uncertainty exists for the genera Gehyra, Dixonius and Heteronotia, and other species marked with a "?". As described previously, some groups such as Dibamidae, Cordylidae, Teiidae or Amphisbenia have been poorly studied and certainly contain new sex chromosome systems. Other groups such as non-caenophidian snakes, geckos (especially in Gekkonidae family) or chameleons are already known to possess more than one sex determination system, but only a small percentage of their species have been investigated. Future studies by modern cytogenetics or molecular methods will certainly reveal a more diverse variability of sex chromosome systems in these groups. As seen in the first part of this review, modern cytogenetics with CGH or rRNA FISH experiments allow the identification of XY or ZW chromosomes, whereas molecular methods such as genome coverage analysis between male and female and RADseq experiments identify the syntenic genomic region which became sex chromosomes. However, genome coverage analysis gives only access to the gene content of $\mathrm{X}$ or $\mathrm{Z}$ 
chromosomes, whereas validated RAD-seq markers are only Y- or W-specific. So, how to go further and identify MSD gene in reptiles?

Ideally, a candidate gene must meet four criteria before being declared an MSD gene: (1) it must be localized in the sex-specific part of the sex chromosome, (2) it must be expressed in the gonads at the right period (i.e., at least in the undifferentiated gonad just before the first histological signs of differentiation), (3) its inactivation in one sex must lead to complete sex reversal, and (4) its overexpression in the other sex must cause the opposite sex reversal. Until recently, these last two functional criteria could not be satisfied in reptiles. However, the establishment of a lentivirus-mediated RNAi gene-modulating method through injection of turtle eggs [316] and the establishment of transgenic lizards by CRISPR-Cas9 gene editing through microinjection of unfertilized oocytes [317] open the way for functional genetic studies in reptiles. We want to stress that all four criteria are important and that the two functional criteria alone are not sufficient. In the softshell turtle $P$. sinensis for instance, there is masculinization of the $\mathrm{ZZ}$ embryos overexpressing Dmrt1 and feminization of the ZZ gonads following Dmrt1 knockdown [216]; however, the Dmrt1 gene localizes to chromosome 4 [91] and not to the sex minichromosome. Moreover, Amh overexpression or loss of function gives the same phenotype as for Dmrt1 [318]. Therefore, at least two genes meet the two functional criteria, but none of them is the MSD gene. In order to meet the four criteria, many animals are needed, and this is a major drawback when the species is rare or does not reproduce in captivity. Several methods using next-generation sequencing data, can be used to circumvent this problem (see [310] for review). One of them is a male-female transcriptomic [216] or transcriptome/genome [283] subtraction approach allowing the identification of $\mathrm{Y}$ - or $\mathrm{W}$-linked transcripts. This direct identification of gametologs, coupled with the measure of their Ks, leads to a very short list of candidate MSD genes. A major caveat of this approach is its inability to identify the MSD gene when the MSD gene is not a gametolog but acts instead in a dose-dependent manner as a male gene on the $\mathrm{Z}$ chromosome or a female gene on the $\mathrm{X}$ chromosome. This seems to be the case in caenophidian snakes, trionychid turtles or lacertid lizards, for example. In the case of trionychid turtles, two groups identified 100-120 X-linked genes devoid of SNPs as potential candidate MSD genes in the genus Apalone [104,105]. There are two ways to condense this list. The first transcriptional approach consists of mining the RNA-seq data to discard every gene not expressed in gonads or expressed at similar levels in gonads of both sexes at the time of gonad differentiation. The second genomic approach is to sequence the genome of the most divergent species sharing the same sex chromosome system, in the hope that the speed and trajectory of W degeneration was different enough, which should produce a slightly different list of candidate genes for comparison. In the case of trionychids, a Cycloderma species which belongs to the other subfamily could be a good choice. It is likely that MSD genes acting in a dose-dependent manner will be much more difficult to identify than MSD genes which are gametologs. For this latter category, the recent advances in high-fidelity long-read sequencing have made these techniques, combined with Hi-C, powerful enough to produce the sequence of both sex chromosomes by sequencing only the heterogametic sex. It is thus the method of choice for rare or endangered species.

\section{Conclusions}

There is no doubt that the identification of the first MSD gene in reptiles will be made in the near future. Today the best candidate is PPP1CCY (Protein phosphatase 1, catalytic subunit gamma isozyme) in Pleurodonts [283]. Its inactivation or overexpression in the anole lizard is now technically feasible [317] and could be tested soon. Another good candidate is PPP1R12A (Protein Phosphatase 1 Regulatory subunit12A) in skinks [217]. Up to now there are no transgenic skinks, but some skinks are relatively easy to breed in captivity and there is no reason the technique of transgenesis by CRISPR-Cas9 gene editing through microinjection of unfertilized oocytes could not be implemented in skinks. Knowledge of sex-linked genes of trionychids is currently the most advanced in turtles. 
However, the likely dose-dependent nature of its MSD gene impairs its chance to be identified and tested by knock-down experiments. The study of turtle sex chromosomes may unveil some candidates to be tested in chelids or S. crassicollis. The decreasing cost of high-fidelity long-read sequencing will make it easier to obtain more numerous and more complete sequences of reptilian sex chromosomes. Their study and comparison will shed light on the evolutionary dynamics of sex chromosomes, give clues as to why so many ancient reptilian sex chromosomes still are homomorphic, and help to explain why global gene dosage compensation mechanisms are only found in certain lineages. However, as recently emphasized [319], high-quality genomes are only a starting point to understanding sex evolution and must be completed by an integrative approach to achieve a complete understanding of the sexome in all its complexity.

Supplementary Materials: The following are available online at https:/ / www.mdpi.com/article/10 .3390 /genes12111822/s1, Table S1: Sex-chromosome variation in reptiles.

Funding: This work was supported by the INRAE “Biology of Reproduction, Environment, Epigenetics and Development" unit and by the Agence Nationale pour la Recherche (RNA-Sex grant, ANR-19-CE14-0012).

Institutional Review Board Statement: Not applicable.

Informed Consent Statement: Not applicable.

Data Availability Statement: Not applicable.

Acknowledgments: The author expresses his gratitude to Elodie Poumerol for help in preparing figures and to Michelle Halstead for linguistic improvements of the manuscript.

Conflicts of Interest: The author declares no conflict of interest.

\section{References}

1. Imarazene, B.; Du, K.; Beille, S.; Jouanno, E.; Feron, R.; Pan, Q.; Torres-Paz, J.; Lopez-Roques, C.; Castinel, A.; Gil, L.; et al. A supernumerary "B-sex" chromosome drives male sex determination in the Pachón cavefish, Astyanax mexicanus. Curr. Biol. 2021, 31, 4800-4809. [CrossRef] [PubMed]

2. Ponnikas, S.; Sigeman, H.; Abbott, J.K.; Hansson, B. Why Do Sex Chromosomes Stop Recombining? Trends Genet. 2018, 34, 492-503. [CrossRef] [PubMed]

3. Sinclair, A.H.; Berta, P.; Palmer, M.S.; Hawkins, J.R.; Griffiths, B.L.; Smith, M.J.; Foster, J.W.; Frischauf, A.M.; Lovell-Badge, R.; Goodfellow, P.N. A gene from the human sex-determining region encodes a protein with homology to a conserved DNA-binding motif. Nature 1990, 346, 240-244. [CrossRef] [PubMed]

4. Koopman, P.; Gubbay, J.; Vivian, N.; Goodfellow, P.; Lovell-Badge, R. Male development of chromosomally female mice transgenic for Sry. Nature 1991, 351, 117-121. [CrossRef] [PubMed]

5. Takehana, Y.; Matsuda, M.; Myosho, T.; Suster, M.L.; Kawakami, K.; Shin-I, T.; Kohara, Y.; Kuroki, Y.; Toyoda, A.; Fujiyama, A.; et al. Co-option of Sox3 as the male-determining factor on the Y chromosome in the fish Oryzias dancena. Nat. Commun. 2014, 5, 4157. [CrossRef]

6. Smith, C.A.; Roeszler, K.N.; Ohnesorg, T.; Cummins, D.M.; Farlie, P.G.; Doran, T.J.; Sinclair, A.H. The avian Z-linked gene DMRT1 is required for male sex determination in the chicken. Nature 2009, 461, 267-271. [CrossRef]

7. Ioannidis, J.; Taylor, G.; Zhao, D.; Liu, L.; Idoko-Akoh, A.; Gong, D.; Lovell-Badge, R.; Guioli, S.; McGrew, M.J.; Clinton, M. Primary sex determination in birds depends on DMRT1 dosage, but gonadal sex does not determine adult secondary sex characteristics. Proc. Natl. Acad. Sci. USA 2021, 118, e2020909118. [CrossRef]

8. Chen, S.; Zhang, G.; Shao, C.; Huang, Q.; Liu, G.; Zhang, P.; Song, W.; An, N.; Chalopin, D.; Volff, J.-N.; et al. Whole-genome sequence of a flatfish provides insights into ZW sex chromosome evolution and adaptation to a benthic lifestyle. Nat. Genet. 2014, 46, 253-260. [CrossRef]

9. Yoshimoto, S.; Okada, E.; Umemoto, H.; Tamura, K.; Uno, Y.; Nishida-Umehara, C.; Matsuda, Y.; Takamatsu, N.; Shiba, T.; Ito, M. A W-linked DM-domain gene, DM-W, participates in primary ovary development in Xenopus laevis. Proc. Natl. Acad. Sci. USA 2008, 105, 2469-2474. [CrossRef]

10. Matsuda, M.; Nagahama, Y.; Shinomiya, A.; Sato, T.; Matsuda, C.; Kobayashi, T.; Morrey, C.E.; Shibata, N.; Asakawa, S.; Shimizu, $\mathrm{N}$.; et al. DMY is a Y-specific DM-domain gene required for male development in the medaka fish. Nature 2002, 417, 559-563. [CrossRef]

11. Nanda, I.; Kondo, M.; Hornung, U.; Asakawa, S.; Winkler, C.; Shimizu, A.; Shan, Z.; Haaf, T.; Shimizu, N.; Shima, A.; et al. A duplicated copy of DMRT1 in the sex-determining region of the Y chromosome of the medaka, Oryzias latipes. Proc. Natl. Acad. Sci. USA 2002, 99, 11778-11783. [CrossRef] 
12. Matsuda, M.; Sato, T.; Toyazaki, Y.; Nagahama, Y.; Hamaguchi, S.; Sakaizumi, M. Oryzias curvinotus Has DMY, a Gene That Is Required for Male Development in the Medaka, O. latipes. Zoolog. Sci. 2003, 20, 159-161. [CrossRef]

13. Myosho, T.; Otake, H.; Masuyama, H.; Matsuda, M.; Kuroki, Y.; Fujiyama, A.; Naruse, K.; Hamaguchi, S.; Sakaizumi, M. Tracing the Emergence of a Novel Sex-Determining Gene in Medaka, Oryzias luzonensis. Genetics 2012, 191, 163-170. [CrossRef] [PubMed]

14. Reichwald, K.; Petzold, A.; Koch, P.; Downie, B.R.; Hartmann, N.; Pietsch, S.; Baumgart, M.; Chalopin, D.; Felder, M.; Bens, M.; et al. Insights into Sex Chromosome Evolution and Aging from the Genome of a Short-Lived Fish. Cell 2015, 163, 1527-1538. [CrossRef] [PubMed]

15. Hattori, R.S.; Murai, Y.; Oura, M.; Masuda, S.; Majhi, S.K.; Sakamoto, T.; Fernandino, J.I.; Somoza, G.M.; Yokota, M.; Strüssmann, C.A. A Y-linked anti-Müllerian hormone duplication takes over a critical role in sex determination. Proc. Natl. Acad. Sci. USA 2012, 109, 2955-2959. [CrossRef]

16. Pan, Q.; Feron, R.; Yano, A.; Guyomard, R.; Jouanno, E.; Vigouroux, E.; Wen, M.; Busnel, J.-M.; Bobe, J.; Concordet, J.-P.; et al. Identification of the master sex determining gene in Northern pike (Esox lucius) reveals restricted sex chromosome differentiation. PLoS Genet. 2019, 15, e1008013. [CrossRef] [PubMed]

17. Peichel, C.L.; McCann, S.R.; Ross, J.A.; Naftaly, A.F.S.; Urton, J.R.; Cech, J.N.; Grimwood, J.; Schmutz, J.; Myers, R.M.; Kingsley, D.M.; et al. Assembly of the threespine stickleback $\mathrm{Y}$ chromosome reveals convergent signatures of sex chromosome evolution. Genome Biol. 2020, 21, 177. [CrossRef]

18. Kamiya, T.; Kai, W.; Tasumi, S.; Oka, A.; Matsunaga, T.; Mizuno, N.; Fujita, M.; Suetake, H.; Suzuki, S.; Hosoya, S.; et al. A Trans-Species Missense SNP in Amhr2 Is Associated with Sex Determination in the Tiger Pufferfish, Takifugu rubripes (Fugu). PLoS Genet. 2012, 8, e1002798. [CrossRef] [PubMed]

19. Feron, R.; Zahm, M.; Cabau, C.; Klopp, C.; Roques, C.; Bouchez, O.; Eché, C.; Valière, S.; Donnadieu, C.; Haffray, P.; et al. Characterization of a Y-specific duplication/insertion of the anti-Mullerian Hormone type II receptor gene based on a chromosomescale genome assembly of yellow perch, Perca flavescens. Mol. Ecol. Resour. 2020, 20, 531-543. [CrossRef]

20. Nakamoto, M.; Uchino, T.; Koshimizu, E.; Kuchiishi, Y.; Sekiguchi, R.; Wang, L.; Sudo, R.; Endo, M.; Guiguen, Y.; Schartl, M.; et al. A Y-linked anti-Müllerian hormone type-II receptor is the sex-determining gene in ayu, Plecoglossus altivelis. PLoS Genet. 2021, 17, e1009705. [CrossRef]

21. Cortez, D.; Marin, R.; Toledo-Flores, D.; Froidevaux, L.; Liechti, A.; Waters, P.D.; Grützner, F.; Kaessmann, H. Origins and Functional Evolution of Y Chromosomes across Mammals. Nature 2014, 508, 488-493. [CrossRef]

22. Zhou, Y.; Shearwin-Whyatt, L.; Li, J.; Song, Z.; Hayakawa, T.; Stevens, D.; Fenelon, J.C.; Peel, E.; Cheng, Y.; Pajpach, F.; et al. Platypus and Echidna Genomes Reveal Mammalian Biology and Evolution. Nature 2021, 592, 756-762. [CrossRef]

23. Graham, P.; Penn, J.K.M.; Schedl, P. Masters Change, Slaves Remain. BioEssays 2003, 25, 1-4. [CrossRef]

24. Yano, A.; Guyomard, R.; Nicol, B.; Jouanno, E.; Quillet, E.; Klopp, C.; Cabau, C.; Bouchez, O.; Fostier, A.; Guiguen, Y. An Immune-Related Gene Evolved into the Master Sex-Determining Gene in Rainbow Trout, Oncorhynchus mykiss. Curr. Biol. 2012, 22, 1423-1428. [CrossRef]

25. Bertho, S.; Herpin, A.; Branthonne, A.; Jouanno, E.; Yano, A.; Nicol, B.; Muller, T.; Pannetier, M.; Pailhoux, E.; Miwa, M.; et al. The Unusual Rainbow Trout Sex Determination Gene Hijacked the Canonical Vertebrate Gonadal Differentiation Pathway. Proc. Natl. Acad. Sci. USA 2018, 115, 12781-12786. [CrossRef] [PubMed]

26. Bao, L.; Tian, C.; Liu, S.; Zhang, Y.; Elaswad, A.; Yuan, Z.; Khalil, K.; Sun, F.; Yang, Y.; Zhou, T.; et al. The Y Chromosome Sequence of the Channel Catfish Suggests Novel Sex Determination Mechanisms in Teleost Fish. BMC Biol. 2019, 17, 6. [CrossRef]

27. Keinath, M.C.; Timoshevskaya, N.; Timoshevskiy, V.A.; Voss, S.R.; Smith, J.J. Miniscule Differences between Sex Chromosomes in the Giant Genome of a Salamander. Sci. Rep. 2018, 8, 17882. [CrossRef] [PubMed]

28. Ion, A.; Telvi, L.; Chaussain, J.L.; Galacteros, F.; Valayer, J.; Fellous, M.; McElreavey, K. A Novel Mutation in the Putative DNA Helicase XH2 Is Responsible for Male-to-Female Sex Reversal Associated with an Atypical Form of the ATR-X Syndrome. Am. J. Hum. Genet. 1996, 58, 1185-1191. [PubMed]

29. Charnier, M. Action of temperature on the sex ratio in the Agama agama (Agamidae, Lacertilia) embryo. Comptes Rendus Seances Soc. Biol. Fil. 1966, 160, 620-622.

30. Pieau, C. Sex ratio in the embryos of 2 chelonians (Testudo graeca L. and Emys orbicularis L.) born of artificially incubated ova. Comptes Rendus Hebd. Seances Acad. Sci. Ser. Sci. Nat. 1971, 272, 3071-3074.

31. Zardoya, R.; Meyer, A. The Evolutionary Position of Turtles Revised. Naturwissenschaften 2001, 88, 193-200. [CrossRef]

32. Crawford, N.G.; Faircloth, B.C.; McCormack, J.E.; Brumfield, R.T.; Winker, K.; Glenn, T.C. More than 1000 Ultraconserved Elements Provide Evidence That Turtles Are the Sister Group of Archosaurs. Biol. Lett. 2012, 8, 783-786. [CrossRef] [PubMed]

33. Shen, X.-X.; Liang, D.; Wen, J.-Z.; Zhang, P. Multiple Genome Alignments Facilitate Development of NPCL Markers: A Case Study of Tetrapod Phylogeny Focusing on the Position of Turtles. Mol. Biol. Evol. 2011, 28, 3237-3252. [CrossRef]

34. Chiari, Y.; Cahais, V.; Galtier, N.; Delsuc, F. Phylogenomic Analyses Support the Position of Turtles as the Sister Group of Birds and Crocodiles (Archosauria). BMC Biol. 2012, 10, 65. [CrossRef]

35. Shaffer, H.B.; Minx, P.; Warren, D.E.; Shedlock, A.M.; Thomson, R.C.; Valenzuela, N.; Abramyan, J.; Amemiya, C.T.; Badenhorst, D.; Biggar, K.K.; et al. The Western Painted Turtle Genome, a Model for the Evolution of Extreme Physiological Adaptations in a Slowly Evolving Lineage. Genome Biol. 2013, 14, 1-23. [CrossRef] 
36. Wang, Z.; Pascual-Anaya, J.; Zadissa, A.; Li, W.; Niimura, Y.; Huang, Z.; Li, C.; White, S.; Xiong, Z.; Fang, D.; et al. The Draft Genomes of Soft-Shell Turtle and Green Sea Turtle Yield Insights into the Development and Evolution of the Turtle-Specific Body Plan. Nat. Genet. 2013, 45, 701-706. [CrossRef] [PubMed]

37. Crawford, N.G.; Parham, J.F.; Sellas, A.B.; Faircloth, B.C.; Glenn, T.C.; Papenfuss, T.J.; Henderson, J.B.; Hansen, M.H.; Simison, W.B. A Phylogenomic Analysis of Turtles. Mol. Phylogenet. Evol. 2015, 83, 250-257. [CrossRef] [PubMed]

38. Zheng, Y.; Wiens, J.J. Combining Phylogenomic and Supermatrix Approaches, and a Time-Calibrated Phylogeny for Squamate Reptiles (Lizards and Snakes) Based on 52 Genes and 4162 Species. Mol. Phylogenet. Evol. 2016, 94, 537-547. [CrossRef] [PubMed]

39. Pereira, A.G.; Sterli, J.; Moreira, F.R.R.; Schrago, C.G. Multilocus Phylogeny and Statistical Biogeography Clarify the Evolutionary History of Major Lineages of Turtles. Mol. Phylogenet. Evol. 2017, 113, 59-66. [CrossRef]

40. Shaffer, H.B.; McCartney-Melstad, E.; Near, T.J.; Mount, G.G.; Spinks, P.Q. Phylogenomic Analyses of 539 Highly Informative Loci Dates a Fully Resolved Time Tree for the Major Clades of Living Turtles (Testudines). Mol. Phylogenet. Evol. 2017, 115, 7-15. [CrossRef]

41. Thomson, R.C.; Spinks, P.Q.; Shaffer, H.B. A Global Phylogeny of Turtles Reveals a Burst of Climate-Associated Diversification on Continental Margins. Proc. Natl. Acad. Sci. USA 2021, 118, e2012215118. [CrossRef] [PubMed]

42. Deeming, D.C. Prevalence of TSD in Crocodilians. In Temperature Dependent Sex Determination in Vertebrates; Valenzuela, N., Lance, V.A., Eds.; Smithsonian Books: Whashington, DC, USA, 2004; pp. 33-41.

43. Zhou, Q.; Zhang, J.; Bachtrog, D.; An, N.; Huang, Q.; Jarvis, E.D.; Gilbert, M.T.P.; Zhang, G. Complex Evolutionary Trajectories of Sex Chromosomes across Bird Taxa. Science 2014, 346, 1246338. [CrossRef] [PubMed]

44. Gunski, R.J.; Cañedo, A.D.; Garnero, A.D.V.; Ledesma, M.A.; Coria, N.; Montalti, D.; Degrandi, T.M. Multiple Sex Chromosome System in Penguins (Pygoscelis, Spheniscidae). Comp. Cytogenet. 2017, 11, 541-552. [CrossRef] [PubMed]

45. Sigeman, H.; Ponnikas, S.; Hansson, B. Whole-Genome Analysis across 10 Songbird Families within Sylvioidea Reveals a Novel Autosome-Sex Chromosome Fusion. Biol. Lett. 2020, 16, 20200082. [CrossRef]

46. Küpper, C.; Augustin, J.; Edwards, S.; Székely, T.; Kosztolányi, A.; Burke, T.; Janes, D.E. Triploid Plover Female Provides Support for a Role of the W Chromosome in Avian Sex Determination. Biol. Lett. 2012, 8, 787-789. [CrossRef]

47. Kuroiwa, A. Sex-Determining Mechanism in Avians. Adv. Exp. Med. Biol. 2017, 1001, 19-31. [CrossRef]

48. Ewert, M.A.; Nelson, C.E. Sex Determination in Turtles: Diverse Patterns and Some Possible Adaptive Values. Copeia 1991, 1991, 50-69. [CrossRef]

49. Janzen, F.J.; Phillips, P.C. Exploring the Evolution of Environmental Sex Determination, Especially in Reptiles. J. Evol. Biol. 2006, 19, 1775-1784. [CrossRef]

50. Valenzuela, N.; Adams, D.C. Chromosome Number and Sex Determination Coevolve in Turtles. Evol. Int. J. Org. Evol. 2011, 65, 1808-1813. [CrossRef] [PubMed]

51. Petzold, A.; Vargas-Ramírez, M.; Kehlmaier, C.; Vamberger, M.; Branch, W.R.; Preez, L.D.; Hofmeyr, M.D.; Meyer, L.; Schleicher, A.; Siroký, P.; et al. A Revision of African Helmeted Terrapins (Testudines: Pelomedusidae: Pelomedusa), with Descriptions of Six New Species. Zootaxa 2014, 3795, 523-548. [CrossRef]

52. Fritz, U.; Branch, W.R.; Hofmeyr, M.D.; Maran, J.; Prokop, H.; Schleicher, A.; Širokỳ, P.; Stuckas, H.; Vargas-Ramírez, M.; Vences, M. Molecular Phylogeny of African Hinged and Helmeted Terrapins (Testudines: Pelomedusidae: Pelusios and Pelomedusa). Zool. Scr. 2011, 40, 115-125. [CrossRef]

53. Noonan, B.P. Does the Phylogeny of Pelomedusoid Turtles Reflect Vicariance Due to Continental Drift? J. Biogeogr. 2000, 27, 1245-1249. [CrossRef]

54. Vargas-Ramírez, M.; Castaño-Mora, O.V.; Fritz, U. Molecular Phylogeny and Divergence Times of Ancient South American and Malagasy River Turtles (Testudines: Pleurodira: Podocnemididae). Org. Divers. Evol. 2008, 8, 388-398. [CrossRef]

55. Ayres, M.; Sampaio, M.M.; Barros, R.M.; Dias, L.B.; Cunha, O.R. A Karyological Study of Turtles from the Brazilian Amazon Region. Cytogenetics 1969, 8, 401-409. [CrossRef] [PubMed]

56. Huang, C.C.; Clark, H.F. Chromosome Studies of the Cultured Cells of Two Species of Side-Necked Turtles (Podocnemis unifilis and P. Expansa). Chromosoma 1969, 26, 245-253. [CrossRef] [PubMed]

57. Killebrew, F.C. Mitotic Chromosomes of Turtles: I. the Pelomedusidae. J. Herpetol. 1975, 281-285. [CrossRef]

58. Bull, J.J. Sex Determination in Reptiles. Q. Rev. Biol. 1980, 55, 3-21. [CrossRef]

59. Fantin, C.; Monjeló, L.A.D.S. Cytogenetic Studies in Podocnemis Expansa and Podocnemis Sextuberculata (Testudines, Podocnemididae), Turtles of the Brazilian Amazon. Caryologia 2011, 64, 154-157. [CrossRef]

60. Gunski, R.J.; Cunha, I.S.; Degrandi, T.M.; Ledesma, M.; Garnero, A.D.V. Cytogenetic Comparison of Podocnemis expansa and Podocnemis unifilis: A Case of Inversion and Duplication Involving Constitutive Heterochromatin. Genet. Mol. Biol. 2013, 36, 353-356. [CrossRef]

61. Ventura, K.; Moreira, C.N.; Moretti, R.; Yonenaga-Yassuda, Y.; Rodrigues, M.T. The Lowest Diploid Number in Testudines: Banding Patterns, Telomeric and 45S RDNA FISH in Peltocephalus dumerilianus, 2n = 26 and FN = 52 (Pleurodira, Podocnemididae). Genet. Mol. Biol. 2014, 37, 61-63. [CrossRef]

62. Noronha, R.C.R.; Barros, L.M.R.; Araújo, R.E.F.; Marques, D.F.; Nagamachi, C.Y.; Martins, C.; Pieczarka, J.C. New Insights of Karyoevolution in the Amazonian Turtles Podocnemis expansa and Podocnemis unifilis (Testudines, Podocnemidae). Mol. Cytogenet. 2016, 9, 73. [CrossRef] 
63. Rhodin, A.G.J.; Mittermeier, R.A.; Gardner, A.L.; Medem, F. Karyotypic Analysis of the Podocnemis Turtles. Copeia 1978, 1978, 723-728. [CrossRef]

64. Alho, C.J.R.; Danni, T.M.S.; Padua, L.F.M. Temperature-Dependent Sex Determination in Podocnemis expansa (Testudinata: Pelomedusidae). Biotropica 1985, 17, 75-78. [CrossRef]

65. Valenzuela, N. Constant, Shift, and Natural Temperature Effects on Sex Determination in Podocnemis expansa Turtles. Ecology 2001, 82, 3010-3024. [CrossRef]

66. De Souza, R.R.; Vogt, R.C. Incubation Temperature Influences Sex and Hatchling Size in the Neotropical Turtle Podocnemis unifilis. J. Herpetol. 1994, 28, 453-464. [CrossRef]

67. Vogt, R.C. Amazon Turtles; Wust Editions, Grafica Biblos: Lima, Peru, 2008.

68. Páez, V.P.; Correa, J.C.; Cano, A.M.; Bock, B.C. A Comparison of Maternal and Temperature Effects on Sex, Size, and Growth of Hatchlings of the Magdalena River Turtle (Podocnemis lewyana) Incubated under Field and Controlled Laboratory Conditions. Copeia 2009, 2009, 698-704. [CrossRef]

69. Gómez-Saldarriaga, C.; Valenzuela, N.; Ceballos, C.P. Effects of Incubation Temperature on Sex Determination in the Endangered Magdalena River Turtle, Podocnemis lewyana. Chelonian Conserv. Biol. 2016, 15, 43-53. [CrossRef]

70. Vogt, R.C. Reproduction of The Cabeçudo, Peltocephalus dumerilianus, in the Biological Reserve of Rio Trombetas, Brazil. Chelonian Conserv. Biol. 1994, 1, 145-148.

71. De La Ossa, J.; Vogt, R.C.; De La Ossa-Lacayo, A. Sexo Termo Dependencia y Su Relación Con La Idoneidad En Neonatos de Peltocephalus dumerilianus (Testudines, Podocnemididae). Rev. Asoc. Colomb. Cienc. Biol. 2014, 1, 145-151.

72. Garcia, G. Ecology, Human Impact and Conservation for the Madagascan Side-Necked Turtle (Eretmochelys madagascariensis Grandidier, 1876) at Ankarafantsika National Park, Madagascar. Ph.D. Thesis, The Durrell Institut of Conservation and Ecology, The University of Kent, Canterbury, UK, 2005.

73. Ewert, M.A.; Etchberger, C.R.; Nelson, C.E. Turtle Sex-Determining Modes and TSD Patterns, and Some TSD Pattern Correlates. In Temperature Dependent Sex Determination in Vertebrates; Valenzuela, N., Lance, V.A., Eds.; Smithsonian Books: Whashington, DC, USA, 2004; pp. 21-32.

74. Bull, J.J.; Legler, J.M.; Vogt, R.C. Non-Temperature Dependent Sex Determination in Two Suborders of Turtles. Copeia 1985, 1985, 784-786. [CrossRef]

75. Thompson, M.B. Influence of Incubation Temperature and Water Potential on Sex Determination in Emydura macquarii (Testudines: Pleurodira). Herpetologica 1988, 44, 86-90.

76. Georges, A. Sex Determination Is Independent of Incubation Temperature in Another Chelid Turtle, Chelodina longicollis. Copeia 1988, 1988, 248-254. [CrossRef]

77. Georges, A.; McInnes, S. Temperature Fails to Influence Hatchling Sex in Another Genus and Species of Chelid Turtle, Elusor macrurus. J. Herpetol. 1998, 32, 596-598. [CrossRef]

78. Barros, R.M.; Sampaio, M.M.; Assis, M.F.; Ayres, M.; Cunha, O.R. General Considerations on the Karyotypic Evolution of Chelonia from the Amazon Region of Brazil. Cytologia 1976, 41, 559-565. [CrossRef]

79. Noleto, R.B.; Kantek, D.L.Z.; Swarça, A.C.; Dias, A.L.; Fenocchio, A.S.; Cestari, M.M. Karyotypic Characterization of Hydromedusa tectifera (Testudines, Pleurodira) from the Upper Iguaçu River in the Brazilian State of Paraná. Genet. Mol. Biol. 2006, $29,263-266$. [CrossRef]

80. Reed, K.M.; Greenbaum, I.F.; Hanks, B.G.; Bickham, J.W.; Rhodin, A.G.J.; Mittermeier, R.A.; Fedullo, L.P. Cytogenetic Analysis Of The Pleurodine Turtle Phrynops hogei And Its Taxonomic Implications. Amphib.-Reptil. 1991, 12, 203-212. [CrossRef]

81. Killebrew, F.C. Mitotic Chromosomes of Turtles: II. The Chelidae. Texas J. Sci. 1976, 27, 149-154.

82. McBee, K.; Bickham, J.W.; Rhodin, A.G.; Mittermeier, R.A. Karyotypic Variation in the Genus Platemys (Testudines: Pleurodira). Copeia 1985, 1985, 445-449. [CrossRef]

83. Ezaz, T.; Valenzuela, N.; Grützner, F.; Miura, I.; Georges, A.; Burke, R.L.; Graves, J.A.M. An XX/XY Sex Microchromosome System in a Freshwater Turtle, Chelodina longicollis (Testudines: Chelidae) with Genetic Sex Determination. Chromosome Res. Int. J. Mol. Supramol. Evol. Asp. Chromosome Biol. 2006, 14, 139-150. [CrossRef] [PubMed]

84. Martinez, P.A.; Ezaz, T.; Valenzuela, N.; Georges, A.; Marshall Graves, J.A. An XX/XY Heteromorphic Sex Chromosome System in the Australian Chelid Turtle Emydura macquarii: A New Piece in the Puzzle of Sex Chromosome Evolution in Turtles. Chromosome Res. Int. J. Mol. Supramol. Evol. Asp. Chromosome Biol. 2008, 16, 815-825. [CrossRef] [PubMed]

85. Lee, L.; Montiel, E.E.; Valenzuela, N. Discovery of Putative XX/XY Male Heterogamety in Emydura subglobosa Turtles Exposes a Novel Trajectory of Sex Chromosome Evolution in Emydura. Cytogenet. Genome Res. 2019, 158, 160-169. [CrossRef]

86. Mazzoleni, S.; Augstenová, B.; Clemente, L.; Auer, M.; Fritz, U.; Praschag, P.; Protiva, T.; Velenský, P.; Kratochvíl, L.; Rovatsos, M. Sex Is Determined by XX/XY Sex Chromosomes in Australasian Side-Necked Turtles (Testudines: Chelidae). Sci. Rep. 2020, 10, 4276. [CrossRef] [PubMed]

87. Matsubara, K.; O’Meally, D.; Azad, B.; Georges, A.; Sarre, S.D.; Graves, J.A.M.; Matsuda, Y.; Ezaz, T. Amplification of Microsatellite Repeat Motifs Is Associated with the Evolutionary Differentiation and Heterochromatinization of Sex Chromosomes in Sauropsida. Chromosoma 2016, 125, 111-123. [CrossRef] [PubMed]

88. Cavalcante, M.G.; Bastos, C.E.M.C.; Nagamachi, C.Y.; Pieczarka, J.C.; Vicari, M.R.; Noronha, R.C.R. Physical Mapping of Repetitive DNA Suggests 2n Reduction in Amazon Turtles Podocnemis (Testudines: Podocnemididae). PLoS ONE 2018, 13, e0197536. [CrossRef] 
89. Clemente, L.; Mazzoleni, S.; Bellavia, E.P.; Augstenová, B.; Auer, M.; Praschag, P.; Protiva, T.; Velenský, P.; Wagner, P.; Fritz, U.; et al. Interstitial Telomeric Repeats Are Rare in Turtles. Genes 2020, 11, 657. [CrossRef] [PubMed]

90. Viana, P.F.; Feldberg, E.; Cioffi, M.B.; de Carvalho, V.T.; Menezes, S.; Vogt, R.C.; Liehr, T.; Ezaz, T. The Amazonian Red Side-Necked Turtle Rhinemys rufipes (Spix, 1824) (Testudines, Chelidae) Has a GSD Sex-Determining Mechanism with an Ancient XY Sex Microchromosome System. Cells 2020, 9, 2088. [CrossRef]

91. Lee, L.; Montiel, E.E.; Navarro-Domínguez, B.M.; Valenzuela, N. Chromosomal Rearrangements during Turtle Evolution Altered the Synteny of Genes Involved in Vertebrate Sex Determination. Cytogenet. Genome Res. 2019, 157, 77-88. [CrossRef]

92. Webb, G.J.; Choquenot, D.; Whitehead, P.J. Nests, Eggs, and Embryonic Development of Carettochelys insculpta (Chelonia: Carettochelidae) from Northern Australia. J. Zool. 1986, 1, 521-550. [CrossRef]

93. Bickham, J.W.; Bull, J.J.; Legler, J.M. Karyotypes and Evolutionary Relationships of Trionychoid Turtles. Cytologia 1983, 48, 177-183. [CrossRef]

94. Sato, H.; Ota, H. Karyotype of the Chinese Soft-Shelled Turtle, Pelodiscus sinensis, from Japan and Taiwan, with Chromosomal Data for Dogania subplana. Curr. Herpetol. 2001, 20, 19-25. [CrossRef]

95. Stock, A.D. Karyological Relationships in Turtles (Reptilia: Chelonia). Can. J. Genet. Cytol. 1972, 14, 859-868. [CrossRef] [PubMed]

96. Vogt, R.C.; Bull, J.J. Genetic Sex Determination in the Spiny Softshell Trionyx spiniferus (Testudines: Trionychidae)? Copeia 1982, 1982, 699-700. [CrossRef]

97. Choo, B.L.; Chou, L.M. Does Incubation Temperature Influence the Sex of Embryos in Trionyx sinensis? J. Herpetol. 1992, 26, 341-342. [CrossRef]

98. Janzen, F.J. The Influence of Incubation Temperature and Family on Eggs, Embryos, and Hatchlings of the Smooth Softshell Turtle (Apalone mutica). Physiol. Zool. 1993, 66, 349-373. [CrossRef]

99. Kawai, A.; Nishida-Umehara, C.; Ishijima, J.; Tsuda, Y.; Ota, H.; Matsuda, Y. Different Origins of Bird and Reptile Sex Chromosomes Inferred from Comparative Mapping of Chicken Z-Linked Genes. Cytogenet. Genome Res. 2007, 117, 92-102. [CrossRef] [PubMed]

100. Mu, Y.; Zhao, B.; Tang, W.-Q.; Sun, B.-J.; Zeng, Z.-G.; Valenzuela, N.; Du, W.-G. Temperature-Dependent Sex Determination Ruled out in the Chinese Soft-Shelled Turtle (Pelodiscus sinensis) via Molecular Cytogenetics and Incubation Experiments across Populations. Sex. Dev. Genet. Mol. Biol. Evol. Endocrinol. Embryol. Pathol. Sex Determ. Differ. 2015, 9, 111-117. [CrossRef] [PubMed]

101. Kawagoshi, T.; Uno, Y.; Matsubara, K.; Matsuda, Y.; Nishida, C. The ZW Micro-Sex Chromosomes of the Chinese Soft-Shelled Turtle (Pelodiscus sinensis, Trionychidae, Testudines) Have the Same Origin as Chicken Chromosome 15. Cytogenet. Genome Res. 2009, 125, 125-131. [CrossRef] [PubMed]

102. Badenhorst, D.; Stanyon, R.; Engstrom, T.; Valenzuela, N. A ZZ/ZW Microchromosome System in the Spiny Softshell Turtle, Apalone spinifera, Reveals an Intriguing Sex Chromosome Conservation in Trionychidae. Chromosome Res. Int. J. Mol. Supramol. Evol. Asp. Chromosome Biol. 2013, 21, 137-147. [CrossRef]

103. Rovatsos, M.; Praschag, P.; Fritz, U.; Kratochvšl, L. Stable Cretaceous Sex Chromosomes Enable Molecular Sexing in Softshell Turtles (Testudines: Trionychidae). Sci. Rep. 2017, 7, 42150. [CrossRef]

104. Rovatsos, M.; Kratochvíl, L. Evolution of Dosage Compensation Does Not Depend on Genomic Background. Mol. Ecol. 2021, 30, 1836-1845. [CrossRef]

105. Bista, B.; Wu, Z.; Literman, R.; Valenzuela, N. Thermosensitive Sex Chromosome Dosage Compensation in ZZ/ZW Softshell Turtles, Apalone spinifera. Philos. Trans. R. Soc. Lond. B. Biol. Sci. 2021, 376, 20200101. [CrossRef] [PubMed]

106. Mrosovsky, N.; Fretey, J.; Lescure, J.; Pieau, C.; Rimblot, F. Sexual Differentiation as a Function of the Incubation Temperature of Eggs in the Sea-Turtle Dermochelys coriacea (Vandelli, 1761). Amphib.-Reptil. 1985, 6, 83-92. [CrossRef]

107. Mrosovsky, N.; Dutton, P.H.; Whitmore, C.P. Sex Ratios of Two Species of Sea Turtle Nesting in Suriname. Can. J. Zool. 1984, 62, 2227-2239. [CrossRef]

108. Mrosovsky, N.; Bass, A.; Corliss, L.A.; Richardson, J.I.; Richardson, T.H. Pivotal and Beach Temperatures for Hawksbill Turtles Nesting in Antigua. Can. J. Zool. 1992, 70, 1920-1925. [CrossRef]

109. Hewavisenthi, S.; Parmenter, C.J. Hydric Environment and Sex Determination in the Flatback Turtle (Natator depressus Garman) (Chelonia: Cheloniidae). Aust. J. Zool. 2000, 48, 653-659. [CrossRef]

110. Yntema, C.L.; Mrosovsky, N. Incubation Temperature and Sex Ratio in Hatchling Loggerhead Turtles: A Preliminary Report. Mar. Turt. Newsl. 1979, 11, 9-10.

111. McCoy, C.J.; Vogt, R.C.; Censky, E.J. Temperature-Controlled Sex Determination in the Sea Turtle Lepidochelys olivacea. J. Herpetol. 1983, 17, 404-406. [CrossRef]

112. Carrasco, A.; Marquez, M.; Benitez, V.; Diaz, F.; Jimenez, Q. The Effect of Temperature Change on the Sex Ratio of Kemp's Ridley Nests in the Hatchery Center at Rancho Nuevo, Tamaulipas, Mexico. In Proceedings of the Nineteenth Annual Symposium on Sea Turtle Conservation and Biology, South Padre Island, TX, USA, 2-6 March 1999; Kalb, H., Wibbels, T., Eds.; NOAA Tech Memo, NMFS-SEFSC-443. Southeast Fisheries Science Center (U.S.): Miami, FL, USA, 2000; pp. 128-129.

113. Yntema, C.L. Effects of Incubation Temperatures on Sexual Differentiation in the Turtle, Chelydra serpentina. J. Morphol. 1976, 150, 453-461. [CrossRef] [PubMed]

114. Vogt, R.C.; Flores-Villela, O. Effects of Incubation Temperature on Sex Determination in a Community of Neotropical Freshwater Turtles in Southern Mexico. Herpetologica 1992, 48, 265-270. 
115. Janzen, F.J.; Paukstis, G.L. Environmental Sex Determination in Reptiles: Ecology, Evolution, and Experimental Design. Q. Rev. Biol. 1991, 66, 149-179. [CrossRef]

116. Bull, J.J.; Moon, R.G.; Legler, J.M. Male Heterogamety in Kinosternid Turtles (Genus Staurotypus). Cytogenet. Cell Genet. 1974, 13, 419-425. [CrossRef]

117. Kawagoshi, T.; Uno, Y.; Nishida, C.; Matsuda, Y. The Staurotypus Turtles and Aves Share the Same Origin of Sex Chromosomes but Evolved Different Types of Heterogametic Sex Determination. PLoS ONE 2014, 9, e105315. [CrossRef] [PubMed]

118. Janes, D.E.; Organ, C.L.; Stiglec, R.; O’Meally, D.; Sarre, S.D.; Georges, A.; Graves, J.A.M.; Valenzuela, N.; Literman, R.A.; Rutherford, K.; et al. Molecular Evolution of Dmrt1 Accompanies Change of Sex-Determining Mechanisms in Reptilia. Biol. Lett. 2014, 10, 20140809. [CrossRef] [PubMed]

119. Radhakrishnan, S.; Valenzuela, N. Chromosomal Context Affects the Molecular Evolution of Sex-Linked Genes and Their Autosomal Counterparts in Turtles and Other Vertebrates. J. Hered. 2017, 108, 720-730. [CrossRef]

120. Sites, J.W.; Bickham, J.W.; Haiduk, M.W.; Derived, X. Chromosome in the Turtle Genus Staurotypus. Science 1979, $206,1410-1412$. [CrossRef]

121. Kuchling, G.; Goode, E.V.; Praschag, P. Endoscopic imaging of gonads, sex ratio, and temperature-dependent sex determination in juvenile captive-bred radiated tortoises, Astrochelys radiata. Chelonian Conserv. Biol. 2013, 6, 171-177.

122. Ligon, D.B.; Bidwell, J.R.; Lovern, M.B. Incubation Temperature Effects on Hatchling Growth and Metabolic Rate in the African Spurred Tortoise, Geochelone sulcata. Can. J. Zool. 2009, 87, 64-72. [CrossRef]

123. Sancho, A.; Gutzke, W.H.; Snell, H.L.; Rea, S.; Wilson, M.; Burke, R.L. Temperature Sex Determination, Incubation Duration, and Hatchling Sexual Dimorphism in the Española Giant Tortoise (Chelonoidis hoodensis) of the Galápagos Islands. Amphib. Reptile Conserv. 2017, 11, 44-50.

124. Spotila, J.R.; Zimmerman, L.C.; Binckley, C.A.; Grumbles, J.S.; Rostal, D.C.; List, A.; Beyer, E.C.; Phillips, K.M.; Kemp, S.J. Effects of Incubation Conditions on Sex Determination, Hatching Success, and Growth of Hatchling Desert Tortoises, Gopherus agassizii. Herpetol. Monogr. 1994, 8, 103-116. [CrossRef]

125. Burke, R.; Ewert, M.; McLemore, J.; Jackson, D. Temperature-Dependent Sex Determination and Hatching Success in the Gopher Tortoise (Gopherus polyphemus). Chelonian Conserv. Biol. 1996, 86-88.

126. Demuth, J.P. The Effects of Constant and Fluctuating Incubation Temperatures on Sex Determination, Growth, and Performance in the Tortoise Gopherus polyphemus. Can. J. Zool. 2001, 79, 1609-1620. [CrossRef]

127. Emer, S.A. Temperature-Dependent Sex Determination in Manouria emys Emys, The Asian Forest Tortoise. Master's Thesis, Georgia State University, Atlanta, GA, USA, 5 April 2007. Available online: https://scholarworks.gsu.edu/biology_theses/11 (accessed on 17 November 2021).

128. Eendebak, B. Incubation Period and Sex Ratio of Hermann's Tortoise, Testudo hermanni boettgeri. Chelonian Conserv. Biol. 1995, 1, 227-231.

129. Kuchling, G.; Goode, E.V.; Praschag, P. Endoscopic Imaging of Gonads, Sex Ratio and Temperature Dependent Sex Determination in Captive Bred Juvenile Burmese Star Tortoises Geochelone platynota. Asian Herpetol. Res. 2011, 2, 240-244. [CrossRef]

130. Pearson, D.W. Ecological Husbandry and Reproduction of Madagascar Spider (Pyxis arachnoides) and Flat-Tailed (Pyxis planicauda) Tortoises. Chelonian Conserv. Biol. 2013, 6, 146-152.

131. Zhu, X.P.; Chen, Y.L.; Wei, C.Q.; Liu, Y.H.; Gui, J.F. Temperature Effects on Sex Determination in Yellow Pond Turtle (Mauremys mutica Cantor). Acta Ecol. Sin. 2006, 26, 620-625.

132. Du, W.G.; Wang, L.; Shen, J.W. Optimal Temperatures for Egg Incubation in Two Geoemydid Turtles: Ocadia sinensis and Mauremys mutica. Aquaculture 2010, 305, 138-142. [CrossRef]

133. Wu, M.; Zhao, B.; Zhang, W.; Lu, H. Effects of Incubation Temperature on Embryonic Development and Hatchling Traits in the Asian Yellow Pond Turtle, Mauremys mutica. Acta Ecol. Sin. 2014, 34, 5398-5404. [CrossRef]

134. Okada, Y.; Yabe, T.; Oda, S.-I. Temperature-Dependent Sex Determination in the Japanese Pond Turtle, Mauremys japonica (Reptilia: Geoemydidae). Curr. Herpetol. 2010, 29, 1-10. [CrossRef]

135. Hou, L. Sex Determination by Temperature for Incubation in Chinemys reevesii. Acta Herpetol. Sin. 1985, 4, 130.

136. Farrell, L. Update: Temperature Sex Determination (TSD) Project for the Yellow-Margined Box Turtle, Cuora flavomarginata. Turt. Surviv. Alliance Newsl. 2007, 2007, 18.

137. Ewert, M.A.; Jackson, D.R.; Nelson, C.E. Patterns of Temperature-Dependent Sex Determination in Turtles. J. Exp. Zool. 1994, 270, 3-15. [CrossRef]

138. Pewphong, R.; Kitana, N.; Kitana, J. Effect of temperature on development: The case of the Malayan snail-eating turtle Malayemys macrocephala. In Naturalists, Explorers and Field Scientists in South-East Asia and Australasia; Das, I., Tuen, A.A., Eds.; Springer: Berlin/Heidelberg, Germany, 2016; pp. 157-169.

139. WHO De Smet. The Chromosomes of 11 Species of Chelonia (Reptilia). Acta Zool. Pathol. Antverp. 1978, 70, 15-34.

140. Bickham, J.W. Two-Hundred-Million-Year-Old Chromosomes: Deceleration of the Rate of Karyotypic Evolution in Turtles. Science 1981, 212, 1291-1293. [CrossRef] [PubMed]

141. Haiduk, M.W.; Bickham, J.W. Chromosomal Homologies and Evolution of Testudinoid Turtles with Emphasis on the Systematic Placement of Platysternon. Copeia 1982, 1982, 60-66. [CrossRef]

142. Carr, J.L.; Bickham, J.W. Phylogenetic Implications of Karyotypic Variation in the Batagurinae (Testudines: Emydidae). Genetica 1986, 70, 89-106. [CrossRef] 
143. Bickham, J.W.; Carr, J.L. Taxonomy and Phylogeny of the Higher Categories of Cryptodiran Turtles Based on a Cladistic Analysis of Chromosomal Data. Copeia 1983, 1983, 918-932. [CrossRef]

144. Siripiyasing, P.; Tanomtong, A.; Jumrusthanasan, S.; Patawang, I.; Phimphan, S.; Sanoamuang, L. First Cytogenetic Study of Malayan Snail-Eating Turtle, Malayemys Macrocephala (Testudines, Geoemydidae) in Thailand. Cytologia 2013, 78, 125-132. [CrossRef]

145. Sharma, G.P.; Kaur, P.; Nakhasi, U. Female Heterogamety in the Indian Cryptodiran Chelonian, Kachuga smithi Gray. In Dr. B.S. Chauhan Commemoration; Tiwari, K.K., Srivistava, C.B., Eds.; Zoological Society of India: Orissa, India, 1975.

146. Mazzoleni, S.; Augstenová, B.; Clemente, L.; Auer, M.; Fritz, U.; Praschag, P.; Protiva, T.; Velenský, P.; Kratochvíl, L.; Rovatsos, M. Turtles of the Genera Geoemyda and Pangshura (Testudines: Geoemydidae) Lack Differentiated Sex Chromosomes: The End of a 40-Year Error Cascade for Pangshura. PeerJ 2019, 7, e6241. [CrossRef]

147. Carr, J.L.; Bickham, J.W. Sex Chromosomes of the Asian Black Pond Turtle, Siebenrockiella crassicollis (Testudines: Emydidae). Cytogenet. Cell Genet. 1981, 31, 178-183. [CrossRef] [PubMed]

148. Kawagoshi, T.; Nishida, C.; Matsuda, Y. The Origin and Differentiation Process of X and Y Chromosomes of the Black Marsh Turtle (Siebenrockiella crassicollis, Geoemydidae, Testudines). Chromosome Res. 2012, 20, 95-110. [CrossRef]

149. Matsuda, Y.; Nishida-Umehara, C.; Tarui, H.; Kuroiwa, A.; Yamada, K.; Isobe, T.; Ando, J.; Fujiwara, A.; Hirao, Y.; Nishimura, O.; et al. Highly Conserved Linkage Homology between Birds and Turtles: Bird and Turtle Chromosomes Are Precise Counterparts of Each Other. Chromosome Res. 2005, 13, 601-615. [CrossRef]

150. Hammes, A.; Guo, J.K.; Lutsch, G.; Leheste, J.R.; Landrock, D.; Ziegler, U.; Gubler, M.C.; Schedl, A. Two Splice Variants of the Wilms' Tumor 1 Gene Have Distinct Functions during Sex Determination and Nephron Formation. Cell 2001, 106, 319-329. [CrossRef]

151. Eozenou, C.; Gonen, N.; Touzon, M.S.; Jorgensen, A.; Yatsenko, S.A.; Fusee, L.; Kamel, A.K.; Gellen, B.; Guercio, G.; Singh, P.; et al. Testis Formation in XX Individuals Resulting from Novel Pathogenic Variants in Wilms' Tumor 1 (WT1) Gene. Proc. Natl. Acad. Sci. USA 2020, 117, 13680-13688. [CrossRef]

152. Rhen, T.; Fagerlie, R.; Schroeder, A.; Crossley, D.A.; Lang, J.W. Molecular and Morphological Differentiation of Testes and Ovaries in Relation to the Thermosensitive Period of Gonad Development in the Snapping Turtle, Chelydra serpentina. Differ. Res. Biol. Divers. 2015, 89, 31-41. [CrossRef] [PubMed]

153. Taylor, E.H. Philippine turtles. Philipp. J. Sci. 1920, 16, 111-144. [CrossRef]

154. Diesmos, A.C.; Gee, G.V.; Diesmos, M.L.; Brown, R.M.; Widmann, P.J.; Dimalibot, J.C. Rediscovery of the Philippine Forest Turtle, Heosemys leytensis (Chelonia; Bataguridae), from Palawan Island, Philippines. Asiat. Herpetol. Res. 2004, 10, $22-27$.

155. Diesmos, A.C.; Parham, J.F.; Stuart, B.L.; Brown, R.M. The Phylogenetic Position of the Recently Rediscovered Philippine Forest Turtle (Bataguridae: Heosemys leytensis). Proc. Calif. Acad. Sci. 2005, 56, 31.

156. Bickham, J.W. A Cytosystematic Study of Turtles in the Genera Clemmys, Mauremys and Sacalia. Herpetologica 1975, 31, 198-204.

157. Montiel, E.E.; Badenhorst, D.; Tamplin, J.; Burke, R.L.; Valenzuela, N. Discovery of the Youngest Sex Chromosomes Reveals First Case of Convergent Co-Option of Ancestral Autosomes in Turtles. Chromosoma 2017, 126, 105-113. [CrossRef]

158. Badenhorst, D.; Hillier, L.W.; Literman, R.; Montiel, E.E.; Radhakrishnan, S.; Shen, Y.; Minx, P.; Janes, D.E.; Warren, W.C.; Edwards, S.V.; et al. Physical Mapping and Refinement of the Painted Turtle Genome (Chrysemys picta) Inform Amniote Genome Evolution and Challenge Turtle-Bird Chromosomal Conservation. Genome Biol. Evol. 2015, 7, 2038-2050. [CrossRef] [PubMed]

159. Literman, R.; Radhakrishnan, S.; Tamplin, J.; Burke, R.; Dresser, C.; Valenzuela, N. Development of Sexing Primers in Glyptemys insculpta and Apalone spinifera Turtles Uncovers an XX/XY Sex-Determining System in the Critically-Endangered Bog Turtle Glyptemys muhlenbergii. Conserv. Genet. Resour. 2017, 9, 651-658. [CrossRef]

160. Gorman, G. The Chromosomes of the Reptilian, a Cytotaxonomy Interpretation. In Cytotaxonomy and Vertebrate Evolution; Chiarelli, A.B., Capanna, E., Eds.; Academic Press: Cambridge, MA, USA, 1973.

161. Cao, D.; Wang, M.; Ge, Y.; Gong, S. Draft Genome of the Big-Headed Turtle Platysternon megacephalum. Sci. Data 2019, 6, 60. [CrossRef]

162. Rohilla, M.S.; Rao, R.J.; Tiwari, P.K. Use of Peripheral Blood Lymphocyte Culture in the Karyological Analysis of Indian Freshwater Turtles, Lissemys punctata and Geoclemys hamiltoni. Curr. Sci. 2006, 90, 1130-1134.

163. Literman, R.; Burrett, A.; Bista, B.; Valenzuela, N. Putative Independent Evolutionary Reversals from Genotypic to TemperatureDependent Sex Determination Are Associated with Accelerated Evolution of Sex-Determining Genes in Turtles. J. Mol. Evol. 2018, 86, 11-26. [CrossRef]

164. Bista, B.; Valenzuela, N. Turtle Insights into the Evolution of the Reptilian Karyotype and the Genomic Architecture of Sex Determination. Genes 2020, 11, 416. [CrossRef] [PubMed]

165. Deveson, I.W.; Holleley, C.E.; Blackburn, J.; Marshall Graves, J.A.; Mattick, J.S.; Waters, P.D.; Georges, A. Differential Intron Retention in Jumonji Chromatin Modifier Genes Is Implicated in Reptile Temperature-Dependent Sex Determination. Sci. Adv. 2017, 3, e1700731. [CrossRef]

166. Ge, C.; Ye, J.; Weber, C.; Sun, W.; Zhang, H.; Zhou, Y.; Cai, C.; Qian, G.; Capel, B. The Histone Demethylase KDM6B Regulates Temperature-Dependent Sex Determination in a Turtle Species. Science 2018, 360, 645-648. [CrossRef]

167. Weber, C.; Zhou, Y.; Lee, J.G.; Looger, L.L.; Qian, G.; Ge, C.; Capel, B. Temperature-Dependent Sex Determination Is Mediated by PSTAT3 Repression of Kdm6b. Science 2020, 368, 303-306. [CrossRef] [PubMed] 
168. Wilson Sayres, M.A.; Makova, K.D. Genome Analyses Substantiate Male Mutation Bias in Many Species. BioEssays 2011, 33, 938-945. [CrossRef] [PubMed]

169. Mitchell, N.J.; Nelson, N.J.; Cree, A.; Pledger, S.; Keall, S.N.; Daugherty, C.H. Support for a Rare Pattern of TemperatureDependent Sex Determination in Archaic Reptiles: Evidence from Two Species of Tuatara (Sphenodon). Front. Zool. $2006,3,9$. [CrossRef] [PubMed]

170. Vidal, N.; Hedges, S.B. The molecular evolutionary tree of lizards, snakes, and amphisbaenians. Comptes Rendus Biol. 2009, 332, 129-139. [CrossRef]

171. Burbrink, F.T.; Grazziotin, F.G.; Pyron, R.A.; Cundall, D.; Donnellan, S.; Irish, F.; Keogh, J.S.; Kraus, F.; Murphy, R.W.; Noonan, B.; et al. Interrogating Genomic-Scale Data for Squamata (Lizards, Snakes, and Amphisbaenians) Shows No Support for Key Traditional Morphological Relationships. Syst. Biol. 2020, 69, 502-520. [CrossRef]

172. Cole, C.J.; Gans, C. The Karyotype of Dibamus novaeguineae (Squamata: Dibamidae). Herpetologica 1997, $229-232$.

173. Wagner, E. Temperature-Dependent Sex Determination in a Gekko Lizard. Q. Rev. Biol. 1980, 55, 21.

174. King, M.; Rofe, R. Karyotypic Variation in the Australian Gekko Phyllodactylus marmoratus (Gray) (Gekkonidae: Reptilia). Chromosoma 1976, 54, 75-87. [CrossRef] [PubMed]

175. Gorman, G.C.; Gress, F. Sex Chromosomes of a Pygopodid Lizard, Lialis burtonis. Experientia 1970, 26, 206-207. [CrossRef]

176. Solleder, E.; Schmid, M. XX/XY-Sex Chromosomes in Gekko Gecko (Sauria, Reptilia). Amphib.-Reptil. 1984, 5, 339-345. [CrossRef]

177. Kawai, A.; Ishijima, J.; Nishida, C.; Kosaka, A.; Ota, H.; Kohno, S.; Matsuda, Y. The ZW Sex Chromosomes of Gekko hokouensis (Gekkonidae, Squamata) Represent Highly Conserved Homology with Those of Avian Species. Chromosoma 2009, 118 , 43-51. [CrossRef]

178. Gamble, T. A Review of Sex Determining Mechanisms in Geckos (Gekkota: Squamata). Sex. Dev. 2010, 4, 88-103. [CrossRef] [PubMed]

179. Pokorná, M.; Rens, W.; Rovatsos, M.; Kratochvíl, L. A ZZ/ZW Sex Chromosome System in the Thick-Tailed Gecko (Underwoodisaurus milii; Squamata: Gekkota: Carphodactylidae), a Member of the Ancient Gecko Lineage. Cytogenet. Genome Res. 2014, 142, 190-196. [CrossRef]

180. Koubová, M.; Johnson Pokorná, M.; Rovatsos, M.; Farkačová, K.; Altmanová, M.; Kratochvíl, L. Sex Determination in Madagascar Geckos of the Genus Paroedura (Squamata: Gekkonidae): Are Differentiated Sex Chromosomes Indeed so Evolutionary Stable? Chromosome Res. 2014, 22, 441-452. [CrossRef]

181. Rovatsos, M.; Johnson Pokorná, M.; Altmanová, M.; Kratochvíl, L. Mixed-Up Sex Chromosomes: Identification of Sex Chromosomes in the X1X1X2X2/X1X2Y System of the Legless Lizards of the Genus Lialis (Squamata: Gekkota: Pygopodidae). Cytogenet. Genome Res. 2016, 149, 282-289. [CrossRef] [PubMed]

182. Gamble, T.; Coryell, J.; Ezaz, T.; Lynch, J.; Scantlebury, D.P.; Zarkower, D. Restriction Site-Associated DNA Sequencing (RAD-Seq) Reveals an Extraordinary Number of Transitions among Gecko Sex-Determining Systems. Mol. Biol. Evol. 2015, 32, $1296-1309$. [CrossRef]

183. Gamble, T.; McKenna, E.; Meyer, W.; Nielsen, S.V.; Pinto, B.J.; Scantlebury, D.P.; Higham, T.E. XX/XY Sex Chromosomes in the South American Dwarf Gecko (Gonatodes humeralis). J. Hered. 2017, 109, 462-468. [CrossRef]

184. Nielsen, S.V.; Daza, J.D.; Pinto, B.J.; Gamble, T. ZZ/ZW Sex Chromosomes in the Endemic Puerto Rican Leaf-Toed Gecko (Phyllodactylus wirshingi). Cytogenet. Genome Res. 2019, 157, 89-97. [CrossRef]

185. Keating, S.E.; Griffing, A.H.; Nielsen, S.V.; Scantlebury, D.P.; Gamble, T. Conserved ZZ/ZW Sex Chromosomes in Caribbean Croaking Geckos (Aristelliger: Sphaerodactylidae). J. Evol. Biol. 2020, 33, 1316-1326. [CrossRef]

186. Jeffries, D.L.; Lavanchy, G.; Sermier, R.; Sredl, M.J.; Miura, I.; Borzée, A.; Barrow, L.N.; Canestrelli, D.; Crochet, P.-A.; Dufresnes, C.; et al. A Rapid Rate of Sex-Chromosome Turnover and Non-Random Transitions in True Frogs. Nat. Commun. 2018, 9, 4088. [CrossRef]

187. Gammerdinger, W.J.; Kocher, T.D. Unusual Diversity of Sex Chromosomes in African Cichlid Fishes. Genes 2018, 9, 480. [CrossRef] [PubMed]

188. Matsubara, K.; Gamble, T.; Matsuda, Y.; Zarkower, D.; Sarre, S.D.; Georges, A.; Marshall Graves, J.A.; Ezaz, T. Non-homologous sex chromosomes in two geckos (Gekkonidae: Gekkota) with female heterogamy. Cytogenet. Genome Res. 2014, 143, 251-258. [CrossRef] [PubMed]

189. Srikulnath, K.; Uno, Y.; Nishida, C.; Ota, H.; Matsuda, Y. Karyotype Reorganization in the Hokou Gecko (Gekko Hokouensis, Gekkonidae): The Process of Microchromosome Disappearance in Gekkota. PLoS ONE 2015, 10, e0134829. [CrossRef] [PubMed]

190. Rovatsos, M.; Farkačová, K.; Altmanová, M.; Johnson Pokorná, M.; Kratochvíl, L. The Rise and Fall of Differentiated Sex Chromosomes in Geckos. Mol. Ecol. 2019, 28, 3042-3052. [CrossRef] [PubMed]

191. Pyron, R.A.; Burbrink, F.T.; Wiens, J.J. A Phylogeny and Revised Classification of Squamata, Including 4161 Species of Lizards and Snakes. BMC Evol. Biol. 2013, 13, 93. [CrossRef]

192. Keating, S.E.; Blumer, M.; Grismer, L.L.; Lin, A.; Nielsen, S.V.; Thura, M.K.; Wood, P.L.; Quah, E.S.H.; Gamble, T. Sex Chromosome Turnover in Bent-Toed Geckos (Cyrtodactylus). Genes 2021, 12, 116. [CrossRef] [PubMed]

193. Ota, H.; Hikida, T.; Matsui, M.; Mori, A. Karyotypes of Two Species of the Genus Cyrtodactylus (Squamata: Gekkonidae) from Sarawak, Malaysia. Caryologia 1992, 45, 43-49. [CrossRef]

194. Pensabene, E.; Kratochvíl, L.; Rovatsos, M. Independent Evolution of Sex Chromosomes in Eublepharid Geckos, A Lineage with Environmental and Genotypic Sex Determination. Life 2020, 10, 342. [CrossRef] [PubMed] 
195. Kluge, A.G. Phylogenetic Relationships and Evolutionary Trends in the Eublepharine Lizard Genus Coleonyx. Copeia 1975, 1975, 24-35. [CrossRef]

196. Dial, B.E.; Grismer, L.L. A Phylogenetic Analysis of Physiological-Ecological Character Evolution in the Lizard Genus Coleonyx and Its Implications for Historical Biogeographic Reconstruction. Syst. Biol. 1992, 41, 178-195. [CrossRef]

197. Viets, B.E.; Ewert, M.A.; Talent, L.G.; Nelson, C.E. Sex-Determining Mechanisms in Squamate Reptiles. J. Exp. Zool. 1994, 270, 45-56. [CrossRef]

198. Pokorná, M.; Rábová, M.; Ráb, P.; Ferguson-Smith, M.A.; Rens, W.; Kratochvíl, L. Differentiation of Sex Chromosomes and Karyotypic Evolution in the Eye-Lid Geckos (Squamata: Gekkota: Eublepharidae), a Group with Different Modes of Sex Determination. Chromosome Res. 2010, 18, 809-820. [CrossRef]

199. Augstenová, B.; Pensabene, E.; Veselý, M.; Kratochvíl, L.; Rovatsos, M. Are Geckos Special in Sex Determination? Independently Evolved Differentiated ZZ/ZW Sex Chromosomes in Carphodactylid Geckos. Genome Biol. Evol. 2021, 13, evab119. [CrossRef] [PubMed]

200. Rovatsos, M.; Gamble, T.; Nielsen, S.V.; Georges, A.; Ezaz, T.; Kratochvíl, L. Do Male and Female Heterogamety Really Differ in Expression Regulation? Lack of Global Dosage Balance in Pygopodid Geckos. Philos. Trans. R. Soc. Lond. B. Biol. Sci. 2021, 376, 20200102. [CrossRef] [PubMed]

201. Matsubara, K.; Knopp, T.; Sarre, S.D.; Georges, A.; Ezaz, T. Karyotypic Analysis and FISH Mapping of Microsatellite Motifs Reveal Highly Differentiated XX/XY Sex Chromosomes in the Pink-Tailed Worm-Lizard (Aprasia parapulchella, Pygopodidae, Squamata). Mol. Cytogenet. 2013, 6, 60. [CrossRef] [PubMed]

202. Kostmann, A.; Kratochvíl, L.; Rovatsos, M. First Report of Sex Chromosomes in Plated Lizards (Squamata: Gerrhosauridae). Sex. Dev. 2020, 14, 60-65. [CrossRef] [PubMed]

203. Nielsen, S.V.; Pinto, B.J.; Guzmán-Méndez, I.A.; Gamble, T. First Report of Sex Chromosomes in Night Lizards (Scincoidea: Xantusiidae). J. Hered. 2020, 111, 307-317. [CrossRef]

204. Kratochvíl, L.; Vukić, J.; Červenka, J.; Kubička, L.; Pokorná, M.J.; Kukačková, D.; Rovatsos, M.; Piálek, L. Mixed-Sex Offspring Produced via Cryptic Parthenogenesis in a Lizard. Mol. Ecol. 2020, 29, 4118-4127. [CrossRef]

205. Katoh-Fukui, Y.; Tsuchiya, R.; Shiroishi, T.; Nakahara, Y.; Hashimoto, N.; Noguchi, K.; Higashinakagawa, T. Male-to-Female Sex Reversal in M33 Mutant Mice. Nature 1998, 393, 688-692. [CrossRef]

206. Biason-Lauber, A.; Konrad, D.; Meyer, M.; DeBeaufort, C.; Schoenle, E.J. Ovaries and Female Phenotype in a Girl with 46,XY Karyotype and Mutations in the CBX2 Gene. Am. J. Hum. Genet. 2009, 84, 658-663. [CrossRef]

207. Kuroiwa, A.; Handa, S.; Nishiyama, C.; Chiba, E.; Yamada, F.; Abe, S.; Matsuda, Y. Additional Copies of CBX2 in the Genomes of Males of Mammals Lacking SRY, the Amami Spiny Rat (Tokudaia osimensis) and the Tokunoshima Spiny Rat (Tokudaia tokunoshimensis). Chromosome Res. 2011, 19, 635-644. [CrossRef] [PubMed]

208. Robert, K.A.; Thompson, M.B. Sex Determination. Viviparous Lizard Selects Sex of Embryos. Nature 2001, 412, 698-699. [CrossRef]

209. Wapstra, E.; Olsson, M.; Shine, R.; Edwards, A.; Swain, R.; Joss, J.M.P. Maternal Basking Behaviour Determines Offspring Sex in a Viviparous Reptile. Proc. Biol. Sci. 2004, 271 (Suppl. S4), S230-S232. [CrossRef]

210. Shine, R.; Elphick, M.J.; Donnellan, S. Co-Occurrence of Multiple, Supposedly Incompatible Modes of Sex Determination in a Lizard Population. Ecol. Lett. 2002, 5, 486-489. [CrossRef]

211. Pen, I.; Uller, T.; Feldmeyer, B.; Harts, A.; While, G.M.; Wapstra, E. Climate-Driven Population Divergence in Sex-Determining Systems. Nature 2010, 468, 436-438. [CrossRef]

212. Cunningham, G.D.; While, G.M.; Wapstra, E. Climate and Sex Ratio Variation in a Viviparous Lizard. Biol. Lett. 2017, 13, 20170218. [CrossRef] [PubMed]

213. Radder, R.S.; Quinn, A.E.; Georges, A.; Sarre, S.D.; Shine, R. Genetic Evidence for Co-Occurrence of Chromosomal and Thermal Sex-Determining Systems in a Lizard. Biol. Lett. 2008, 4, 176-178. [CrossRef] [PubMed]

214. Quinn, A.E.; Radder, R.S.; Sarre, S.D.; Georges, A.; Ezaz, T.; Shine, R. Isolation and Development of a Molecular Sex Marker for Bassiana duperreyi, a Lizard with XX/XY Sex Chromosomes and Temperature-Induced Sex Reversal. Mol. Genet. Genom. MGG 2009, 281, 665-672. [CrossRef]

215. Hill, P.L.; Burridge, C.P.; Ezaz, T.; Wapstra, E. Conservation of Sex-Linked Markers among Conspecific Populations of a Viviparous Skink, Niveoscincus ocellatus, Exhibiting Genetic and Temperature-Dependent Sex Determination. Genome Biol. Evol. 2018, 10, 1079-1087. [CrossRef]

216. Cornejo-Páramo, P.; Dissanayake, D.S.B.; Lira-Noriega, A.; Martínez-Pacheco, M.L.; Acosta, A.; Ramírez-Suástegui, C.; Méndezde-la-Cruz, F.R.; Székely, T.; Urrutia, A.O.; Georges, A.; et al. Viviparous Reptile Regarded to Have Temperature-Dependent Sex Determination Has Old XY Chromosomes. Genome Biol. Evol. 2020, 12, 924-930. [CrossRef] [PubMed]

217. Kostmann, A.; Kratochvíl, L.; Rovatsos, M. Poorly Differentiated XX/XY Sex Chromosomes Are Widely Shared across Skink Radiation. Proc. Biol. Sci. 2021, 288, 20202139. [CrossRef]

218. Dissanayake, D.S.B.; Holleley, C.E.; Hill, L.K.; O’Meally, D.; Deakin, J.E.; Georges, A. Identification of Y Chromosome Markers in the Eastern Three-Lined Skink (Bassiana duperreyi) Using in Silico Whole Genome Subtraction. BMC Genom. 2020, 21, 667. [CrossRef]

219. Hughes, J.J.; Alkhunaizi, E.; Kruszka, P.; Pyle, L.C.; Grange, D.K.; Berger, S.I.; Payne, K.K.; Masser-Frye, D.; Hu, T.; Christie, M.R.; et al. Loss-of-Function Variants in PPP1R12A: From Isolated Sex Reversal to Holoprosencephaly Spectrum and Urogenital Malformations. Am. J. Hum. Genet. 2020, 106, 121-128. [CrossRef] 
220. Varmuza, S.; Jurisicova, A.; Okano, K.; Hudson, J.; Boekelheide, K.; Shipp, E.B. Spermiogenesis Is Impaired in Mice Bearing a Targeted Mutation in the Protein Phosphatase 1cgamma Gene. Dev. Biol. 1999, 205, 98-110. [CrossRef]

221. Patawang, I.; Chuaykern, Y.; Supanuam, P.; Maneechot, N.; Pinthong, K.; Tanomtong, A. Cytogenetics of the skinks (Reptilia, Scincidae) from Thailand; IV: Newly investigated karyotypic features of Lygosoma quadrupes and Scincella melanostica. Caryologia 2018, 71, 29-34. [CrossRef]

222. Wright, J.W. Evolution of the X1X2Y Sex Chromosome Mechanism in the Scincid Lizard Scincella laterale (Say). Chromosoma 1973, 43, 101-108. [PubMed]

223. Castiglia, R.; Bezerra, A.; Flores-Villela, O.; Annesi, F.; Muñoz, A.; Gornung, E. Comparative Cytogenetics of Two Species of Ground Skinks: Scincella assata and S. cherriei (Squamata: Scincidae: Lygosominae) from Chiapas, Mexico. Acta Herpetol. 2013, 8 , 69-73. [CrossRef]

224. Bull, J. Sex Chromosome Differentiation: An Intermediate Stage in a Lizard. Can. J. Genet. Cytol. 1978, 20, 205-209. [CrossRef]

225. Peccinini-Seale, D.; Rocha, C.F.D.; Almeida, T.M.B.; Araújo, A.F.B.; De Sena, M.A. Cytogenetics of the Brazilian Whiptail Lizard Cnemidophorus littoralis (Teiidae) from a Restinga Area (Barra de Maricá) in Southeastern Brazil. Braz. J. Biol. 2004, 64, 661-667. [CrossRef] [PubMed]

226. Cole, C.J.; Dessauer, H.C.; Townsend, C.R.; Arnold, M.G. Unisexual Lizards of the Genus Gymnophthalmus (Reptilia, Teiidae) in the Neotropics: Genetics, Origin, and Systematics. Am. Mus. Novit. 1990, 2994, 1-29.

227. Pellegrino, K.C.; Rodrigues, M.T.; Yonenaga-Yassuda, Y. Chromosomal Polymorphisms Due to Supernumerary Chromosomes and Pericentric Inversions in the Eyelidless Microteiid Lizard Nothobachia ablephara (Squamata, Gymnophthalmidae). Chromosome Res. 1999, 7, 247-254. [CrossRef]

228. Yonenaga-Yassudal, Y.; Rodrigues, M.T. Supernumerary Chromosome Variation, Heteromorphic Sex Chromosomes and Banding Patterns in Microteiid Lizards of the Genus Micrablepharus (Squamata, Gymnophthalmidae). Chromosome Res. 1999, 7, 21-29. [CrossRef] [PubMed]

229. Yonenaga-Yassuda, Y.; Rodrigues, M.T.; Pellegrino, K.C.M. Chromosomal Banding Patterns in the Eyelid-Less Microteiid Lizard Radiation: The X1X1X2X2: X1X2Y Sex Chromosome System in Calyptommatus and the Karyotypes of Psilophthalmus and Tretioscincus (Squamata, Gymnophthalmidae). Genet. Mol. Biol. 2005, 28, 700-709. [CrossRef]

230. Cole, C.J.; Gans, C. Chromosomes of Bipes, Mesobaena, and Other Amphisbaenians (Reptilia), with Comments on Their Evolution. Am. Mus. Novit. 1987, 2689, 1-9.

231. Rovatsos, M.; Vukić, J.; Mrugała, A.; Suwala, G.; Lymberakis, P.; Kratochvíl, L. Little Evidence for Switches to Environmental Sex Determination and Turnover of Sex Chromosomes in Lacertid Lizards. Sci. Rep. 2019, 9, 7832. [CrossRef] [PubMed]

232. Rovatsos, M.; Vukić, J.; Kratochvíl, L. Mammalian X Homolog Acts as Sex Chromosome in Lacertid Lizards. Heredity 2016, 117, 8-13. [CrossRef] [PubMed]

233. Achermann, J.C.; Ito, M.; Hindmarsh, P.C.; Jameson, J.L. A Mutation in the Gene Encoding Steroidogenic Factor-1 Causes XY Sex Reversal and Adrenal Failure in Humans. Nat. Genet. 1999, 22, 125-126. [CrossRef]

234. Ikeda, Y.; Tagami, A.; Maekawa, M.; Nagai, A. The Conditional Deletion of Steroidogenic Factor 1 (Nr5a1) in Sox9-Cre Mice Compromises Testis Differentiation. Sci. Rep. 2021, 11, 4486. [CrossRef]

235. Oike, A.; Kodama, M.; Yasumasu, S.; Yamamoto, T.; Nakamura, Y.; Ito, E.; Nakamura, M. Participation of Androgen and Its Receptor in Sex Determination of an Amphibian Species. PLoS ONE 2017, 12, e0178067. [CrossRef]

236. Parma, P.; Veyrunes, F.; Pailhoux, E. Sex Reversal in Non-Human Placental Mammals. Sex. Dev. 2016, 10, 326-344. [CrossRef]

237. Danielyan, F.; Arakelyan, M.; Stepanyan, I. Hybrids of Darevskia Valentini, D. Armeniaca and D. Unisexualis from a Sympatric Population in Armenia. Amphib.-Reptil. 2008, 29, 487-504. [CrossRef]

238. King, M.; King, D. Chromosomal Evolution in the Lizard Genus Varanus (Reptilia). Aust. J. Biol. Sci. 1975, 28, 89-108. [CrossRef] [PubMed]

239. King, M.; Mengden, G.A.; King, D. A Pericentric-Inversion Polymorphism and s ZZ/ZW Sex-Chromosome System in Varanus acanthurus Boulenger Analyzed by G-and C-Banding and Ag Staining. Genetica 1982, 58, 39-45. [CrossRef]

240. Matsubara, K.; Sarre, S.D.; Georges, A.; Matsuda, Y.; Marshall Graves, J.A.; Ezaz, T. Highly Differentiated ZW Sex Microchromosomes in the Australian Varanus Species Evolved through Rapid Amplification of Repetitive Sequences. PLoS ONE 2014, 9, e95226. [CrossRef]

241. Patawang, I.; Tanomtong, A.; Getlekha, N.; Phimphan, S.; Pinthong, K.; Neeratanaphan, L. Standardized Karyotype and Idiogram of Bengal Monitor Lizard, Varanus bengalensis (Squamata, Varanidae). Cytologia 2017, 82, 75-82. [CrossRef]

242. Johnson Pokorná, M.; Altmanová, M.; Rovatsos, M.; Velenský, P.; Vodička, R.; Rehák, I.; Kratochvíl, L. First Description of the Karyotype and Sex Chromosomes in the Komodo Dragon (Varanus Komodoensis). Cytogenet. Genome Res. 2016, 148, $284-291$. [CrossRef]

243. Iannucci, A.; Altmanová, M.; Ciofi, C.; Ferguson-Smith, M.; Milan, M.; Pereira, J.C.; Pether, J.; Rehák, I.; Rovatsos, M.; Stanyon, R.; et al. Conserved Sex Chromosomes and Karyotype Evolution in Monitor Lizards (Varanidae). Heredity 2019, 123, $215-227$. [CrossRef] [PubMed]

244. Johnson Pokorná, M.; Rovatsos, M.; Kratochvíl, L. Sex Chromosomes and Karyotype of the (Nearly) Mythical Creature, the Gila Monster, Heloderma suspectum (Squamata: Helodermatidae). PLoS ONE 2014, 9, e104716. [CrossRef]

245. Rovatsos, M.; Rehák, I.; Velenský, P.; Kratochvíl, L. Shared Ancient Sex Chromosomes in Varanids, Beaded Lizards, and Alligator Lizards. Mol. Biol. Evol. 2019, 36, 1113-1120. [CrossRef] 
246. Augstenová, B.; Pensabene, E.; Kratochvíl, L.; Rovatsos, M. Cytogenetic Evidence for Sex Chromosomes and Karyotype Evolution in Anguimorphan Lizards. Cells 2021, 10, 1612. [CrossRef] [PubMed]

247. Hattori, R.S.; Somoza, G.M.; Fernandino, J.I.; Colautti, D.C.; Miyoshi, K.; Gong, Z.; Yamamoto, Y.; Strüssmann, C.A. The Duplicated Y-Specific amhy Gene Is Conserved and Linked to Maleness in Silversides of the Genus Odontesthes. Genes 2019, 10, 679. [CrossRef]

248. Bej, D.K.; Miyoshi, K.; Hattori, R.S.; Strüssmann, C.A.; Yamamoto, Y. A Duplicated, Truncated amh Gene Is Involved in Male Sex Determination in an Old World Silverside. G3 Genes Genomes Genet. 2017, 7, 2489-2495. [CrossRef]

249. Curzon, A.Y.; Shirak, A.; Dor, L.; Zak, T.; Perelberg, A.; Seroussi, E.; Ron, M. A Duplication of the Anti-Müllerian Hormone Gene Is Associated with Genetic Sex Determination of Different Oreochromis niloticus Strains. Heredity 2020, 125, 317-327. [CrossRef]

250. Harlow, P. Temperature-Dependent Sex Determination in Lizards. In Temperature Dependent Sex Determination in Vertebrates; Valenzuela, N., Lance, V.A., Eds.; Smithsonian Books: Whashington, DC, USA, 2004; pp. 42-52.

251. Sidhom, M.; Said, K.; Chatti, N.; Guarino, F.M.; Odierna, G.; Petraccioli, A.; Picariello, O.; Mezzasalma, M. Karyological Characterization of the Common Chameleon (Chamaeleo chamaeleon) Provides Insights on the Evolution and Diversification of Sex Chromosomes in Chamaeleonidae. Zool. Jena Ger. 2020, 141, 125738. [CrossRef]

252. Andrews, R.M. Incubation Temperature and Sex Ratio of the Veiled Chameleon (Chamaeleo calyptratus). J. Herpetol. 2005, 39, 515-518. [CrossRef]

253. Rovatsos, M.; Johnson Pokorná, M.; Altmanová, M.; Kratochvíl, L. Female Heterogamety in Madagascar Chameleons (Squamata: Chamaeleonidae: Furcifer): Differentiation of Sex and Neo-Sex Chromosomes. Sci. Rep. 2015, 5, 13196. [CrossRef]

254. Rovatsos, M.; Altmanová, M.; Augstenová, B.; Mazzoleni, S.; Velenský, P.; Kratochvíl, L. ZZ/ZW Sex Determination with Multiple Neo-Sex Chromosomes Is Common in Madagascan Chameleons of the Genus Furcifer (Reptilia: Chamaeleonidae). Genes 2019, 10, 1020. [CrossRef] [PubMed]

255. Rovatsos, M.; Altmanová, M.; Johnson Pokorná, M.; Velenský, P.; Sánchez Baca, A.; Kratochvíl, L. Evolution of Karyotypes in Chameleons. Genes 2017, 8, 382. [CrossRef] [PubMed]

256. Nielsen, S.V.; Banks, J.L.; Diaz, R.E.; Trainor, P.A.; Gamble, T. Dynamic Sex Chromosomes in Old World Chameleons (Squamata: Chamaeleonidae). J. Evol. Biol. 2018, 31, 484-490. [CrossRef] [PubMed]

257. Pokorná, M.; Giovannotti, M.; Kratochvíl, L.; Kasai, F.; Trifonov, V.A.; O’Brien, P.C.M.; Caputo, V.; Olmo, E.; Ferguson-Smith, M.A.; Rens, W. Strong Conservation of the Bird Z Chromosome in Reptilian Genomes Is Revealed by Comparative Painting despite 275 Million Years Divergence. Chromosoma 2011, 120, 455-468. [CrossRef] [PubMed]

258. Kratochvíl, L.; Gamble, T.; Rovatsos, M. Sex Chromosome Evolution among Amniotes: Is the Origin of Sex Chromosomes Non-Random? Philos. Trans. R. Soc. Lond. B. Biol. Sci. 2021, 376, 20200108. [CrossRef]

259. Ganesh, S.; Raman, R. Sex Reversal by Testosterone and Not by Estradiol or Temperature in Calotes versicolor, the Lizard Lacking Sex Chromosomes. J. Exp. Zool. 1995, 271, 139-144. [CrossRef]

260. Doddamani, L.S.I.; Vani, V.; Seshagiri, P.B. A Tropical Oviparous Lizard, Calotes versicolor, Exhibiting a Potentially Novel FMFM Pattern of Temperature-Dependent Sex Determination. J. Exp. Zool. Part Ecol. Genet. Physiol. 2012, 317, 32-46. [CrossRef]

261. Wilson, C.A.; Priyanka; Titus, T.; Batzel, P.; Postlethwait, J.H.; Raman, R. A Search for Sex-Linked Loci in the Agamid Lizard, Calotes versicolor. Sex. Dev. 2019, 13, 143-150. [CrossRef] [PubMed]

262. Alam, S.M.I.; Altmanová, M.; Prasongmaneerut, T.; Georges, A.; Sarre, S.D.; Nielsen, S.V.; Gamble, T.; Srikulnath, K.; Rovatsos, M.; Kratochvíl, L.; et al. Cross-Species BAC Mapping Highlights Conservation of Chromosome Synteny across Dragon Lizards (Squamata: Agamidae). Genes 2020, 11, 698. [CrossRef] [PubMed]

263. Zeng, X.M.; Wang, Y.Z.; Liu, Z.J.; Fang, Z.L.; Wu, G.F.; Papenfuss, T.J.; Macey, R.J. Karyotypes of Nine Species in the Genus Phrynocephalus, with Discussion of Karyotypic Evolution of Chinese Phrynocephalus. Acta Zool. Sin. 1997, 43, 399-410.

264. Yang, W.; Qi, Y.; Fu, J. Exploring the Genetic Basis of Adaptation to High Elevations in Reptiles: A Comparative Transcriptome Analysis of Two Toad-Headed Agamas (Genus Phrynocephalus). PLoS ONE 2014, 9, e112218. [CrossRef] [PubMed]

265. Gao, W.; Sun, Y.-B.; Zhou, W.-W.; Xiong, Z.-J.; Chen, L.; Li, H.; Fu, T.-T.; Xu, K.; Xu, W.; Ma, L.; et al. Genomic and Transcriptomic Investigations of the Evolutionary Transition from Oviparity to Viviparity. Proc. Natl. Acad. Sci. USA 2019, 116, $3646-3655$. [CrossRef]

266. Uller, T.; Mott, B.; Odierna, G.; Olsson, M. Consistent Sex Ratio Bias of Individual Female Dragon Lizards. Biol. Lett. 2006, 2, 569-572. [CrossRef]

267. Ezaz, T.; Quinn, A.E.; Miura, I.; Sarre, S.D.; Georges, A.; Marshall Graves, J.A. The Dragon Lizard Pogona vitticeps Has ZZ/ZW Micro-Sex Chromosomes. Chromosome Res. 2005, 13, 763-776. [CrossRef]

268. Ezaz, T.; Quinn, A.E.; Sarre, S.D.; O’Meally, D.; Georges, A.; Graves, J.A.M. Molecular Marker Suggests Rapid Changes of Sex-Determining Mechanisms in Australian Dragon Lizards. Chromosome Res. 2009, 17, 91-98. [CrossRef]

269. Quinn, A.E.; Ezaz, T.; Sarre, S.D.; Graves, J.M.; Georges, A. Extension, Single-Locus Conversion and Physical Mapping of Sex Chromosome Sequences Identify the Z Microchromosome and Pseudo-Autosomal Region in a Dragon Lizard, Pogona vitticeps. Heredity 2010, 104, 410-417. [CrossRef]

270. Young, M.J.; O’Meally, D.; Sarre, S.D.; Georges, A.; Ezaz, T. Molecular Cytogenetic Map of the Central Bearded Dragon, Pogona vitticeps (Squamata: Agamidae). Chromosome Res. 2013, 21, 361-374. [CrossRef] 
271. Georges, A.; Li, Q.; Lian, J.; O’Meally, D.; Deakin, J.; Wang, Z.; Zhang, P.; Fujita, M.; Patel, H.R.; Holleley, C.E.; et al. High-Coverage Sequencing and Annotated Assembly of the Genome of the Australian Dragon Lizard Pogona vitticeps. GigaScience $2015,4,45$. [CrossRef] [PubMed]

272. Deakin, J.E.; Edwards, M.J.; Patel, H.; O’Meally, D.; Lian, J.; Stenhouse, R.; Ryan, S.; Livernois, A.M.; Azad, B.; Holleley, C.E.; et al. Anchoring Genome Sequence to Chromosomes of the Central Bearded Dragon (Pogona vitticeps) Enables Reconstruction of Ancestral Squamate Macrochromosomes and Identifies Sequence Content of the Z Chromosome. BMC Genom. 2016, $17,447$. [CrossRef] [PubMed]

273. Ezaz, T.; Azad, B.; O’Meally, D.; Young, M.J.; Matsubara, K.; Edwards, M.J.; Zhang, X.; Holleley, C.E.; Deakin, J.E.; Marshall Graves, J.A.; et al. Sequence and Gene Content of a Large Fragment of a Lizard Sex Chromosome and Evaluation of Candidate Sex Differentiating Gene R-Spondin 1. BMC Genom. 2013, 14, 899. [CrossRef]

274. Luo, X.; Ikeda, Y.; Lala, D.; Rice, D.; Wong, M.; Parker, K.L. Steroidogenic Factor 1 (SF-1) Is Essential for Endocrine Development and Function. J. Steroid Biochem. Mol. Biol. 1999, 69, 13-18. [CrossRef]

275. Quinn, A.E.; Georges, A.; Sarre, S.D.; Guarino, F.; Ezaz, T.; Graves, J.A.M. Temperature Sex Reversal Implies Sex Gene Dosage in a Reptile. Science 2007, 316, 411. [CrossRef] [PubMed]

276. Holleley, C.E.; O’Meally, D.; Sarre, S.D.; Marshall Graves, J.A.; Ezaz, T.; Matsubara, K.; Azad, B.; Zhang, X.; Georges, A. Sex Reversal Triggers the Rapid Transition from Genetic to Temperature-Dependent Sex. Nature 2015, 523, 79-82. [CrossRef] [PubMed]

277. Pokorná, M.; Kratochvíl, L. Phylogeny of Sex-Determining Mechanisms in Squamate Reptiles: Are Sex Chromosomes an Evolutionary Trap? Zool. J. Linn. Soc. 2009, 156, 168-183. [CrossRef]

278. Gorman, G.C.; Atkins, L. Chromosomal Heteromorphism in Some Male Lizards of the Genus Anolis. Am. Nat. 1966, 100, 579-583. [CrossRef]

279. Cole, C.J.; Lowe, C.H.; Wright, J.W. Sex Chromosomes in Lizards. Science 1967, 155, 1028-1029. [CrossRef]

280. Alföldi, J.; Di Palma, F.; Grabherr, M.; Williams, C.; Kong, L.; Mauceli, E.; Russell, P.; Lowe, C.B.; Glor, R.E.; Jaffe, J.D.; et al. The Genome of the Green Anole Lizard and a Comparative Analysis with Birds and Mammals. Nature 2011, 477, 587-591. [CrossRef]

281. Rovatsos, M.; Altmanová, M.; Pokorná, M.J.; Kratochvíl, L. Novel X-Linked Genes Revealed by Quantitative Polymerase Chain Reaction in the Green Anole, Anolis carolinensis. G3 Genes Genomes Genet. 2014, 4, 2107-2113. [CrossRef]

282. Rupp, S.M.; Webster, T.H.; Olney, K.C.; Hutchins, E.D.; Kusumi, K.; Sayres, M.A.W. Evolution of Dosage Compensation in Anolis carolinensis, a Reptile with XX/XY Chromosomal Sex Determination. Genome Biol. Evol. 2017, 9, 231-240. [CrossRef]

283. Marin, R.; Cortez, D.; Lamanna, F.; Pradeepa, M.M.; Leushkin, E.; Julien, P.; Liechti, A.; Halbert, J.; Brüning, T.; Mössinger, K.; et al. Convergent Origination of a Drosophila-like Dosage Compensation Mechanism in a Reptile Lineage. Genome Res. 2017, 27, 1974-1987. [CrossRef] [PubMed]

284. Gamble, T.; Geneva, A.J.; Glor, R.E.; Zarkower, D. Anolis Sex Chromosomes Are Derived from a Single Ancestral Pair. Evol. Int. J. Org. Evol. 2014, 68, 1027-1041. [CrossRef] [PubMed]

285. Rovatsos, M.; Altmanová, M.; Pokorná, M.; Kratochvíl, L. Conserved Sex Chromosomes across Adaptively Radiated Anolis Lizards. Evol. Int. J. Org. Evol. 2014, 68, 2079-2085. [CrossRef] [PubMed]

286. Kichigin, I.G.; Giovannotti, M.; Makunin, A.I.; Ng, B.L.; Kabilov, M.R.; Tupikin, A.E.; Barucchi, V.C.; Splendiani, A.; Ruggeri, P.; Rens, W.; et al. Evolutionary Dynamics of Anolis Sex Chromosomes Revealed by Sequencing of Flow Sorting-Derived Microchromosome-Specific DNA. Mol. Genet. Genom. MGG 2016, 291, 1955-1966. [CrossRef]

287. Giovannotti, M.; Trifonov, V.A.; Paoletti, A.; Kichigin, I.G.; O’Brien, P.C.M.; Kasai, F.; Giovagnoli, G.; Ng, B.L.; Ruggeri, P.; Cerioni, P.N.; et al. New Insights into Sex Chromosome Evolution in Anole Lizards (Reptilia, Dactyloidae). Chromosoma 2017, 126, 245-260. [CrossRef]

288. Rovatos, M.; Pokorná, M.; Altmanová, M.; Kratochvíl, L. Cretaceous Park of Sex Determination: Sex Chromosomes Are Conserved across Iguanas. Biol. Lett. 2014, 10, 20131093. [CrossRef]

289. Altmanová, M.; Rovatsos, M.; Johnson Pokorná, M.; Veselý, M.; Wagner, F.; Kratochvíl, L. All Iguana Families with the Exception of Basilisks Share Sex Chromosomes. Zool. Jena Ger. 2018, 126, 98-102. [CrossRef] [PubMed]

290. Gamble, T.; Zarkower, D. Identification of Sex-Specific Molecular Markers Using Restriction Site-Associated DNA Sequencing. Mol. Ecol. Resour. 2014, 14, 902-913. [CrossRef] [PubMed]

291. Acosta, A.; Martínez-Pacheco, M.L.; Díaz-Barba, K.; Porras, N.; Gutiérrez-Mariscal, M.; Cortez, D. Deciphering Ancestral Sex Chromosome Turnovers Based on Analysis of Male Mutation Bias. Genome Biol. Evol. 2019, 11, 3054-3067. [CrossRef]

292. Conrad, T.; Akhtar, A. Dosage Compensation in Drosophila Melanogaster: Epigenetic Fine-Tuning of Chromosome-Wide Transcription. Nat. Rev. Genet. 2012, 13, 123-134. [CrossRef]

293. Nielsen, S.V.; Guzmán-Méndez, I.A.; Gamble, T.; Blumer, M.; Pinto, B.J.; Kratochvíl, L.; Rovatsos, M. Escaping the evolutionary trap? Sex chromosome turnover in basilisks and related lizards (Corytophanidae: Squamata). Biol. Lett. 2019, 15, 20190498. [CrossRef]

294. Acosta, A.; Suárez-Varón, G.; Rodríguez-Miranda, L.A.; Lira-Noriega, A.; Aguilar-Gómez, D.; Gutiérrez-Mariscal, M.; HernándezGallegos, O.; Méndez-de-la-Cruz, F.; Cortez, D. Corytophanids Replaced the Pleurodont XY System with a New Pair of XY Chromosomes. Genome Biol. Evol. 2019, 11, 2666-2677. [CrossRef] [PubMed]

295. Mezzasalma, M.; Guarino, F.M.; Odierna, G. Lizards as Model Organisms of Sex Chromosome Evolution: What We Really Know from a Systematic Distribution of Available Data? Genes 2021, 12, 1341. [CrossRef] [PubMed] 
296. Becak, W.; Becak, M.L.; Nazareth, H.R.; Ohno, S. Close karyological kinship between the reptilian suborder Serpentes and the class Aves. Chromosoma 1964, 15, 606-617. [CrossRef]

297. Ohno, S. Sex Chromosomes and Sex-Linked Genes; Springer Science \& Business Media: Berlin/Heidelberg, Germany, $1967 ;$ Volume 1.

298. Rovatsos, M.; Altmanová, M.; Pokorná, M.J.; Augstenová, B.; Kratochvíl, L. Cytogenetics of the Javan File Snake (Acrochordus javanicus) and the Evolution of Snake Sex Chromosomes. J. Zool. Syst. Evol. Res. 2018, 56, 117-125. [CrossRef]

299. Rovatsos, M.; Pokorná, M.J.; Kratochvíl, L. Differentiation of Sex Chromosomes and Karyotype Characterisation in the Dragonsnake Xenodermus javanicus (Squamata: Xenodermatidae). Cytogenet. Genome Res. 2015, 147, 48-54. [CrossRef] [PubMed]

300. Matsubara, K.; Tarui, H.; Toriba, M.; Yamada, K.; Nishida-Umehara, C.; Agata, K.; Matsuda, Y. Evidence for Different Origin of Sex Chromosomes in Snakes, Birds, and Mammals and Step-Wise Differentiation of Snake Sex Chromosomes. Proc. Natl. Acad. Sci. USA 2006, 103, 18190-18195. [CrossRef]

301. Vicoso, B.; Emerson, J.J.; Zektser, Y.; Mahajan, S.; Bachtrog, D. Comparative Sex Chromosome Genomics in Snakes: Differentiation, Evolutionary Strata, and Lack of Global Dosage Compensation. PLoS Biol. 2013, 11, e1001643. [CrossRef]

302. Rovatsos, M.; Vukić, J.; Lymberakis, P.; Kratochvíl, L. Evolutionary Stability of Sex Chromosomes in Snakes. Proc. Biol. Sci. 2015, 282, 20151992. [CrossRef] [PubMed]

303. Rovatsos, M.; Augstenová, B.; Altmanová, M.; Sloboda, M.; Kodym, P.; Kratochvíl, L. Triploid Colubrid Snake Provides Insight into the Mechanism of Sex Determination in Advanced Snakes. Sex. Dev. Genet. Mol. Biol. Evol. Endocrinol. Embryol. Pathol. Sex Determ. Differ. 2018, 12, 251-255. [CrossRef] [PubMed]

304. Booth, W.; Schuett, G.W. The Emerging Phylogenetic Pattern of Parthenogenesis in Snakes. Biol. J. Linn. Soc. 2016, 118, 172-186. [CrossRef]

305. Mallery Jr, C.S.; Carrillo, M.M. A Case Study of Sex-Linkage in Python Regius (Serpentes: Boidae), with New Insights into Sex Determination in Henophidia. Phyllomedusa 2016, 15, 29-42. [CrossRef]

306. Gamble, T.; Castoe, T.A.; Nielsen, S.V.; Banks, J.L.; Card, D.C.; Schield, D.R.; Schuett, G.W.; Booth, W. The Discovery of XY Sex Chromosomes in a Boa and Python. Curr. Biol. 2017, 27, 2148-2153.e4. [CrossRef] [PubMed]

307. Augstenová, B.; Johnson Pokorná, M.; Altmanová, M.; Frynta, D.; Rovatsos, M.; Kratochvíl, L. ZW, XY, and yet ZW: Sex Chromosome Evolution in Snakes Even More Complicated. Evol. Int. J. Org. Evol. 2018. [CrossRef]

308. Augstenová, B.; Mazzoleni, S.; Kostmann, A.; Altmanová, M.; Frynta, D.; Kratochvíl, L.; Rovatsos, M. Cytogenetic Analysis Did Not Reveal Differentiated Sex Chromosomes in Ten Species of Boas and Pythons (Reptilia: Serpentes). Genes 2019, 10, 934. [CrossRef]

309. Matsubara, K.; Kumazawa, Y.; Ota, H.; Nishida, C.; Matsuda, Y. Karyotype Analysis of Four Blind Snake Species (Reptilia: Squamata: Scolecophidia) and Karyotypic Changes in Serpentes. Cytogenet. Genome Res. 2019, 157, 98-106. [CrossRef]

310. Palmer, D.H.; Rogers, T.F.; Dean, R.; Wright, A.E. How to identify sex chromosomes and their turnover. Mol. Ecol. 2019, 28, 4709-4724. [CrossRef]

311. Vicoso, B. Molecular and Evolutionary Dynamics of Animal Sex-Chromosome Turnover. Nat. Ecol. Evol. 2019, 3, $1632-1641$. [CrossRef]

312. Foster, J.W.; Dominguez-Steglich, M.A.; Guioli, S.; Kwok, C.; Weller, P.A.; Stevanović, M.; Weissenbach, J.; Mansour, S.; Young, I.D.; Goodfellow, P.N. Campomelic Dysplasia and Autosomal Sex Reversal Caused by Mutations in an SRY-Related Gene. Nature 1994, 372, 525-530. [CrossRef] [PubMed]

313. Wagner, T.; Wirth, J.; Meyer, J.; Zabel, B.; Held, M.; Zimmer, J.; Pasantes, J.; Bricarelli, F.D.; Keutel, J.; Hustert, E.; et al. Autosomal Sex Reversal and Campomelic Dysplasia Are Caused by Mutations in and around the SRY-Related Gene SOX9. Cell 1994, 79, 1111-1120. [CrossRef]

314. Bi, W.; Huang, W.; Whitworth, D.J.; Deng, J.M.; Zhang, Z.; Behringer, R.R.; de Crombrugghe, B. Haploinsufficiency of Sox9 Results in Defective Cartilage Primordia and Premature Skeletal Mineralization. Proc. Natl. Acad. Sci. USA 2001, 98, 6698-6703. [CrossRef] [PubMed]

315. Gao, F.; Maiti, S.; Alam, N.; Zhang, Z.; Deng, J.M.; Behringer, R.R.; Lécureuil, C.; Guillou, F.; Huff, V. The Wilms Tumor Gene, Wt1, Is Required for Sox9 Expression and Maintenance of Tubular Architecture in the Developing Testis. Proc. Natl. Acad. Sci. USA 2006, 103, 11987-11992. [CrossRef]

316. Sun, W.; Cai, H.; Zhang, G.; Zhang, H.; Bao, H.; Wang, L.; Ye, J.; Qian, G.; Ge, C. Dmrt1 Is Required for Primary Male Sexual Differentiation in Chinese Soft-Shelled Turtle Pelodiscus Sinensis. Sci. Rep. 2017, 7, 4433. [CrossRef]

317. Rasys, A.M.; Park, S.; Ball, R.E.; Alcala, A.J.; Lauderdale, J.D.; Menke, D.B. CRISPR-Cas9 Gene Editing in Lizards through Microinjection of Unfertilized Oocytes. Cell Rep. 2019, 28, 2288-2292.e3. [CrossRef]

318. Zhou, Y.; Sun, W.; Cai, H.; Bao, H.; Zhang, Y.; Qian, G.; Ge, C. The Role of Anti-Müllerian Hormone in Testis Differentiation Reveals the Significance of the TGF- $\beta$ Pathway in Reptilian Sex Determination. Genetics 2019, 213, 1317-1327. [CrossRef]

319. Stöck, M.; Kratochvíl, L.; Kuhl, H.; Rovatsos, M.; Evans, B.J.; Suh, A.; Valenzuela, N.; Veyrunes, F.; Zhou, Q.; Gamble, T.; et al. A brief review of vertebrate sex evolution with a pledge for integrative research: Towards "sexomics". Philos. Trans. R. Soc. Lond. B. Biol. Sci. 2021, 376, 20200426. [CrossRef] 